\title{
Thermal Outgassing of Irradiated Nuclear Fuel: A Literature Review
}

L. G. Morgan

C. L. Matsuzaki

L. L. Burger

L. A. Bray

July 1984

Prepared for the U.S. Department of Energy under Contract DE-AC06-76RLO 1830

Pacific Northwest Laboratory Operated for the U.S. Department of Energy by Battelle Memorial Institute 


\title{
DISCLAIMER
}

This report was prepared as an account of work sponsored by an agency of the United States Government. Neither the United States Government nor any agency thereof, nor any of their employees, makes any warranty, express or implied, or assumes any legal liability or responsibility for the accuracy, completeness, or usefulness of any information, apparatus, product, or process disclosed, or represents that its use would not infringe privately owned rights. Reference herein to any specific commercial product, process, or service by trade name, trademark, manufacturer, or otherwise, does not necessarily constitute or imply its endorsement, recommendation, or favoring by the United States Government or any agency thereof. The views and opinions of authors expressed herein do not necessarily state or reflect those of the United States Government or any agency thereof.

\author{
PACIFIC NORTHWEST LABORATORY \\ operated by \\ BATTELLE \\ for the \\ UNITED STATES DEPARTMENT OF ENERGY \\ under Contract DE-AC06-76RLO 1830
}

\begin{tabular}{|c|c|}
\hline \multicolumn{2}{|c|}{ Printed in the United States of America } \\
\hline \multicolumn{2}{|c|}{ Available from } \\
\hline \multirow{2}{*}{\multicolumn{2}{|c|}{$\begin{array}{l}\text { National Technical Information Service } \\
\text { United States Department of Commerce }\end{array}$}} \\
\hline & \\
\hline \multicolumn{2}{|c|}{ Springfield, Virginia 22161} \\
\hline \multicolumn{2}{|c|}{ NTIS Price Codes } \\
\hline & \\
\hline \multicolumn{2}{|c|}{ Printed Copy } \\
\hline & Price \\
\hline Pages & Codes \\
\hline $001-025$ & $\mathrm{~A} 02$ \\
\hline $026-050$ & $\mathrm{~A} 03$ \\
\hline $051-075$ & $\mathrm{~A} 04$ \\
\hline $076-100$ & A05 \\
\hline $101-125$ & A06 \\
\hline $126-150$ & $\mathrm{~A} 07$ \\
\hline $151-175$ & $\mathrm{~A} 08$ \\
\hline $176-200$ & A09 \\
\hline $201-225$ & A010 \\
\hline $226-250$ & A011 \\
\hline $251-275$ & A 012 \\
\hline $276-300$ & A 013 \\
\hline
\end{tabular}



L. G. Morgan
C. L. Matsuzak $i$
L. L. Burger
L. A. Bray

July 1984

Pacific Northwest Laboratory

Richland, Washington 99352 


\section{'}

, 
SUMMARY

An experimental program at PNL examined the release of volatile and semivolatile radionuclides from irradiated nuclear fuel under different modes of heat treatment. In support of this work, a 1 iterature evaluation was conducted to review the information on: 1) physical changes in fuel and cladding; 2) distribution, migration, and reactions of fission products; and 3) theoretical studies. Omitted from the review are evaluations of various fission gas bubble behavior - swelling models. The different computer codes that have been used to predict fuel behavior are al so not included.

A large amount of work has been done on the behavior of nuclear fuels during irradiation. The goals of this work have been to ensure acceptable mechanical performance, provide safe operation, and assist in fuel design, preparation, and recycle. Many fundamental studies, including diffusion and lattice structures, are also reported.

The primary physical change of the fuel resulting from irradiation is swelling. The part of concern is the swelling due to buildup of solid and gaseous fission products. Except for the effects caused by cesium, which can form complex oxides and thus cause variable temperature dependent effects, the net results from fission solids are generaliy predictable and can be accommodated by fuel design. Swelling caused by gas release is a more complex phenomena and is related to release of fission gases from the grains. Data from actual fuel studies relate this swelling to grain size, burnup, temperature, and grain growth patterns (a function of temperature). Thermal transients impose an additional complexity in that rates, e.g. diffusion and crystal growth, are very important. The temperature in various regions of the fuel may range from a few hundred degrees centigrade to over $3000^{\circ} \mathrm{C}$.

The data on fission product distribution in irradiated fuels are voluminous. Evidence for extensive migration of fission products as well as for chemical changes is very clear: formation of metallic and nonmetallic inclusions, formation of solid solutions with mixed oxide fuel, extensive interaction at the fuel-cladding interface, and high concentrations of certain compounds or elements in void spaces. 
Experimental studies are difficult. Of the more than 30 fission product elements, only a few can be studied by gamma spectroscopy. Electron probe microanalysis has been very useful as an analysis technique. It should be noted that the elements and compounds studied in the post reactor examination are not often those that are formed in fission. Data for 25 elements are surveyed in the document, both as to location in the fuel element and as to chemical form.

High migrations are shown by the more volatile elements such as $T, B r, I$, Cs, Sb, Tc, Te, and Pd. Strong oxide formers, such as $Y$ and the rare earths, migrate little. Although migration is normally along a temperature gradient, the direction is not always predictable.

The behavior of several fission products is a function of the oxygen availability and the oxygen to metal ratio (and the $0_{2}$ free energy), and can be quite critical in determining fuel behavior. In particular, compound formation and the roles of Cs, and to a lesser extent, Mo and Ru, are dependent on this value. The oxygen to metal ratio also affects the fuelcladding interaction. Al though stoichiometric $\mathrm{UO}_{2}$ is stable with respect to cladding attack, extensive reaction can occur after fission changes the oxygen potential. Individual fission element-cladding reactions al so occur.

The very important role of excess oxygen or lack of oxygen in determining fuel behavior and the behavior of individual fission products relates directly to the experimental program conducted by PNL. This work, which utilized oxygen-free conditions, indicated that the atmosphere in which the fuel is heated determines the extent and rate of release of products such as tritium and krypton.

Further experimental work is needed; in particular, studies involving carefully controlled and instrumented fuel testing are needed to supplement the extensive post-irradiation data. 


\section{CONTENTS}

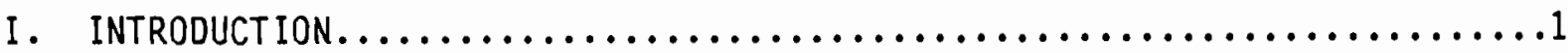

I I. PHYSICAL CHANGES IN THE FUEL AND CLADDING...................

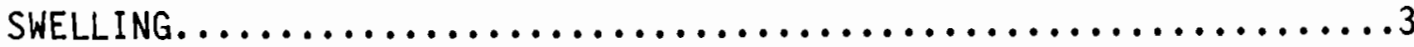

Solid Fission Product Effects.......................

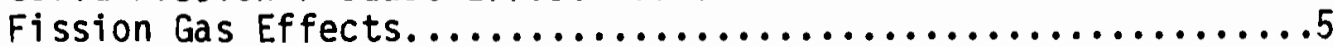

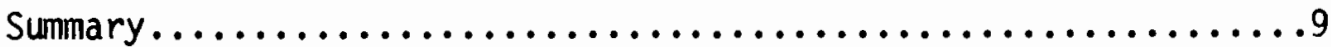

III. DISTRIBUTION, MIGRATION, AND REACTIONS OF FISSION PRODUCTS $\ldots \ldots \ldots \ldots 1$

DISTRIBUTION OF FISSION PRODUCTS IN IRRADIATED FIJEL AND

CLADDING (CONCENTRATION PROFILES) .......................

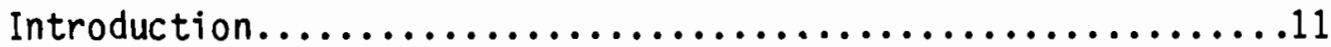

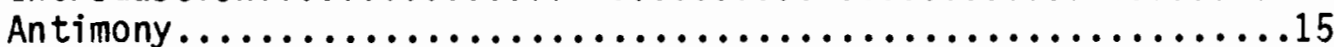

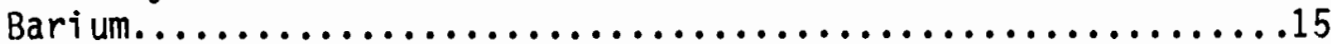

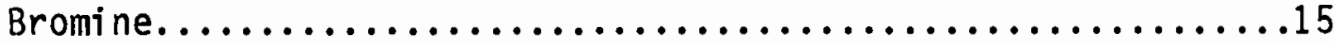

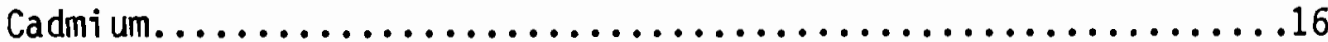

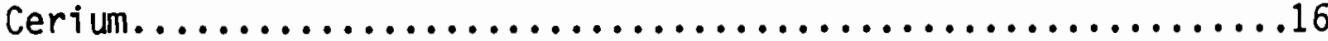

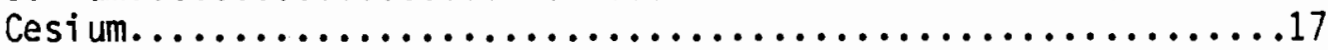

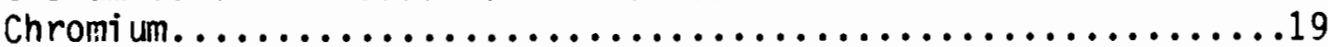

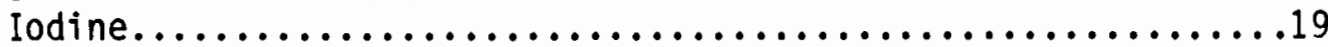

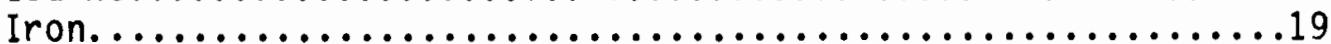

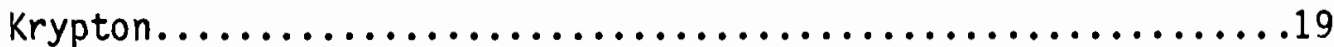

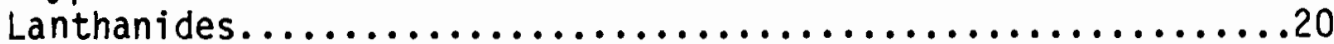

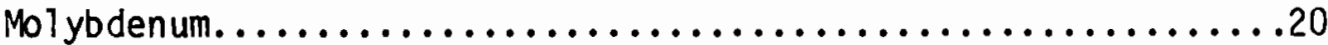

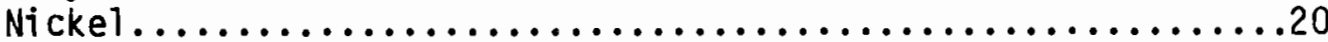

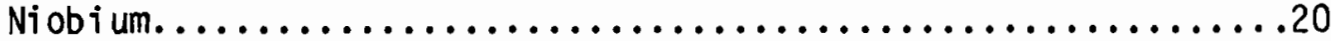

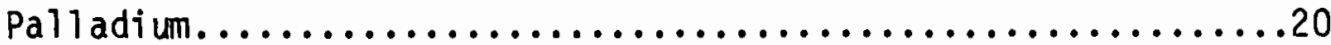

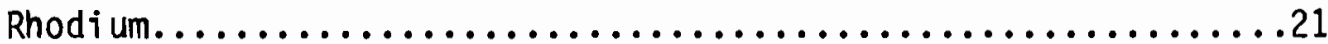

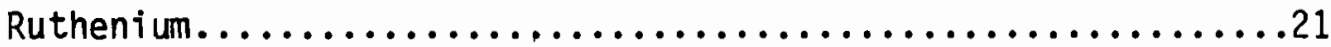

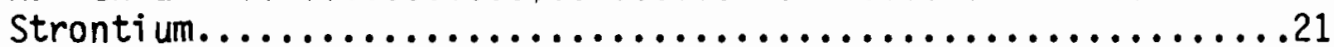

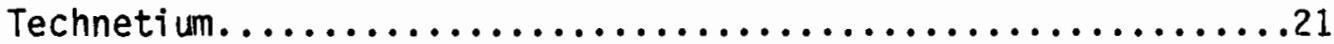

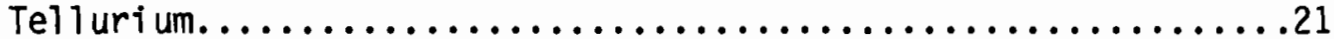

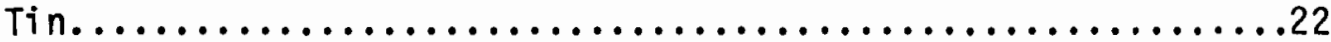

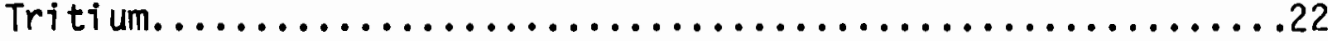

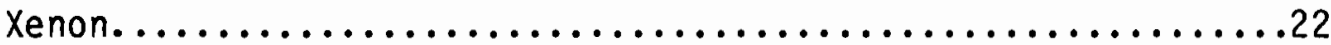

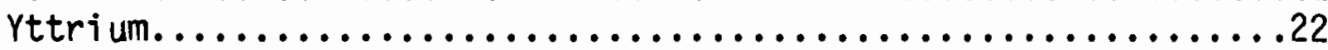

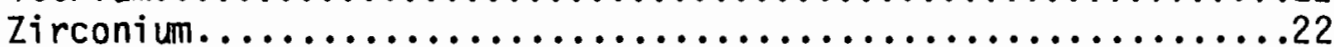

COMPOSITION OF FISSION PRODUCTS IN IRRADIATED FUEL (CHEMICAL

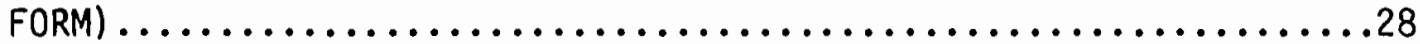

FISSION PRODUCT/CLADDING INTERACTION........................

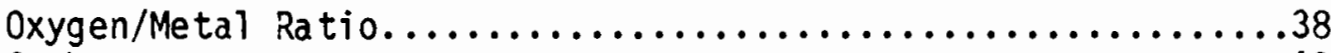

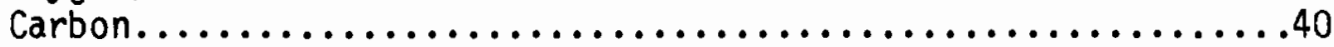

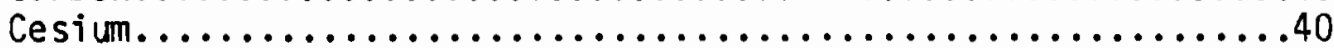

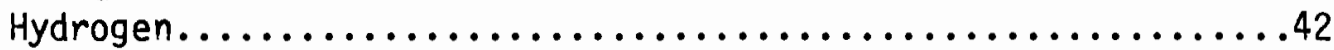




\section{CONTENTS (Continued)}

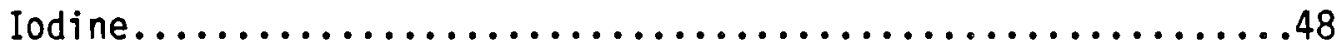

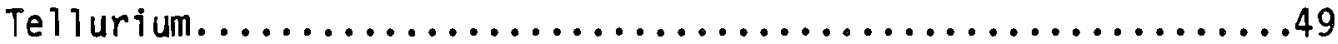

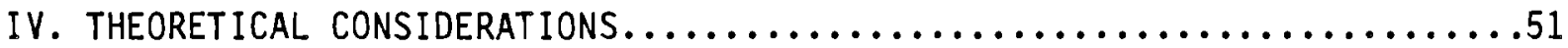

OXYGEN BALANCE.................................

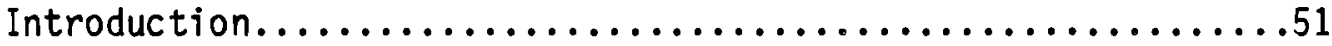

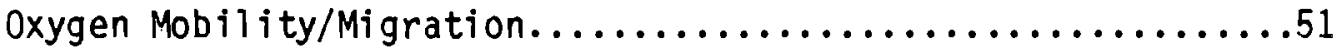

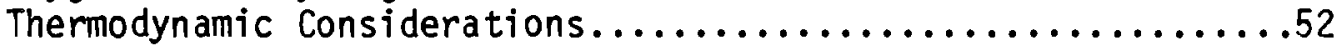

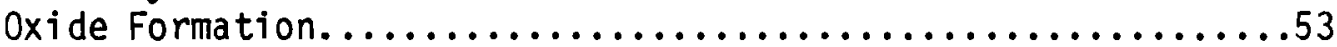

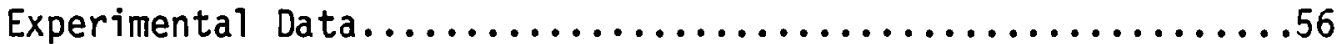

Oxygen Reactions with Fission Products.................57

Other $0 /$ M Effects................................60

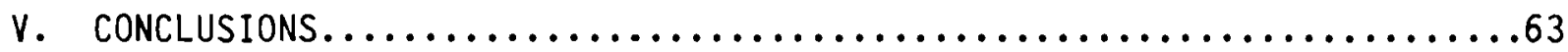

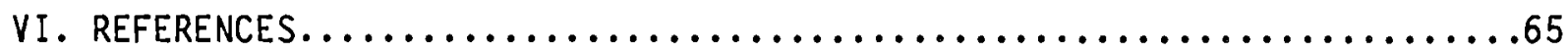


FIGURES

II-1 Swelling of $\mathrm{UO}_{2}$ as a Function of Burnup (Zimmerman 1978).........8

III-1 Radial Variation in Concentrations of Ru, Mo, TC in Metallic Inclusions in the Columnar Grain Region $(U, \mathrm{Pu}) \mathrm{O}_{2}$ with $20 \mathrm{wt} \% \mathrm{PuO}_{2}$, Burnup $5.6 \times 10^{20} \mathrm{Fission} / \mathrm{cm}^{3}$ (Camoszzo 1972).......12

III-2 Radial Distribution of Barium in $\mathrm{UO}_{2}$ (Bazin, Jouan, and Vignesoult 1974).....................................16

III-3 Radial Distribution of Fission Products in a $7 \mathrm{~mm}$ dia. Mixed Oxide Fuel Pin Irradiated in DFR (Bramman and Powell 1975)......17

III-4 Comparison of Gross and Isotopic Activity Traces for Part of Rod-7. ANL Neg. No. MSD-62079 (Kelman 1975)...............18

III-5 Tritium Distribution in Rod CP206 (Grossman and Hegland 1971)....23

III-6 Tritium Distribution in Rod 12FV (Grossman and Hegland 1971).....24

III-7 Longitudinal Distribution of Tritium in Pin Number 309 (Bazin, Jouan, and Vignesoult 1974)....................25

III-8 Axial Variations in the Tritium Concentrations in the Zircaloy Cladding of Pin 309 (Bazin, Jouan, and

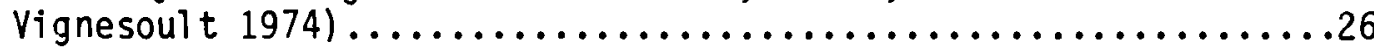

III-9 Relative Radial Profiles of Retained (intragranular) Fission Gas at Axial Midplane Wi thin PNL-9, -10, and -11 Fuel Irradiated to $\sim 50 \mathrm{MWd} / \mathrm{kg}$ (Randklev 1978).................26

III-10 Radial Distribution of Zirconium (EPEL 6, 25,900 MWd/tU) Bazin, Jouan, and Vignesoult 1974)......................27

III-11 TOF 15. Radial Distribution of Zirconium in the $\mathrm{UO}_{2}$ (Bazin, Jouan, and Vignesoult 1974).....................27

III-12 The Effect of Initial Fuel 0/M on the Depth of Attack at 3.6 at. \% Burnup (Lawrence, Hata, and Weber 1979)................39

III-13 Oxygen Activity Change with Burnup in Fuel-Cladding Gap at $725^{\circ} \mathrm{C}$; Schematic, Oxygen and Carbon from Fue1

(Epstein 1975).........................................41

III-14 Maximum Penetration by Fission Products into the Joints of Oxide Grains at the Oxide-Cladding Interface. El ement

Measured: Cs in Grain Joints (Bazin, Jouan, and Vignesoult 1974). 
III-15 Microanalysis of the Zone of Contact Between Oxide and Cladding in Pin TOF 32 (Bazin, Jouan, and

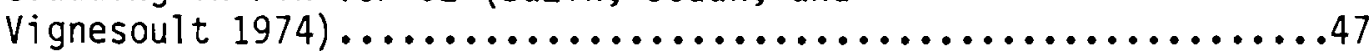

IV-1 Cesium Retention in Fuel Region as a Function of $0 / M$ Ratio (Langer et a 1. 1978).

\section{TABLES}

III-1 Composition of Metallic Inclusions Found in Irradiated Oxide Fuel (Steindler et a1. 1978).

III-2 Location of Fission Products in Irradiated Fuel

(Bazin, Jouan, and Vignesoult 1974)...

III-3 Fission Products in $\mathrm{UO}_{2}, \mathrm{UO}_{2} / \mathrm{PuO}_{2}$ Fuel......................29

III-4 Summary of Isothermal Capsule Tests Containing Te and Other Additives Heated at $725^{\circ} \mathrm{C}$; Series 1 Through 16

(Adamson and Aitken 1974).

IV-1 Distribution of fission-freed oxygen among fission products

(Bazin, Jouan and Vignesoult 1974). *Fission yield for $\mathrm{UO}_{2}$ exposed to thermic neutrons after 100 days of irradiation and

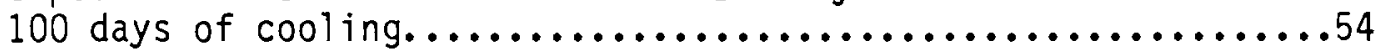

IV-2 Oxygen Demand of Fission Product Compounds (Bullard 1978)......55

IV-3 Final Fuel Composition in Atomic Percentage at 10\% Burnup and Calculation of Oxygen Balance. Condensed from (Davies and

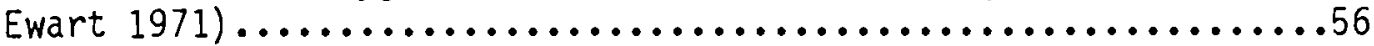

IV-4 Measured Oxygen "Excess" in Irradiated Oxide Fuels vs Burnup (Davies and Ewart 1971) .57 


\section{INTRODUCTION}

A very large amount of work has been done on the behavior of nuclear fuels during irradiation, much of it to ensure acceptable mechanical performance. Other studies relate to safety, fuel preparation, and recycle as a function of fuel type. Still other work has been directed at fundamental studies, e.g., lattice structure changes and diffusion of chemical species. A surprisingly large number of these studies provide information pertinent to the task to be surveyed here: the release of volatile fission products as a result of thermal treatment of irradiated fuels.

The scope of the present study is to review the information available on: 1) physical changes in fuel and cladding; 2) distribution, migration and reactions of fission products; and 3 ) theoretical studies. The present review evaluates selected aspects of nuclear fuel behavior believed to be related to the release of volatile fission products; only documented information has been considered. In particular, review and critique of the various computer codes, either in existence or under development, used to predict fuel behavior under normal and transient reactor conditions has been omitted. Similarly, this review does not attempt to evaluate or critique the various models of swelling, fission gas bubble behavior, etc. This review is restricted largely to those experimental studies conducted under controlled conditions and their results.

This work is in support of an experinental program conducted at PNL which examined the release of gases from irradiated fuels under different modes of heat treatment.

A practical goal is the development of a process to remove certain volatile fission products before fuel dissolution for reprocessing or longterm storage of irradiated fuel. However, it is anticipated that the information obtained will be applicable to other areas of the nuclear program. 


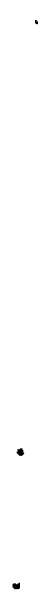




\section{PHYSICAL CHANGES IN THE FUEL AND CLADDING}

SWELLING

Swelling is the term used to denote physical expansion of reactor fuel during irradiation. Swelling is a significant safety concern in reactor fuels because it may rupture the cladding, releasing volatile fission gases and exposing the fuel matrix to the coolant, resulting in additional spread of radioactive fuel and fission products. The concern for maintaining the cladding integrity during both the normal lifetime of the fuel in the reactor, and during transient reactor conditions has resulted in a sizable background of information concerning the cause and magnitude of swelling. In addition, models have been proposed to explain the observed behavior and project fuel behavior as a function of reactor conditions. This background of swelling information is directly related to the thermal release of volatile fission products as will be shown in the following discussion.

Swelling is caused by thermal expansion of the reactor fuel and by the formation of fission products as a consequence of the fission of the fissile nuclei. Thermal expansion is a quantity that has been characterized and is accommodated by proper fuel manufacture--it will not be addressed herein. Both solid fission products and gaseous fission products (primarily $\mathrm{Kr}$ and $\mathrm{Xe}$ ) contribute to fuel swelling. Although it is difficult to determine the magnitude of individual effects, the following are generally accepted as factors related to fuel swelling: 1) burnup, or total number of fissions of fissile nuclei; 2) rate of fission; 3) temperature during irradiation; 4) temperature gradients within the fuel, both axially and radially; 5) grain size; 6) initial operating conditions; 7) power and/or temperature transients during irradiation; and 8 ) the type of fuel (power reactor or fast breeder reactor).

The as-fabricated fuel element consists of stacked fuel pellets $(1$ imited to $\mathrm{UO}_{2}$ or $\mathrm{UO}_{2}-\mathrm{PuO}_{2}$ for purposes of this report) of near theoretical density (typically $>90 \%$ ), but retaining a finite, uniform porosity within each fuel pellet found mostly at the grain boundaries.

Initial operation of the fuel rapidly establishes thermal gradients within the fuel pellet which commonly reach $3000^{\circ} \mathrm{C} / \mathrm{cm}$ in typical power reactor 
fuels (Childs 1963) and may be as high as $10,000^{\circ} \mathrm{C} / \mathrm{cm}$ for fast reactor fuels (Bramman and Powel1 1975). Frequently, these thermal shocks cause radial cracks within the fuel pellet. The number of thermally-induced cracks has been correlated with peak fuel power for at least one type of fuel pellet and its in-reactor operating conditions (Hargreaves and Collins 1976).

Solid Fission Product Effects

The effect of solid fission products on swelling has often been neglected in the literature. The potential release of fission gases has been more apparent and assumed to be the dominant mechanism of fuel swelling. However, solid fission products do contribute to fuel swelling (Bramman and Powell 1975, Hargreaves and Col1ins 1976, Zimmerman 1978). Hargreaves and Collins (1976) state that below $1300 \mathrm{~K}$, fuel swelling is caused primarily by solid fission products at a rate of approximately one volume percent per percent burnup. They (Hargreaves and Collins 1976) indicate that at temperatures of less than $1300 \mathrm{~K}$, the fission gases, $\mathrm{Kr}$ and $\mathrm{Xe}$, do not contribute significantly to fuel swelling because they remain trapped within the individual grains and do not coalesce in large bubbles at the grain boundaries.

Other values reported for the swelling caused by solid fission products include: 0.35 volume percent per percent burnup when cesium was assumed to be present as an unspecified ionic compound (Anselin 1969); 0.5 volume percent per percent burnup, assuming molybdenum is present as an oxide and cesium exists in elemental form (Frost and Wait 1967); and 0.65 volume percent per percent burnup (Zimmerman 1978).

As shown above, estimates of the magnitude of swelling caused by solid fission products do vary. However, swelling caused by solid fission products is not a significant problem because the fuel can be designed to accommodate the buildup of solid fission products as a function of burnup (Hargreaves and Collins 1976). Bramman and Powell (1975) concluded that migration is also not likely to affect fuel swelling because only a small fraction of the fission products soluble in the oxide fuel are likely to migrate as mobile precursors. The existing uncertainty in the form of cesium and its mobility is a concern, however, because it may react with the fuel matrix to form 
incompressible complex oxides in the cooler regions of the fuel; such complex oxides have been experimentally observed (Stalica and Seils 1969).

Fission Gas Effects

During irradiation, $\mathrm{Kr}$ and $\mathrm{Xe}$ are produced at a rate of $\sim 0.3$ atoms per fission event (Dollins 1973). Although some other elements and compounds may be volatile at the fuel temperature, $\mathrm{Kr}$ and $\mathrm{Xe}$ are the primary fission gases, comprising $\sim 12$ at. \% of the total fission products in irradiated natural $\mathrm{UO}_{2}$ (Childs 1963). The solubility of these noble gases in the fuel matrix is low, and they are expected to precipitate (Johnson and Shuttleworth 1959). Once precipitated, the fission gases may: 1) exist as atoms within the individual grains of the fuel; 2) form gas bubbles (2 or more atoms) within the individual grains; 3) migrate as atoms to the grain boundaries; 4) migrate as bubbles to the grain boundaries, or 5) re-enter the fuel matrix as a result of irradiation-induced resolution. Each of these mechanisms occurs, and the degree to which they exist is dependent on the factors previously listed in this discussion.

It is important to note that very little experimental evidence exists that would clarify the behavior of the fission gases and their effect on swelling. Swelling is a physical phenomenon, and therefore $i$ ts magnitude can be determined. However, the role of fission gases in contributing to swelling is usually postulated from a variety of analytical models. The success of a given model is the correlation of its predictions with experimental behavior. Most current models correctly predict the magnitude of swelling based on a presumed fission gas behavior. However, there is little experimental evidence to substantiate the postulated fission gas behavior.

Power reactor fuel operates at a lower centerline temperature and has a smaller radial thermal gradient than fast reactor fuel. Temperature during irradiation is a dominant factor in the behavior of fission gases and swelling. Because of the differing temperatures, swelling is expected to differ for the two types of fuel although general conclusions are applicable to both fuel types.

Low irradiation temperatures are too low for noble gas diffusion, thereby precluding gas bubble formation (Speight 1969). Reported values of this temperature range may vary, but Dollins (1973) estimates these temperatures to 
be $<900^{\circ} \mathrm{C}$. Other authors indicate the fission gases have little effect on swelling below approximately 1300K, al though gas bubble formation does occur within this temperature range (Hargreaves and Collins 1976; Hastings, Notley, and Rose 1978; Haynes and Wood 1977).

Equiaxed grain growth occurs over the temperature range of $\sim 1300-1800 \mathrm{~K}$ and gas bubbles are generated at the grain boundaries. Very small gas bubbles have been identified in the grains over this temperature range (Hargreaves and Collins 1976, Haynes and Wood 1977).

At temperatures $>1873 \mathrm{~K}$, columnar grain growth occurs and gas bubbles can migrate up the temperature gradient toward the center of the fuel pin (Hargreaves and Collins 1976, Haynes and Wood 1977).

Swelling has been determined to reflect the amount and behavior of fission gases in each of the temperature zones. The highest temperature zone, or region of columnar grain growth, is assumed to release essentially all the fission gases within this zone. Hence, fuel swelling caused by fission gases is negligible within the high temperature zone. The lowest temperature regions, the unrestructured zones, retain essentially all their fission gases within the individual grains and also do not contribute significantly to fuel swelling. Fission gases contribute most to fuel swelling within the temperature region in which equiaxed grain growth occurs. Gas bubble growth in the grain boundaries causes fuel swelling, but is limited in magnitude by a "saturated" fission gas bubble population (Hargreaves and Collins 1976; Hastings, Notley, and Rose 1978; Haynes and Wood 1977; Zimmerman 1978). Swelling has also been reported to pass through a maximum value with increasing temperature (Nelson and Zebroski 1966).

Fuel swelling is also dependent upon the grain size of the fuel. Al though the temperature of a given zone of the fuel pellet determines the grain type (columnar, equiaxed, or unrestructured), the as-fabricated grain size and irradiation history are the dominant factors in grain size effects on fuel swelling. Dollins' (1973) model for fission gas swelling is based on the following grain behavior: 1) Irradiation decreases the as-fabricated grain size; 2) Swelling is predicted to have a maximum value as a function of grain size; and 3) Maximum swelling occurs at larger grain sizes with an increasing burnup. 
Other authors do not agree with all of Dollins' (1973) assumptions, but most do agree grain size affects both swelling and fission gas release. Turnbul1 (1973) reported experimental evidence that fine-grained $\mathrm{UO}_{2}$ resulted in greater swelling and fission gas release. The normal explanation for this observation is that diffusion of fission gases created within the individual grains have a shorter path to travel to the grain boundaries in smaller grained material. Hargreaves and Collins (1976) essentially support this mechanism but point out that irradiation-induced grain growth occurs (note the variance with Dollins' (1973) model). They (Hargreaves and Collins 1976) postulate that the irradiation temperature in the first few thousand megawatt days per ton determines the fuel structure and grain size; hence, the swelling and fission gas behavior are determined. Hargreaves and Collins (1976) concluded that if the starting grain size is to have any significant effect on fission gas release, it must be considerably greater than the grain size normally attained as a result of the given reactor conditions.

Zimmermann's (1978) experimental studies found no differences in fission gas release as a function of grain size. These results are in apparent conflict with the experimental studies of Turnbull (1973) and the concepts of Hargreaves and Collins (1976) regarding grain size effects on fission gas release and swelling. However, Zimmerman (1978) indicates that his results are not a contradiction of grain size effects. Rather, he (Zimmermann 1978) states that if the fuel matrix is not saturated with fission gas, both swelling and gas release are determined by grain size. As burnup increases, the fuel develops a subgrain structure that functions essentially the same as the grain boundaries, thereby resulting in an apparent independence of swelling and grain size. Zimmerman (1978) irradiated $\mathrm{UO}_{2}$ in a variable, but uniform (no thermal gradient within the fuel), thermal environment both with and without physical constraint on the fuel. The studies were carefully conducted and represent one of the few experimental studies of swelling conducted under controlled conditions. Unrestrained fuel swelling values exceed those of restrained fuel under the same conditions. Figure II-1 represents Zimmermann's (1978) results. As'expected, swelling has a very strong temperature dependence. However, burnup is also a strong factor as shown by the decreasing rate of swelling with increasing burnup at all temperatures. Caution should be used in utilizing numerical values from Zimmermann's (1978) studies because, as he points out, bubble inigration in 


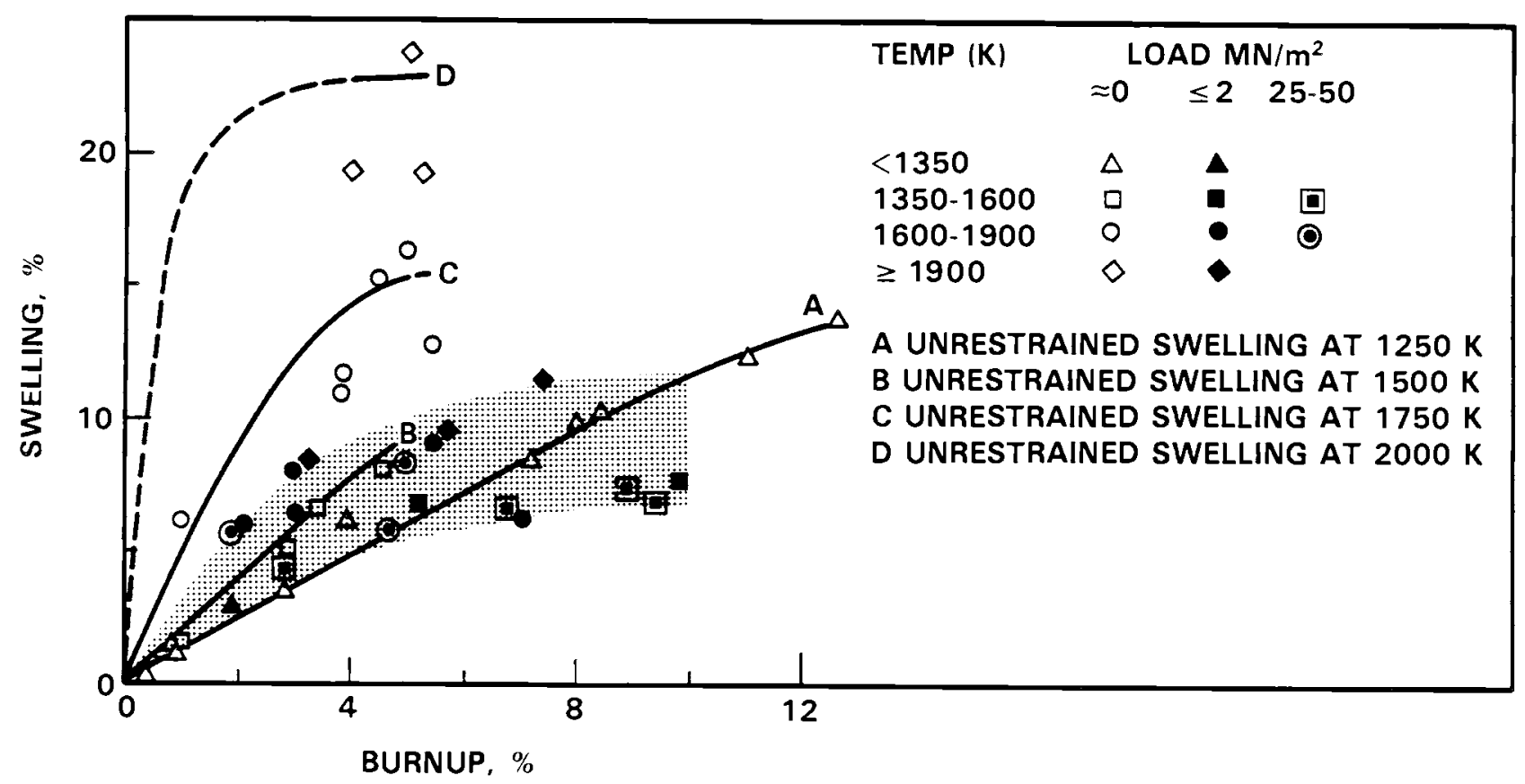

FIGURE II-1. Swelling of $\mathrm{UO}_{2}$ as a Function of Burnup (Zimmerman 1978). Reprinted with permission from North-Holland Publishing Company, Amsterdam, $\odot$ 1978.)

high thermal gradients within actual fuel will reduce the values by as much as a factor of ten.

One of the aspects of swelling that is a significant safety concern is its magnitude during thermal transients. Unfortunately, little has been reported. Dollins' (1981) most recent model of swelling and gas release in oxide fuels during fast temperature transients predicts swelling increases of 2-3 volume percent during the transient. He (Dollins 1981) defines a fast temperature transient as one $>10^{\circ} \mathrm{C} / \mathrm{sec}$. Additional information has been determined on the release of fission gases during thermal transients, and these results will be discussed later.

The nature of the fuel, $\mathrm{UO}_{2}$ or $(\mathrm{U}, \mathrm{Pu}) \mathrm{O}_{2}$, does not appear to be a factor in swelling. Differences in swelling between power reactor fuel and fast 
reactor fuel are attributable to differences in operating temperature, the magnitude of the thermal gradients within the fuel, and the burnup.

Summary

It is generally accepted that swelling caused by solid fission products is 0.5-1.0 volume percent per percent burnup, and its effects can be accommodated by proper fuel design. The possible exception to the predictable solid fission product swelling is cesium, which can form complex oxides and thereby greatly increase swelling.

Swelling caused by fission gases is closely related to the release of these fission gases from the fuel grains. Swelling is greatest in the temperature range that results in equiaxial grain growth, but reaches a "saturation" value determined by grain size, burnup, and temperature. The magnitude of fuel swelling attributable to individual effects is difficult to determine. Most swelling data have been derived from actual reactor fuel and not from carefully controlled experiments.

Thermal transients impose an additional complexity in prediction of fuel swelling. Transients are nonequilibrium situations, and their effects may not coincide with those obtained under equilibrium conditions.

Fuel swelling caused by fission gases is an area that needs additional study. Emphasis should be placed on obtaining accurate and well-characterized experimental data. Model development of swelling will never be satisfactory until the actual mechanisms and their magnitude caused by fission gases are determined. 


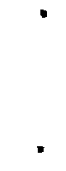


III. DISTRIBUTION, MIGRATION, AND REACTIONS OF FISSION PRODUCTS

DISTRIBUTION OF FISSION PRODUCTS IN IRRADIATED FUEL AND CLADDING

(CONCENTRATION PROFILES)

Introduction

More than thirty elements (approximately 120 isotopes) are produced in the fission of uranium or plutonium. Only a few of the isotopes produced can be studied in detail by gamma spectroscopy, thus the behavior of many must be inferred from the few that can be studied. Electron-probe microanalysis is a second tool capable of confirming general trends (Bramman and Powell 1975).

In general, fission products are very mobile in the environment of the high temperature and radial temperature gradients associated with $\mathrm{UO}_{2}$ and $\mathrm{UO}_{2} / \mathrm{PuO}_{2}$ fuels. The fact that many fission products are found as elements indicates that much migration out of the oxide lattice occurs (Bramman and Powe11 1975).

Camoszzo (1972) described a typical post-irradiation structure of a mixed oxide element (transverse section) as follows:

- an outer zone, which remains at lower temperature and which keeps its initial structure;

- an intermediate zone where equiaxed grains are seen, formed by recrystallization of the material at high temperature;

- an inner zone, where the temperature has reached the highest values, consisting of columnar grains;

- a central void along the axis of the element, with a geometry dependent on the operating conditions.

Camoszzo (1972) indicated that although fission product distribution is not homogeneous within the fuel, specific locations for the various fission products are observed. Inclusions of solid products are always in grain boundaries, which suggests that some products are not soluble in the fuel matrix. Some investigators have established a classification system for fission product distribution (Camoszzo 1972):

- white metaliic inclusions, localized in the zones of columnar and equiaxed grains; 
- non-metallic inclusions, forming the "gray phase" in the zone of equiaxed grains, in proximity to the zone of columnar grains;

- mixed oxide matrix (in homogeneous dispersion, solid solution).

The metallic inclusions contain Mo, Ru, TC, Rh, and Pd. Located in grain boundaries and radial voids of columnar grains, these elements form about $70 \%$ of all inclusions. Mo, Ru and Tc represent 90 weight percent of the total inclusions with distributions as diagrammed in Figure III-1 (Camoszzo 1972). Isolation and analysis of inclusions attached to walls of the central void indicate a hexagonal structure with a composition, in wt\%, of Mo-41.0, Ru-31.9, Tc-14.9, Rh-7.1 and Pd-2.0. Steindler et al. (1978) have compiled a table of the composition of metallic inclusions; these are given in Table III-1.

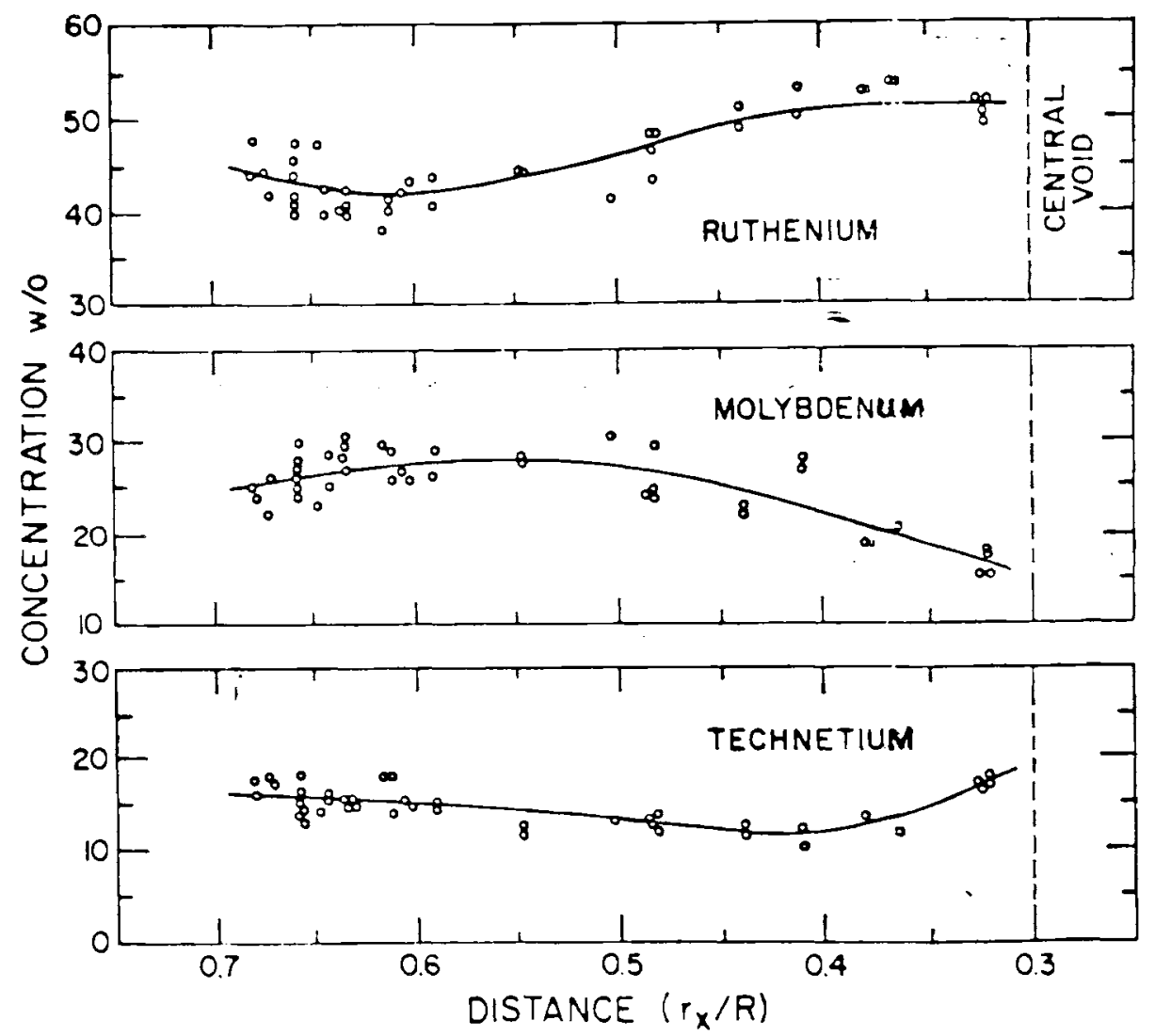

FIGURE III-1. Radial Variation in Concentrations of Ru, Mo, Tc in Metallic Inclusions in the Columnar Grain Region ( $\mathrm{U}, \mathrm{Pu}$ ) $\mathrm{O}_{2}$ with $20 \mathrm{wt}_{\%} \mathrm{PuO}_{2}$, Burnup $5.6 \times 10^{20} \mathrm{Fissions} / \mathrm{cm}^{3}$ ( Camoszzo 1972) 
TABLE III-1. Composition of Metallic Inclusions Found in Irradiated Oxide Fuel (Steindler et al. 1978)

Inclusion Composition, at.\%

\begin{tabular}{|c|c|c|c|c|c|c|c|c|c|c|c|c|c|}
\hline Fuet & Mo & Cs & Ru & TC & $\mathrm{Te}$ & $\mathrm{Rh}$ & $P d$ & $\mathrm{Zr}$ & $\mathrm{Ba}$ & $\mathrm{Ce}$ & Sn & U & $\mathrm{Pu}$ \\
\hline $\mathrm{UO}_{2}{ }^{\mathrm{a}}$ & 60 & -- & 24 & 16 & -- & -- & -- & -- & -- & -- & -- & -- & -- \\
\hline $\mathrm{UO}_{2}^{\mathrm{a}}$ & 54 & -- & 23 & 17 & -- & 6 & -- & -- & -- & -- & -- & -- & -- \\
\hline $\mathrm{VO}_{2}^{\mathrm{a}}$ & 33 & -- & 13 & 9 & -- & -- & -- & 17 & 22 & 6 & -- & -- & -- \\
\hline $\mathrm{UO}_{2}^{\mathrm{a}}$ & -- & -- & -- & -- & -- & -- & -- & 34 & 11 & 55 & -- & -- & -- \\
\hline $\mathrm{PuO}_{1.7^{\mathrm{b}}}$ & 27 & -- & 26 & 14 & -- & 13 & 20 & -- & -- & -- & -- & -- & -- \\
\hline $\mathrm{PuO}_{2} \ddot{\mathrm{b}}$ & 5 & -- & 37 & 8 & -- & 17 & 33 & -- & -- & -- & -- & -- & -- \\
\hline $\mathrm{U}_{0.8^{\mathrm{Pu}}} 0.2^{\mathrm{O}_{2}}$ & - & -- & 1 & -- & -- & 15 & 59 & -- & -- & - & -- & 18 & 8 \\
\hline $\mathrm{U}_{0.8^{\mathrm{Pu}}} 0.2^{\mathrm{O}_{2}}$ & 21 & -- & 48 & 17 & -- & 12 & 2 & -- & -- & -- & -- & -- & -- \\
\hline $\mathrm{U}_{0.85^{\mathrm{Pu}}} 0.15^{\mathrm{O}_{2}}$ & 44 & -- & 32 & 15 & -- & 7 & 2 & -- & -- & -- & -- & -- & - \\
\hline $\mathrm{U}_{0.85^{\mathrm{Pu}}} 0.15^{0} 1.94$ & -- & -- & -- & -- & -- & -- & 74 & -- & -- & -- & -- & 15 & 11 \\
\hline $\mathrm{U}_{0.85^{\mathrm{Pu}}} 0.15^{0} 1.94$ & 37 & -- & 37 & 10 & -- & 11 & 5 & -- & -- & -- & -- & -- & -- \\
\hline $\mathrm{U}_{0.85^{\mathrm{Pu}}} 0.15^{\mathrm{O}} 2.15$ & -- & -- & 62 & 9 & -- & 20 & 9 & -- & -- & -- & -- & -- & -- \\
\hline $\mathrm{U}_{0.85^{\mathrm{Pu}}} 0.15^{\mathrm{O}_{2}} .15$ & -- & -- & -- & -- & 22 & -- & 74 & -- & -- & - & -- & 4 & -- \\
\hline $\mathrm{U}_{0.85^{\mathrm{Pu}} 0.15^{\mathrm{O}} 2.15}$ & -- & -- & -- & -- & 30 & -- & 60 & -- & -- & -- & -- & 10 & -- \\
\hline $\mathrm{U}_{0.85^{\mathrm{Pu}}} \mathrm{u}_{.15^{0}} 2.023$ & -- & 5 & -- & -- & 14 & -- & 74 & -- & -- & -- & 3 & 3 & -- \\
\hline $\mathrm{U}_{0.85^{\mathrm{Pu}}} 0.15^{\mathrm{O}_{2}} 2.023$ & -- & 1 & -- & -- & 21 & -- & 70 & -- & -- & -- & 5 & 3 & -- \\
\hline
\end{tabular}

(a) These inclusions were also reported to contain from 12 to $40 \mathrm{wt} \%$ uranium. (b) Inclusions were not well formed and had entrained fuel material. 
"Gray phase" non-metallic inclusions have a high concentration of barium. Other fission products found in these inclusions include Ce, Sr, Zr, Nd, Mo, Ru, and Tc (Camoszzo 1972).

The oxide matrix has been found to contain $\mathrm{Nd}, \mathrm{Ce}, \mathrm{Hf}, \mathrm{Ba}, \mathrm{Pr}, \mathrm{Sr}$, and $\mathrm{Zr}$ (Bullard 1978; Camoszzo 1972). Bazin, Jouan, and Vignesoult (1974) tabulated the various fission products they observed in irradiated fuel and cladding; these are shown in Table III-2.

TABLE III-2. Location of Fission Products in Irradiated Fuel (Bazin, Jouan, and Vignesoult 1974)

\begin{tabular}{|c|c|c|c|c|}
\hline $\begin{array}{l}\text { Placement in } \\
\text { Fuel Element } \\
\end{array}$ & \begin{tabular}{l}
\multicolumn{2}{c}{ Gaseous } \\
Fission Prod. \\
$\mathrm{T}, \mathrm{Xe}, \mathrm{Kr}$
\end{tabular} & $\begin{array}{l}\text { Volatile } \\
\text { Fission Prod. } \\
\text { Cs (rare) }\end{array}$ & $\begin{array}{l}\text { Soluble } \\
\text { Fission Prod. }\end{array}$ & $\begin{array}{l}\text { Insoluble } \\
\text { Fission Prod. }\end{array}$ \\
\hline $\begin{array}{l}\text { Oxide- } \\
\text { Cladding } \\
\text { Interface }\end{array}$ & & $\mathrm{Cs}, \mathrm{I}, \mathrm{Te}$ & \multicolumn{2}{|c|}{$\begin{array}{l}\text { Two reaction layers } \\
U-Z r-C s-P d-B a-T e-0 \\
\text { Single reaction layer } \\
U-Z r-C s-B a-0\end{array}$} \\
\hline Fuel & $\mathrm{T}, \mathrm{Xe}, \mathrm{Kr}$ & $\begin{array}{l}\text { Cs, I, Te } \\
\text { around the } \\
\text { periphery }\end{array}$ & \multirow[t]{2}{*}{$\begin{array}{l}\mathrm{Zr}, \mathrm{Y} \text {, rare } \\
\text { earths, } \\
\mathrm{Ba}, \mathrm{Nb}, \mathrm{Mo}\end{array}$} & $\begin{array}{l}\text { Metallic in- } \\
\text { clusions } \\
\text { U-Pd-Sn and } \\
\text { Mo-Tc-Ru-Rh-Pd }\end{array}$ \\
\hline Free Volume & $\mathrm{Xe}, \mathrm{Kr}$ & & & $\begin{array}{l}\text { Non-metallic } \\
\text { inclusions } \\
\text { U-Ba-Zr with } \\
\text { Mo-Ce-Nd-Sr-La }\end{array}$ \\
\hline
\end{tabular}


Distributions of fission products in addition to those mentioned above are also cited in the literature. The following discussion gives a more detailed description of various fission products and their distribution in the fuel and cladding.

Antimony

Bramman and Powe 11 (1975) noted that ${ }^{125} \mathrm{Sb}$ migrates radially to the fue $1 /$ cladding interface.

Barium

Electron-probe microanalysis and a scanning electron microscope, used to examine $\mathrm{UO}_{2}$ kernels irradiated at $1250-1350^{\circ} \mathrm{C}$ to $6.7 \%$ heavy-atom burnup, revealed two kinds of barium-containing materials. One type, some small precipitates approximately $1 \mu \mathrm{m}$ in diameter, contained $\mathrm{Ba} \mathrm{plus} \mathrm{Zr}$ and $\mathrm{Sr}$ in a $\mathrm{Ba} / \mathrm{Zr}$ ratio of $\sim 2: 1$ and $\mathrm{a} \mathrm{Ba} / \mathrm{Sr}$ ratio of $\sim(5-6): 1$. The other was a mobile $\mathrm{Ba}$ form that often migrated to the hottest regions of the fuel (Friskney and Simpson 1975). Work by Bazin, Jouan, and Vignesoult (1974) confirms the migration of Ba towards the center (see Figure III-2). Fuels that were operated with a central molten zone show oxidized phases in the central zone with $30 \mathrm{wt} \% \mathrm{Ba}$.

Electron-probe microanalysis by Bramman and Powel1 (1975) indicated radial migration of stable barium (mainly $138_{\mathrm{Ba}}$ ). The barium oxide formed was insoluble in the oxide matrix; it was found in the equiaxed-grain zone and the outer end of the columnar grains. Contrary to elemental Ba migrating to the hotter fuel zones, barium oxide moved toward the cooler end of the columnar grains. Migration down the temperature gradient was usually associated with its precursors, Xe and Cs. A Ba-Mo phase has al so been found in mixed oxide fuel in the outer $1 / 3$ of transverse cross sections and near the cladding (Bramman and Powe11 1975).

Bromine

In irradiated $\mathrm{UO}_{2}$ and $\mathrm{UO}_{2}-\mathrm{PuO}_{2}$ fuels, bromine was driven to the outer cooler regions of the pellet; in some instances it may escape from the fuel ( $\mathrm{Clayton}$ and Riddle 1969). Camoszzo (1972) assumed Br migrated through the matrix using a "distillation" process that concentrated volatile elements in the colder fuel regions. 


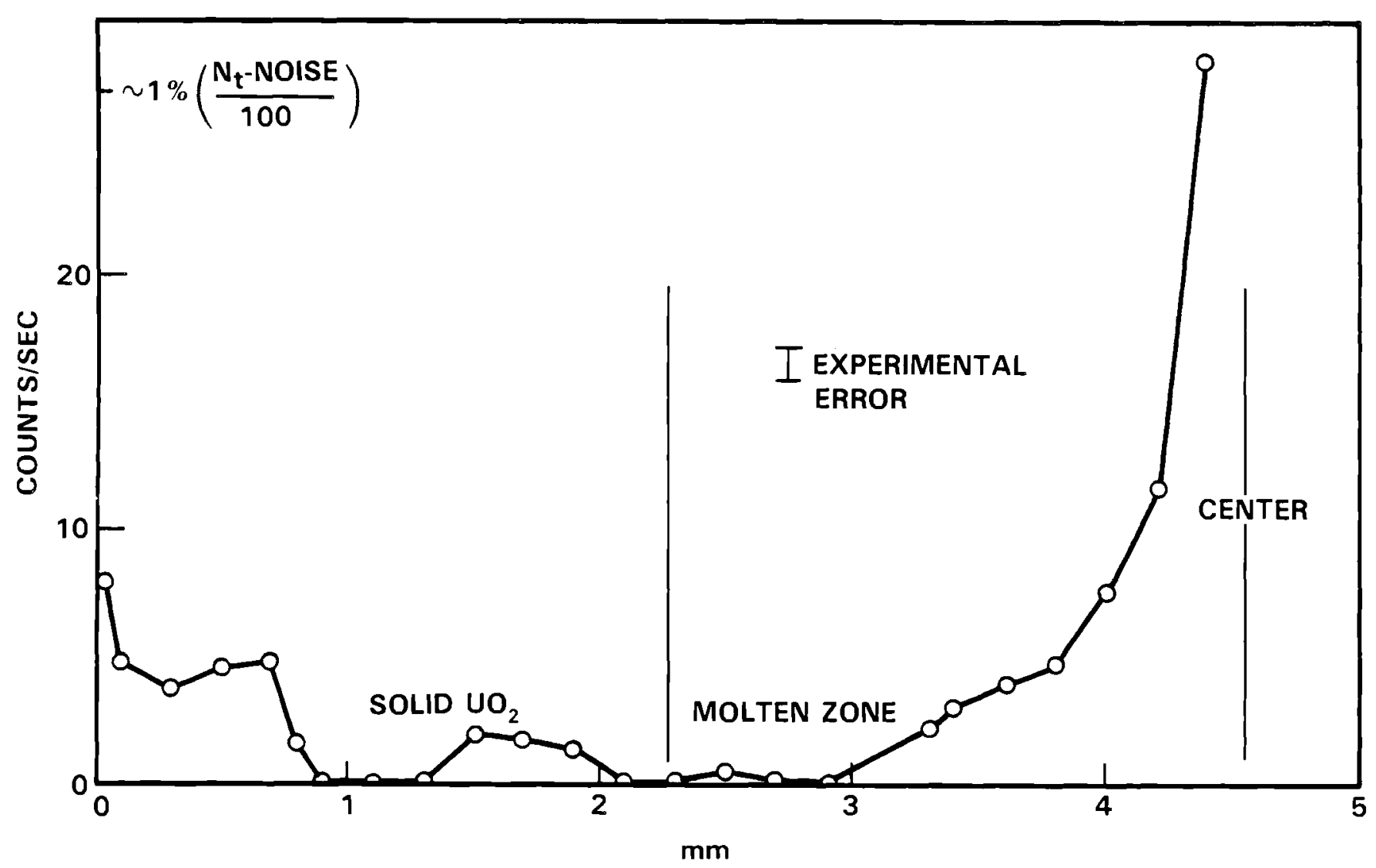

FIGURE III-2. Radial Distribution of Barium in $\mathrm{UO}_{2}$ (Bazin, Jouan, and Vignesoult 1974)

Cadmium

Electron microprobe analysis detected no Cd above background levels in any of four irradiated fuel rod cladding segments (Ivak and Waldman 1979). Camoszzo (1972) indicated that elements with a low boiling point like cd would exist in vapor form in the columnar region where the temperature is about $1700^{\circ} \mathrm{C}$. He assumed a migration through the fuel matrix with the same mechanisin as that used by the inert gases.

Cerium

No radial migration of ${ }^{144} \mathrm{Ce}$ was observed in a $7 \mathrm{~mm}$ diameter fuel pin irradiated in DFR at about $75 \mathrm{KW} / \mathrm{m}$ heating rate (Bramman and Powell 1975) (see Figure III-3). Others have found similar results for ${ }^{141} \mathrm{Ce}$. However, migration of $140_{\mathrm{Ba}} / \mathrm{La}$ as shown by gamma scanning implies the daughter isotope, ${ }^{140} \mathrm{Ce}$, will be nonuniformly distributed. 


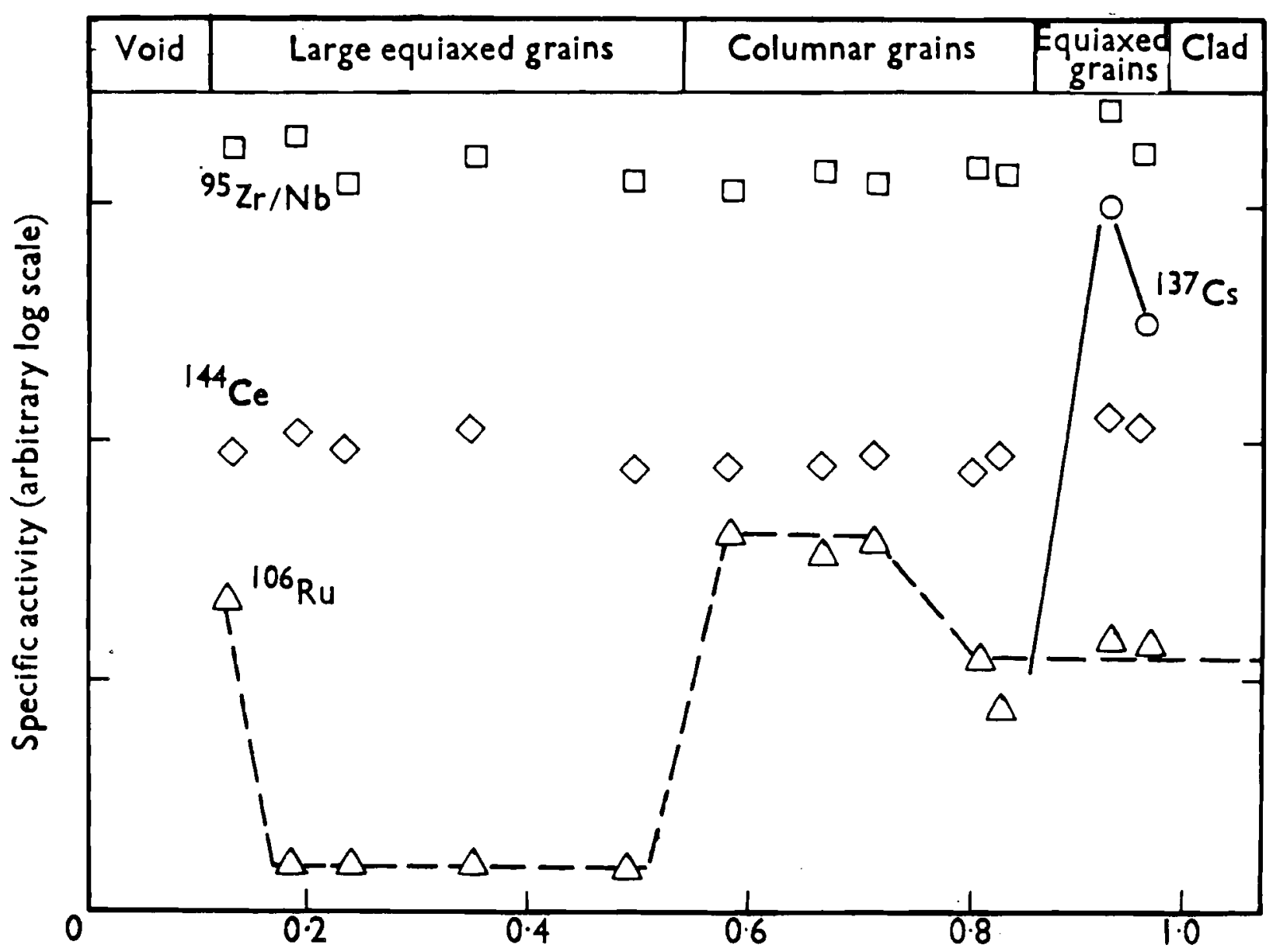

Sample location : fraction of fuel radius

FIGURE III-3. Radial Distribution of Fission Products in a $7 \mathrm{~mm}$ dia. Mixed Oxide Fuel Pin Irradiated in DFR (Bramman and Powell 1975). (Reprinted with permission from the Institution of Civil Engineers, London (a) 1975.)

Cesium

Experimental data on cesium distribution confirmed the view that alkali metals, probably present in highly volatile elemental form, would migrate extensively. Bramman and Powell (1975) indicated the following:

a) Gross radial migration to the cool periphery occurs even in relatively mild irradiation conditions; fuel pins in which only equiaxed grain growth has occurred have been found to have caesium concentrations near the periphery which are a factor of 100 or more greater than those near the centre... 
b) Axial migration of caesium toward the cooler end of pins is frequently observed.

However, Ke1man (1975) found no evidence of axial redistribution in a rod of H. B. Robinson fuel, based on an axial gamma scan (see Figure III-4). A study done on the content of $C S$ in cladding examined the inside diameter surface of four segments of cladding (from 4 separate rods). Two of the four segments showed high concentrations of $C_{s}$, especially at the location corresponding to a pellet-to-pellet interface region (Ivak and Waldman 1979).

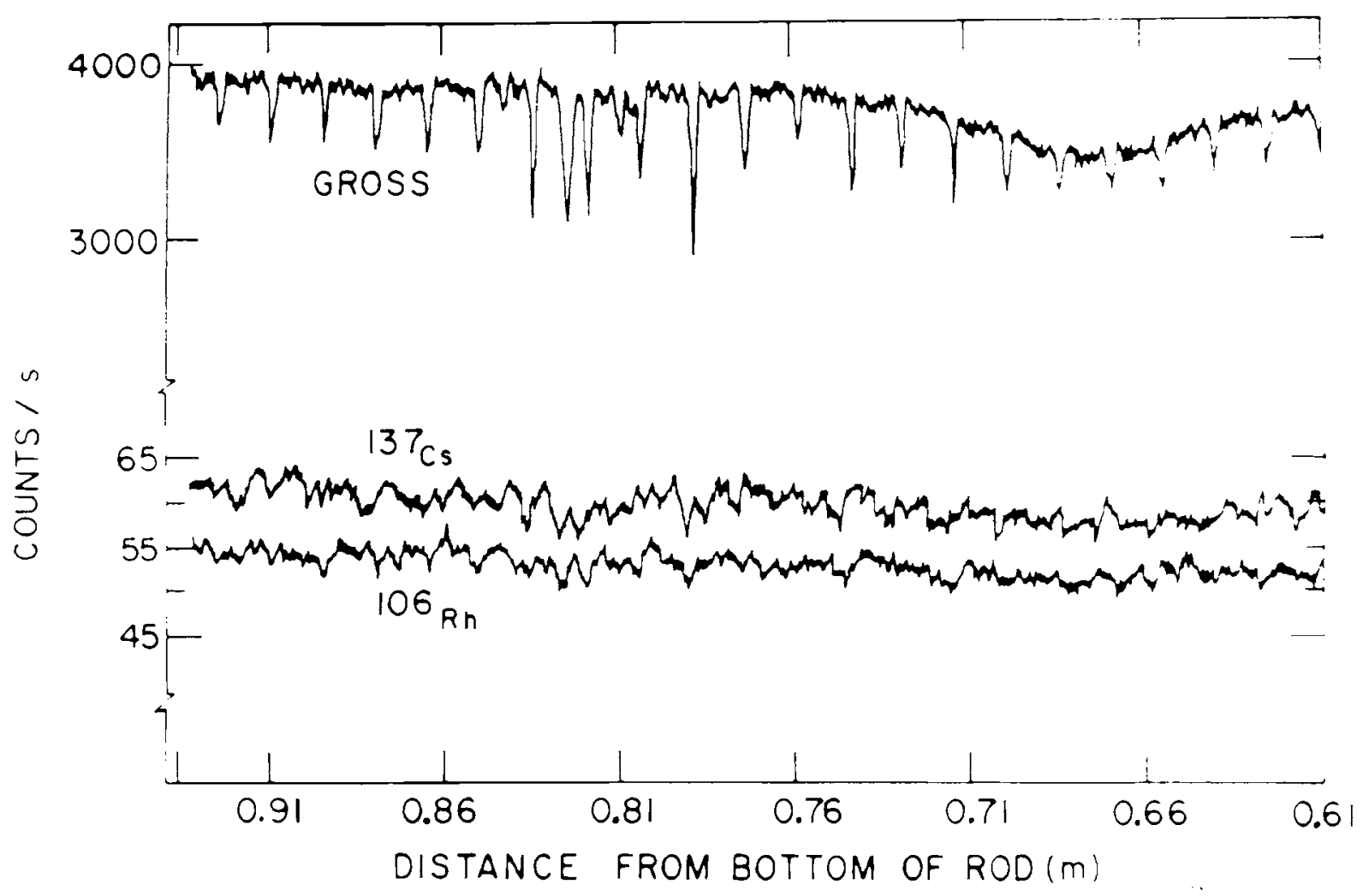

FIGURE III-4 Comparison of Gross and Isotopic Activity Traces

for Part of Rod-7. ANL Neg. No. MSD-62079 (Kelman 1975) 
Chromium

Chromium was once thought to be produced in the fuel as a result of iodine attacking the cladding and transporting the cladding elements into the fuel (Camoszzo 1972). However, such a mechanism has since been shown to be incorrect (Epstein 1975). Whatever the mechanism of transport is, Camoszzo found $\mathrm{Cr}$ hardiy penetrated the fuel matrix and remained in regions near the fuel-clad interface.

Iodine

Various analytical results have indicated the presence of iodine in the cooler, peripheral regions of the fuel (Ivak and Waldman 1979; Clayton and Riddle 1969; Bazin, Jouan, and Vignesoult 1974; Bramman and Powell 1975). Bramman and Powel1 (1975), using gamma scanning on fuel samples and cladding, indicated axial iodine migration towards the cooler end of the fuel pin. Their post-irradiation annealing tests have shown that the released fraction of iodine is as great as that for xenon, a fact indicating extensive radial migration. Camoszzo's (1972) discussion of iodine vapor indicated its migration to the fuel-clad interface and formation of metallic iodides; these iodides in turn were believed to have migrated into the high temperature matrix zones.

Iron

In ( $\mathrm{U}, \mathrm{Pu})_{2}$ fuel elements irradiated to high burnup, metallic inclusions containing iron have been found. The iron was found betiween boundaries of equiaxed and columnar zones; it can be alloyed with Pd or Mo. Camoszzo (1972) proposed the iron was transported from the cladding as an iodide but this mechanism has been shown to be incorrect (Epstein 1975).

\section{Krypton}

Krypton in $\mathrm{UO}_{2}$ and $\mathrm{UO}_{2}-\mathrm{PuO}_{2}$ fuels is driven towards the cooler outer regions of a pellet and may even escape from the fuel ( $\mathrm{Cl}$ ayton and Riddle 1979). It has been found in free and occluded spaces in the matrix and a small fraction penetrated the cladding by recoil but remained inert (Bazin, Jouan, and Vignesoult 1974). 
$\underline{\text { Lanthanides }}$

Lanthanum, praseodymium, neodymium and samarium showed no radial migration when analyzed using the electron microprobe technique (Bramman and Powel1 1975).

Molybdenum

Inclusions in columnar grains, globules in the molten zone and ingots in the central flue all contain molybdenum (Bazin, Jouan, and Vignesoult 1974). The inclusions in the columnar grains were a few microns in diameter; i.e., 5-10 $\mu \mathrm{m}$ (Bramman and Powell 1975), and contained essentially Mo, Ru, Tc; Pd and $\mathrm{Rh}$ accounted for no more than 1-2\% (Bazin, Jouan, and Vignesoult 1974; Bramman and Powel1 1975). The globules in the molten zone were made up of 95 Mo formed from ${ }^{95} \mathrm{Zr}$ and ${ }^{95} \mathrm{Nb}$. $\mathrm{Zr}$ and $\mathrm{Nb}$ moved towards the center through the temperature gradient aboard $\mathrm{Nb}_{2} \mathrm{O}_{5}$; this process resulted in metallic ${ }^{9} 5_{\mathrm{MO}}$ since at temperatures greater than $2000^{\circ} \mathrm{C}$ it cannot form an oxide and gathered into globules. Ingots in the central flue reached a size of $500 \mu \mathrm{m}$ and displayed two hexagonal phases. The first such phase was comprised of $61 \%$ Mo, $19 \% \mathrm{Ru}$ and $20 \% \mathrm{Tc}$ with a structure $\mathrm{Mo}_{5}(x \mathrm{Ru}, y \mathrm{Tc})_{3}$. The second phase contained $38 \%$ Mo, $21 \% \mathrm{TC}$, and $41 \% \mathrm{Ru}$.

Nickel

In general, nickel from the stainless steel cladding does not migrate and was found segregated at grain boundaries of the cladding (Camoszzo 1972).

Ni obium

Niobium enrichment in the center occurred as a result of $\mathrm{Nb}_{2} \mathrm{O}_{5}$ moving through the temperature gradient and volatilizing at temperatures $>1150^{\circ} \mathrm{C}$ (Bazin, Jouan, and Vignesoult 1974).

Palladium

Much of the palladium in fuels was found in the outer zones as a consequence of its high vapor pressure. Bramman and Powell (1975) found Pd in metallic inclusions associated with Fe and Ni. Bazin, Jouan, and Vignesoult (1974) examined TOF4 (French fuel rod irradiated under experimental 
conditions) with a molten zone and found metallic globules containing $\sim 50 \%$ Pd, $30 \% \mathrm{U}$, and $15 \% \mathrm{Sn}$ in a crack near the center.

Rhodium

No evidence of $\mathrm{Rh}$ axial redistribution was found in isotopic trace work done by Kelman (1975) (see Figure III-4). Radial gamma spectrophotometric analysis on a rod with no core melting showed two rings of Rh enrichment-one in the middle and the second around the edge (Bazin, Jouan, and vignesoult 1974).

Rutheni um

Ruthenium was found in ingots located in the central flue in association with Mo and Tc (see section on Mo; Bazin, Jouan, and Vignesoult 1974). Its distribution in inclusions was often found to rise as the radius increased and it was generally more concentrated at the cooler end of the columnar zone (Bramman and Powel1 1975).

Strontium

No Sr-rich areas have been observed; Sr appears to be uniformly distributed within the fuel matrix (Friskney and Simpson 1975).

Technetium

Due to its low boiling point, Camoszzo (1972) expected Tc to exist in vapor form in the columnar region and he assumed migration through the matrix would occur with the same mechanism as the inert gases. Tc in solid form was found in ingots in association with Mo and Ru (see section on Mo; Bazin, Jouan, and Vignesoult 1974).

Tel lurium

Tellurium gathered in the colder regions of the fuel and was more active in the oxide-cladding reaction zone (Bazin, Jouan, and Vignesoult 1974). An electron microprobe analysis of four irradiation tested rods examined the inside surface of four cladding segments. Three segments revealed no Te 
beyond background levels; one segment had a high concentration of Te which the above authors felt was due to the anomalous presence of mercury.

Tin

Tin was found in the outer regions of irradiated fuel in an electron microprobe study (Bramman and Powe11 1975).

Tritium

In an experiment conducted by Grossman and Hegland (1971) on $\mathrm{UO}_{2}$ fuel with a Zircaloy-2 cladding, a well defined trend was found in the $T$ content along the length of the fuel. Distribution in the cladding was also well defined for one rod (identified as $12 F V$ ) and in the second (CP-206). Tritium distribution in Rod 12FV's cladding indicated thermal migration had occurred (see Figures III-5 and III-6). A second study (Bazin, Jouan, and Vignesoult 1974) showed the longitudinal and axial distributions of $T$ in Fuel Pin 309 (see Figures III-7 and III-8).

Xenon

Xenon distribution data was obtained using electron microprobe analysis for axial midplane samples of 3 fuel pins irradiated to $50 \mathrm{MWd} / \mathrm{kg}$. Fission gas retention was restricted mainly to the outer quarter of the fuel radius (see Figure III-9) (Randklev 1978). Clayton and Riddle's (1969) discussion indicated $\mathrm{Xe}$ is expected to be driven towards the cooler outer regions of the pellet and may escape from the fuel.

Yttrium

Yttrium is a strong oxide former; the oxide is refractory and nonvolatile and little migration is expected.

Zirconium

Zirconium enrichment towards the center of the fuel occurred by segregation as the molten zone cooled. Examination of the oxidized phase in the molten zone showed 15 wt\% Zr (Bazin, Jouan, and Vignesoult 1974) (see Figures III-10 and III-11). 


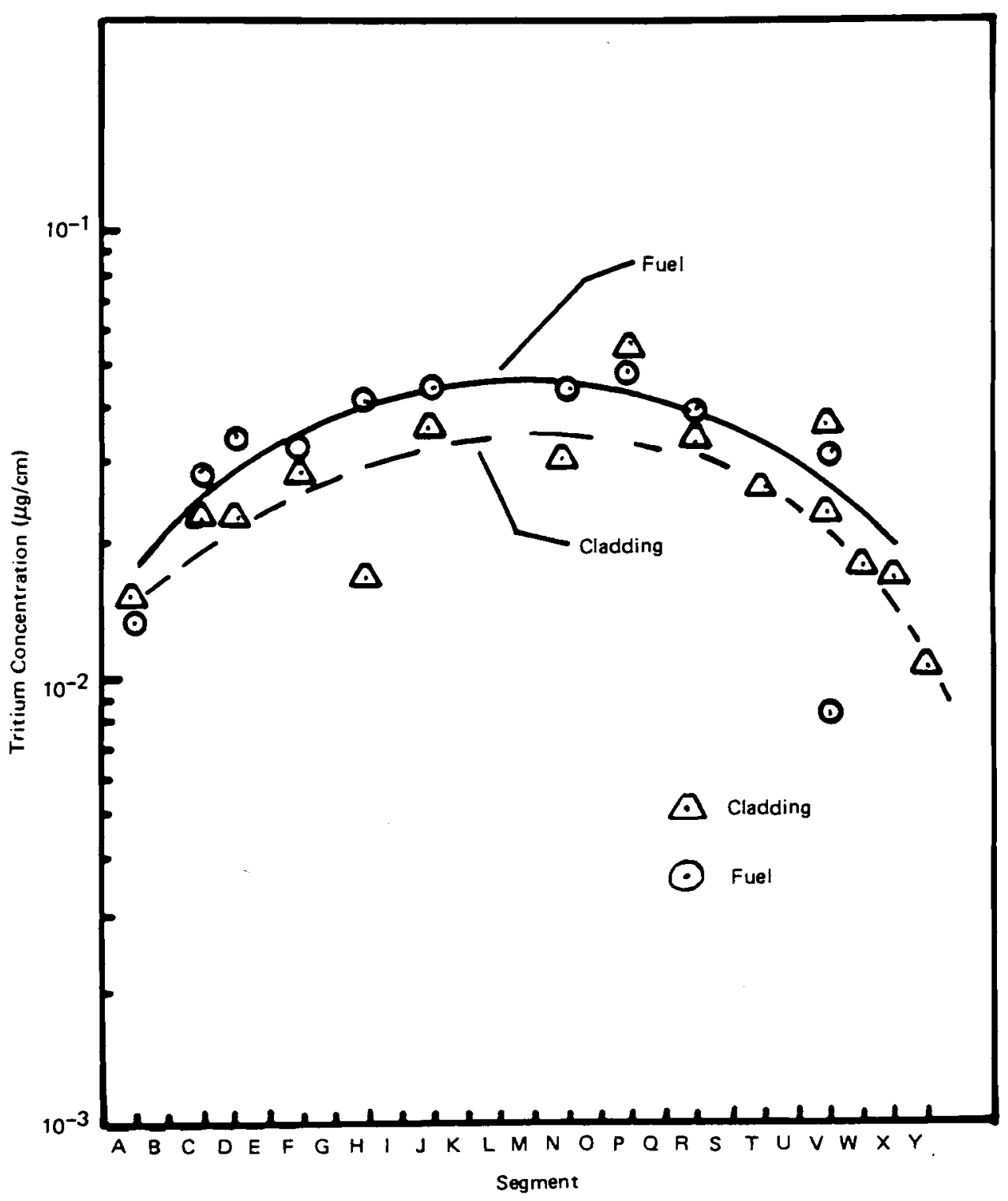

FIGURE III-5: Tritium Distribution in Rod CP206 (Grossman and Hegland 1971). 


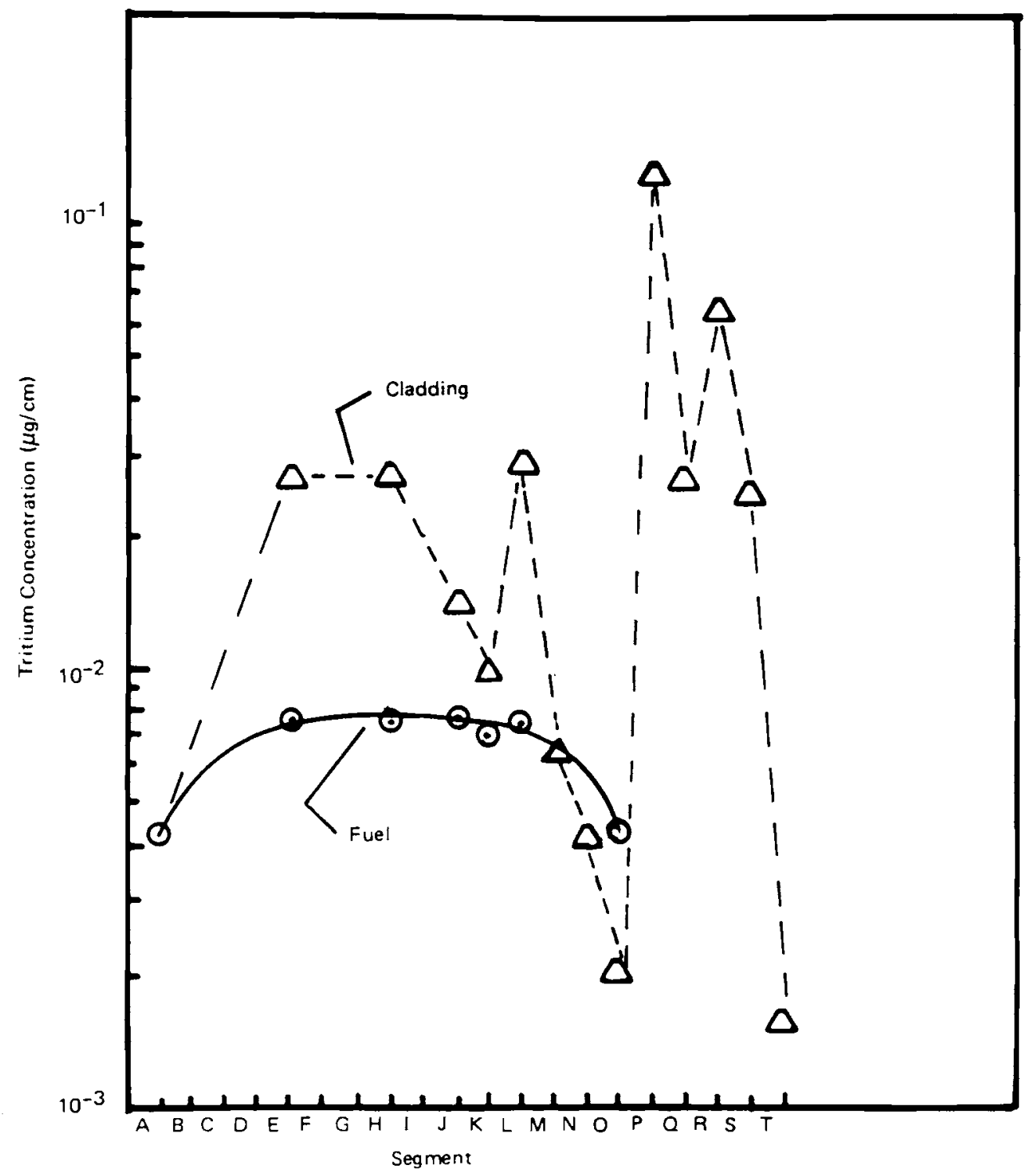

FIGURE III-6. Tritium Distribution in Rod 12FV (Grossman and Hegland 1971) 


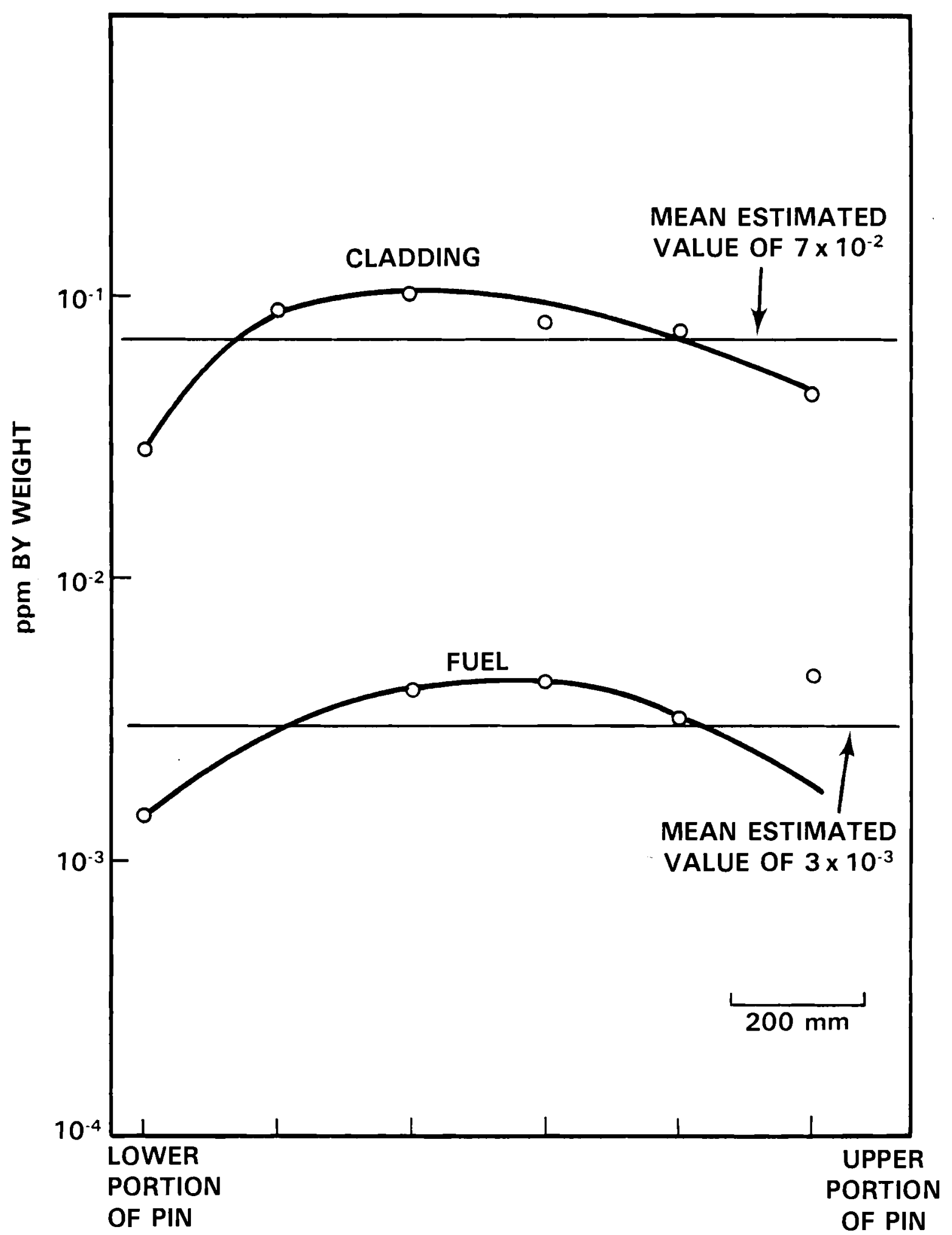

FIGURE III-7. Longitudinal Distribution of Tritium in Pin Number 309 (Bazin, Jouan, and Vignesoult 1974). 


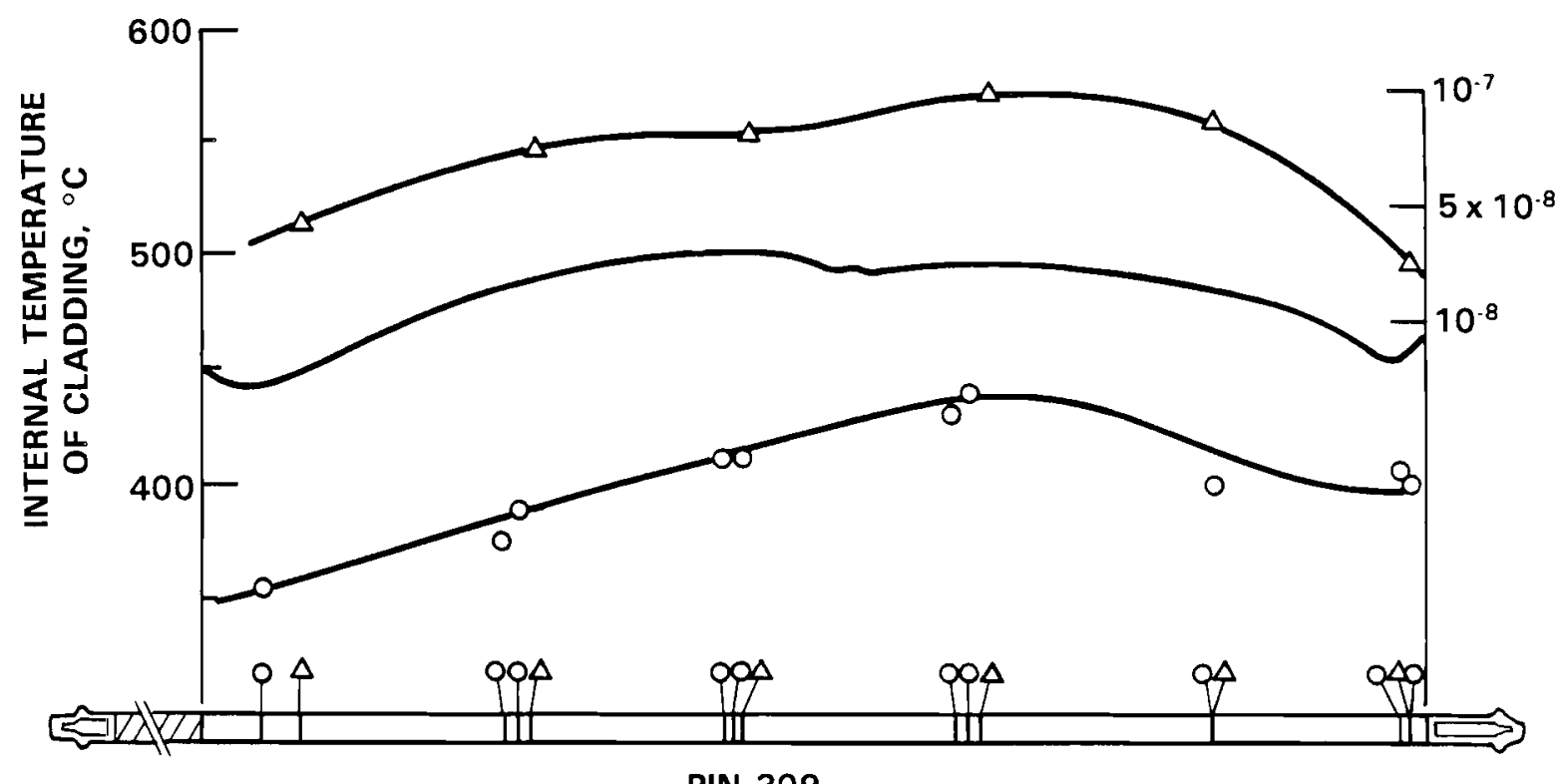

PIN 309

FIGURE III-8. Axial Variations in the Tritium Concentrations

in the Zircaloy Cladding of Pin 309 (Bazin, Jouan, and Vignesoult 1974).

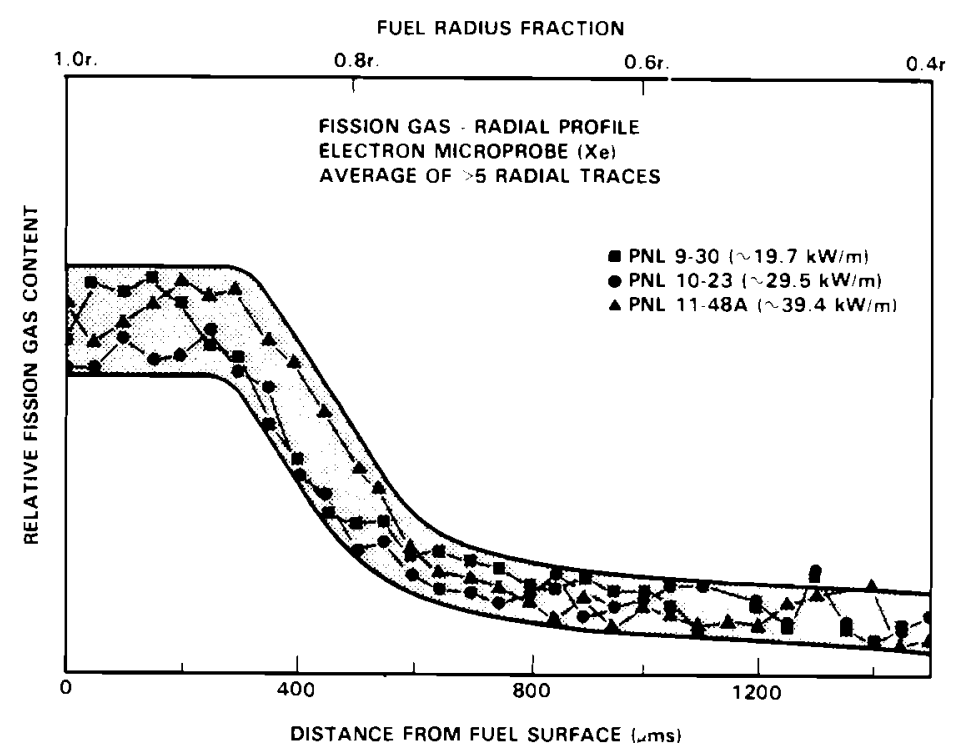

FIGURE III-9. Relative Radial Profiles of Retained (intragranular) Fission Gas at Axial Midplane within PNL-9, -10 , and -11 Fuel Irradiated to $\sim 50 \mathrm{MWd} / \mathrm{kg}$ (Randklev 1978) (Reprinted with permission from American Nuclear Society, La Grange Park, Illinois (- 1978.) 


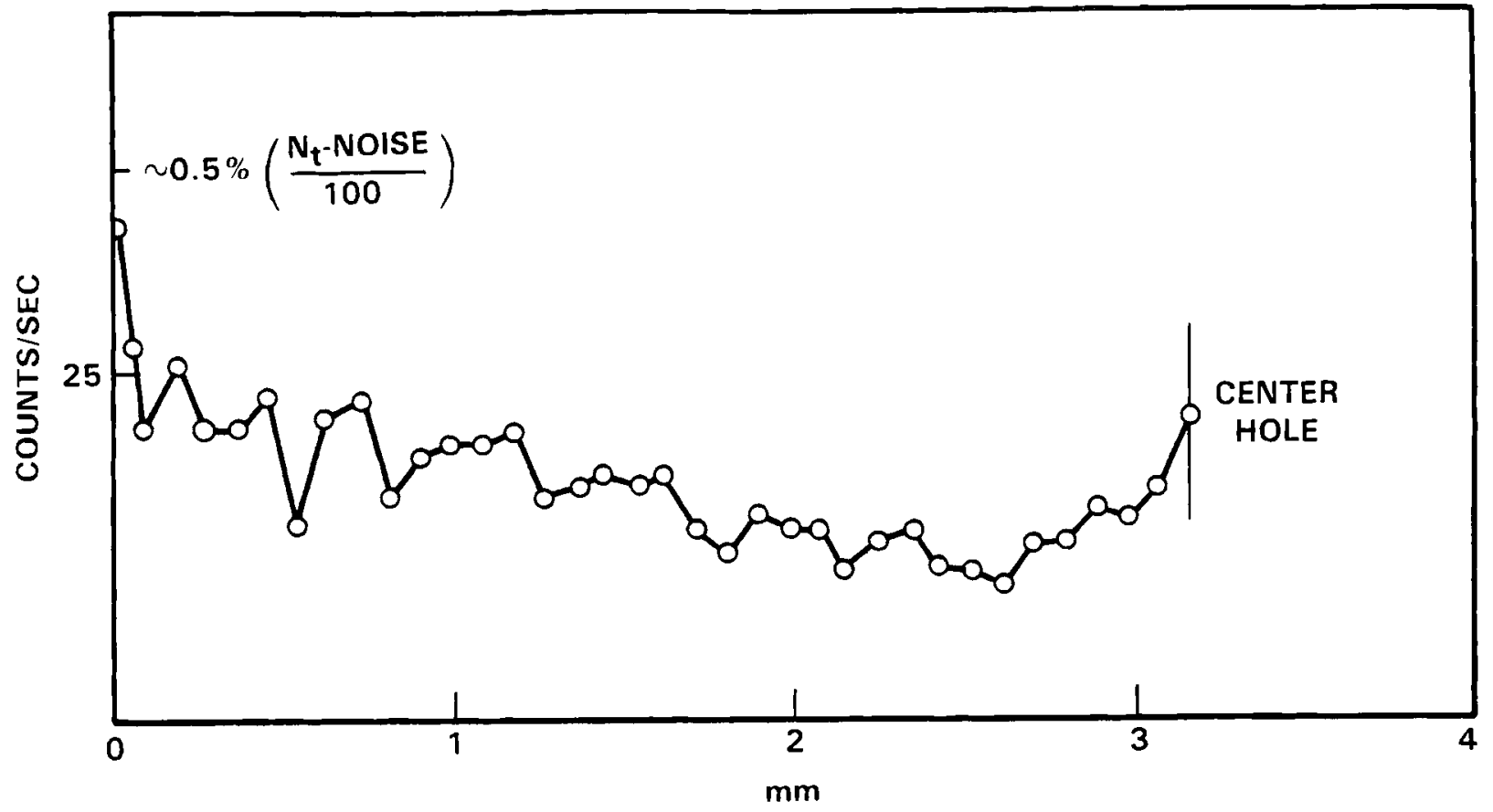

FIGURE III-10. Radial Distribution of Zirconium (EPEL 6, 25,900 MWd/tU) (Bazin, Jouan, and Vignesoult 1974).

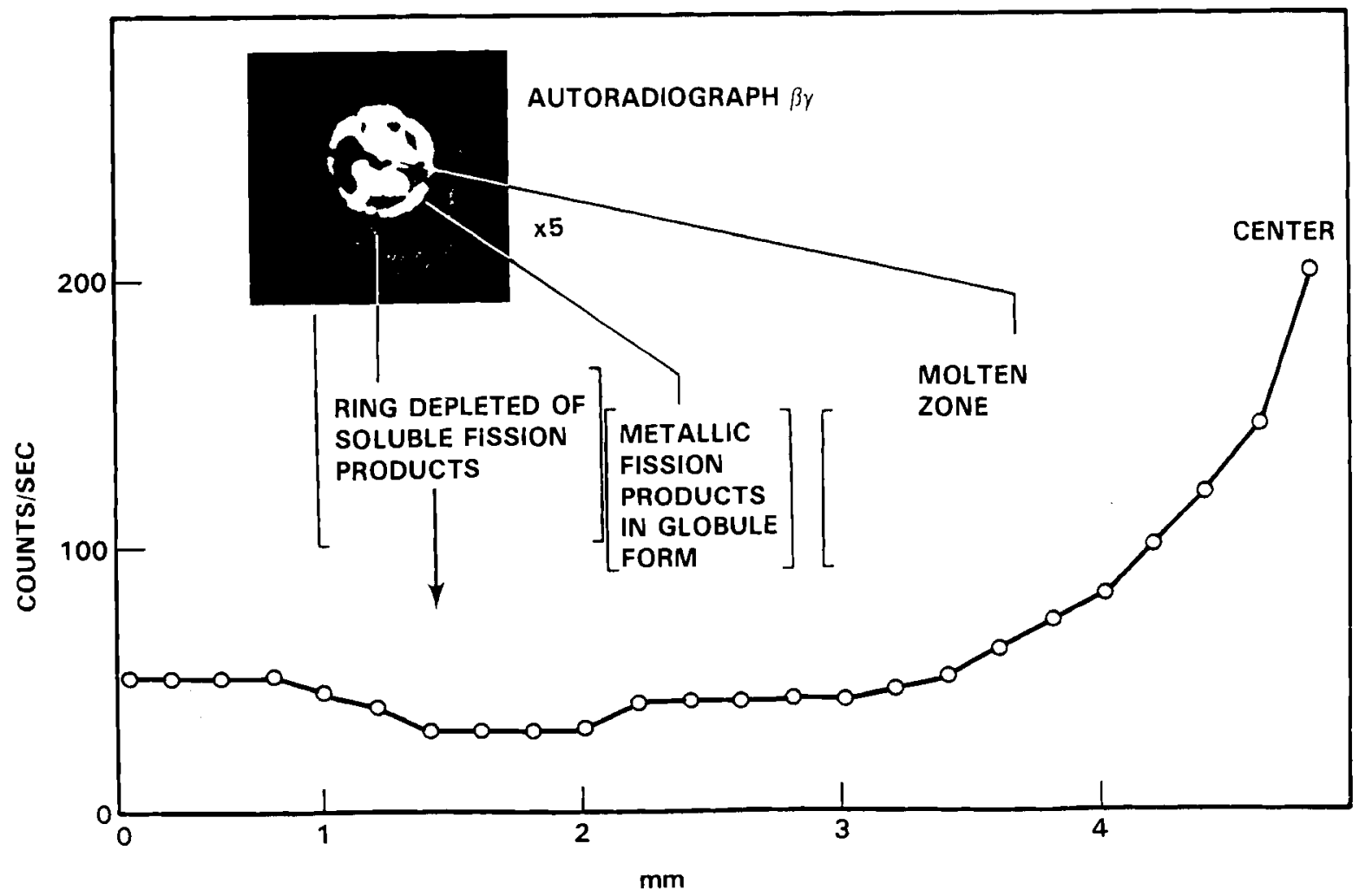

FIGURE III-11. TOF 15. Radial Distribution of Zirconium in the $\mathrm{UO}_{2}$ (Bazin, Jouan, and Vignesoult 1974). 
COMPOSITION OF FISSION PRODUCTS IN IRRADIATED FUEL (CHEMICAL FORM)

Fission products from irradiated $\mathrm{UO}_{2}$ and $\mathrm{UO}_{2} / \mathrm{PuO}_{2}$ fuels consist mainly of the elemental isotopes and their oxides. Bramman and Powell (1975) state that "...none of the fission-product nuclides which are studied during postirradiation examination is produced directly in fission, the primary fission products being radioactive species which undergo several stages of beta decay." Fission products are found distributed in the fuel matrix, on the inner surface of the fuel cladding, and in the gas plenum.

According to Bullard (1978), the value for the oxygen potential, $\Delta G\left(0_{2}\right)$, of the fuel is the deciding factor on whether a fission product will exist as a metal or an oxide. $\Delta G\left(\mathrm{O}_{2}\right)$ depends on four factors: (1) fuel composition; (2) valence of the fertile isotopes; (3) fuel temperature; and (4) degree of burnup. Bullard (1978) states that the form of the elements in the fuel at operating temperature is not likely to change much as the fuel cools.

On the basis of calculations using thermodynamic data, Brook (1972) predicted that: (1) the rare earths should be present as oxides; (2) Ba and $\mathrm{Sr}$ form zirconates; (3) I and $\mathrm{Br}$ combine with $\mathrm{Cs}$; (4) fission products present as elements should be Tc, Te, Sb, Cd, In, Pd, Rh, Ru, Ag, and Sn. Brook (1972) found that Cs made up $10.4 \%$ of all fission products, $R b 0.6 \%$ of all fission products, $\mathrm{Cd}, \mathrm{Sb}$, and Te $3.8 \%$ of the total inventory, and noble gases approximately $12 \%$ of the inventory.

The table which follows is a compilation of information on fission products found in $\mathrm{UO}_{2}$ and $\mathrm{UO}_{2} / \mathrm{PuO}_{2}$. Except for Paulson and Springborn (1968), a majority of the products indicated are from experimental work. Steindler's data (Steindler et al. 1978) are from a table on fission products for which a 1 iterature survey of six authors was conducted; it was assumed herein that these products were experimentally found. Paulson and Springborn's (1968) table of isotopes was compiled to calculate product yields; these were assumed to be potential fission products. 
TABLE III-3. Fission Products in $\mathrm{UO}_{2}, \mathrm{UO}_{2} / \mathrm{PuO}_{2}$ Fuel

\begin{tabular}{|c|c|c|}
\hline Fission Product & Mass No. 1 & Reference \\
\hline Germanium & $\begin{array}{l}72 \\
73 \\
74 \\
76\end{array}$ & $\begin{array}{c}\text { Paulson and Springborn } 1968 \\
" 1 " \\
" \quad "\end{array}$ \\
\hline Arsenic & 75 & Paulson and Springborn 1968 \\
\hline Seleni um & $\begin{array}{l}77 \\
78 \\
79 \\
80 \\
82 \\
--\end{array}$ & $\begin{array}{l}\text { Paul son and } \text { Springborn } 1968 \\
" \text { " } \\
" \text { " " } \\
\text { Steindler et al. } 1978\end{array}$ \\
\hline $\begin{array}{l}\text { Bromine } \\
\qquad \mathrm{CsBr}\end{array}$ & $\begin{array}{l}81 \\
--\end{array}$ & $\begin{array}{l}\text { Paul son and Springborn } 1968 \\
\text { Steindler et al. 1978 } \\
\text { Davies and Ewart 1971; Brook } 1972\end{array}$ \\
\hline Krypton & $\begin{array}{l}83 \\
84 \\
85\end{array}$ & $\begin{array}{l}\text { Paulson and Springborn 1968; } \\
\text { Grossman and Hegland 1971 } \\
\text { Paul son and Springborn 1968; } \\
\text { Grossman and Hegland 1971 } \\
\text { Langer et a1.1978; Paul son and } \\
\text { Springborn 1968; Grossman and Hegland } \\
1971 \text {; Goode and Cox 1970; Scargi11 } \\
1978 \\
\text { Grossman and Hegland 1971; Paul son } \\
\text { and Springborn 1968 } \\
\text { Steindler 1978; Morewitz } 1981\end{array}$ \\
\hline Rubi di um & $\begin{array}{l}85 \\
87 \\
--\end{array}$ & $\begin{array}{l}\text { Paul son and Springborn 1968; Langer } \\
\text { et al. } 1978 \\
\text { Paul son and Springborn 1968; Langer } \\
\text { et al. } 1978 \\
\text { Steindler et al. } 1978 \\
\text { Steindler et al. } 1978\end{array}$ \\
\hline Strontium & $\begin{array}{l}88 \\
89 \\
90\end{array}$ & $\begin{array}{l}\text { Paul son and Springborn 1968; Langer } \\
\text { et al. } 1978 \text { Springborn 1968; Morewitz } \\
\text { Paul son and Spring } \\
1981 \\
\text { Paul son and Springborn 1968; Morewitz } \\
1981 \\
\text { Morewitz } 1981\end{array}$ \\
\hline
\end{tabular}

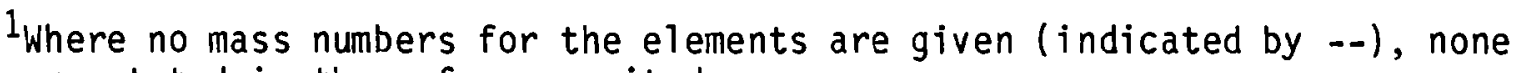
were stated in the reference cited. 
TABLE III-3. (Contd)

\begin{tabular}{|c|c|c|}
\hline Fission Product & Mass No. & Reference \\
\hline Sro & & $\begin{array}{l}\text { Schmitz, Dean, and Hal achmy 1971; } \\
\text { Steindler et al. } 1978\end{array}$ \\
\hline $\mathrm{SrZrO}_{3}$ & & Sari, Walker, and Schumacher 1979 \\
\hline Yttrium & 89 & $\begin{array}{l}\text { Paulson and Springborn 1968; Langer et } \\
\text { al. } 1978\end{array}$ \\
\hline & 91 & $\begin{array}{l}\text { Paulson and Springborn 1968; } \\
\text { Langer et al. } 1978\end{array}$ \\
\hline $\mathrm{YO}_{2}$ & & Steindler et al. 1978 \\
\hline $\mathrm{Y}_{2} \mathrm{O}_{3}$ & & Steindler 1978 \\
\hline Zirconium & $\begin{array}{l}90 \\
91\end{array}$ & $\begin{array}{l}\text { Langer et al. } 1978 \\
\text { Paulson and Springborn 1968; Langer } \\
\text { et al. } 1978\end{array}$ \\
\hline & 92 & $\begin{array}{l}\text { Paulson and Springborn 1968; Langer } \\
\text { et al. } 1978\end{array}$ \\
\hline & 93 & $\begin{array}{l}\text { Paulson and Springborn 1968; Langer } \\
\text { et al. } 1978\end{array}$ \\
\hline & $\begin{array}{l}94 \\
95\end{array}$ & $\begin{array}{l}\text { Paulson and Springborn } 1968 \\
\text { Paulson and Springborn 1968; Dean } \\
\text { et al. 1975; Bramman and Powell } 1975\end{array}$ \\
\hline & 96 & Paulson and Springborn 1968 \\
\hline & -- & $\begin{array}{l}\text { Steindler et al. } 1978 \\
\text { Steindler et al. } 1978\end{array}$ \\
\hline & & \\
\hline$(\mathrm{Ba}, \mathrm{Sr}) \mathrm{ZrO}_{3}$ & & Sari, Walker, and Schumacher 1979 \\
\hline Niobium & $\begin{array}{l}93 \\
95\end{array}$ & $\begin{array}{l}\text { Langer et al. } 1978 \\
\text { Paulson and Springborn 1968; Dean } \\
\text { et al. 1975; Bramman and Powell } 1975\end{array}$ \\
\hline $\mathrm{NbO}_{2}$ & & Steindler et al. 1978 \\
\hline $\mathrm{Nb}_{2} \mathrm{O}_{3}$ & & Steindler et al. 1978 \\
\hline $\mathrm{Nb}_{2} \mathrm{O}_{5}$ & & Steindler et al. 1978 \\
\hline Molybdenum & $\begin{array}{l}95 \\
97 \\
98 \\
100 \\
---\end{array}$ & $\begin{array}{l}\text { Paulson and Springborn } 1968 \\
\text { Paulson and Springborn } 1968 \\
\text { Paulson and Springborn } 1968 \\
\text { Paulson and Springborn } 1968 \\
\text { Epstein 1975; Davies and Ewart 1971; } \\
\text { Steindler et al. 1978 }\end{array}$ \\
\hline $\mathrm{MoO}_{2}$ & & Steindler et al. 1978 \\
\hline $\mathrm{MoO}_{3}$ & & Davies and Ewart 1971 \\
\hline $\mathrm{Cs}_{2} \mathrm{MOO}_{4}$ & & Epstein 1975; Morewitz 1981 \\
\hline
\end{tabular}


TABLE III-3. (contd)

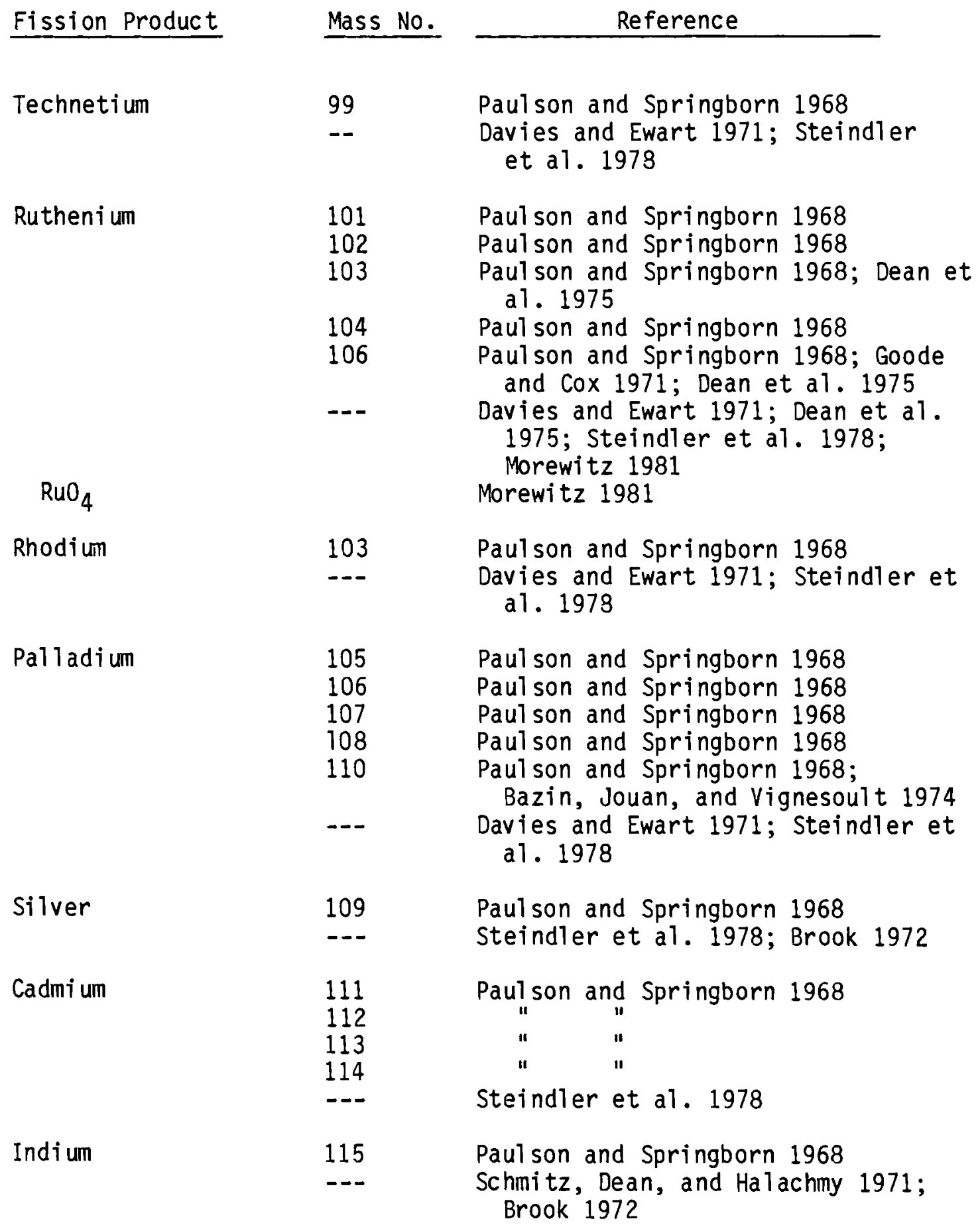


Fission Product

Tin

Antimony

$\mathrm{Sb}_{2} \mathrm{O}_{3}$

Tellurium

125

126

127

128

130

132

$\mathrm{Cs}_{2} \mathrm{Te}$

Iodine

132

133

134

135

127

129

131

$I_{2}$

CSI

$\mathrm{CH}_{3} \mathrm{I}$

117

118

119

120

121

122

124

126

---
TABLE III-3. (Contd)

Mass No. 1

Reference

Paulson and Springborn 1968

11

II

II 11

II

"

11

Steindler et a1. 1978; Bazin, Jouan, and Vignesoult 1974; Bramman and Powel1 1975

Paulson and Springborn 1968

Paulson and Springborn 1968

Paulson and Springborn 1968; Bramman and Powel1 1975

Steindler et a1. 1978; Morewitz 1981 Paulson and Springborn 1968

Paul son and Springborn 1968

1

11

11

4

Dean et a1. 1975

Steindler et al. 1978; Morewitz 1981 Morewitz 1981

Clayton and Riddle 1969

Clayton and Riddle 1969; Clayton 1979

Clayton and Riddle 1969; Dean et al. 1975; Scargil1 1975; Epstein 1975; Morewitz 1981

Clayton 1979; Dean et a1. 1975

" "

Morewitz 1981

Clayton 1979; Brook"1972

II 
TABLE I I -3. (Contd)

Fission Product Mass No. 1

Xenon

Reference

133

134

136

Cesium

134

135

137

$\mathrm{Cs}_{2} \mathrm{O}$
$\mathrm{CsOH}$
$\mathrm{Cs}_{2} \mathrm{CO}_{3}$
$\mathrm{CsBr}$
$\mathrm{CsI}$
$\mathrm{Cs}_{2} \mathrm{MoO}_{4}$
$\mathrm{Cs}_{2} \mathrm{Te}$
$\mathrm{CsUO}_{3}$
$\mathrm{CsUO}_{4}$
$\mathrm{Cs}_{2} \mathrm{U}_{2} \mathrm{O}_{7}$
$\mathrm{Cs}_{1.3}(\mathrm{U}, \mathrm{Pu}) \mathrm{O}_{3}$
$\mathrm{Cs}_{2} \mathrm{U}_{4} \mathrm{O}_{12}$
$\mathrm{Cs}_{x} \mathrm{OO}_{y}$

Paulson and Springborn 1968; Goode and Cox 1970; Grossman and Hegland 1971

Paulson and Springborn 1968; Goode and Cox 1970

Morewitz 1981

Paulson and Springborn 1968; Goode and Cox 1970; Grossman and Hegland 1971

Paulson and Springborn 1968; Goode and Cox 1971; Grossman and Hegland 1971

Paulson and Springborn 1968; Bramman and Powell 1975; Langer et al. 1978 Bramman and Powell 1975; Dean et al. 1975; Epstein 1975; Langer et al. 1978

Paulson and Springborn 1968; Bramman and Powell 1975; Langer et al. 1978

Paulson and Springborn 1968; Bramman and Powe 11 1975; Dean et al. 1975; Goode and Cox 1970; Morewitz 1981; Epstein 1975

Epstein 1975; Steindler et a1. 1978; Morewitz 1981

Morewitz 1981

Steindler et al. 1978

Davies and Ewart 1971; Brook 1972

Steindler et al. 1978; Morewitz 1981; Brook 1972

Epstein 1975; Morewitz 1981

Morewitz 1981

Epstein 1975

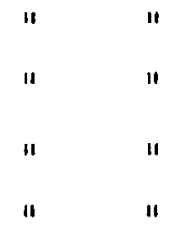

Morewitz 1981 
TABLE III-3. (Contd)

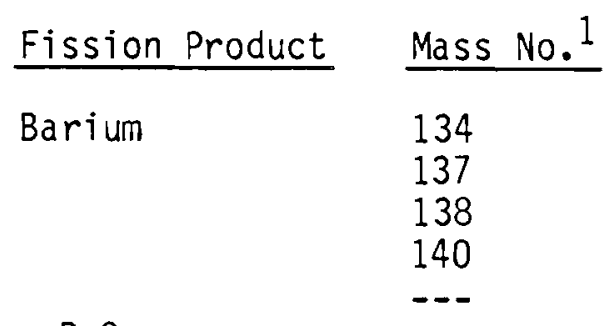

\section{$\mathrm{BaO}$}

$\mathrm{BaCO}_{3}$

$\mathrm{BaZrO}_{3}$

Lanthanum

139

$\mathrm{LaO}_{2}$

$\mathrm{La}_{2} \mathrm{O}_{3}$

Cerium

$\mathrm{CeO}_{2}$

$\mathrm{Ce}_{2} \mathrm{O}_{3}$

Praseodymium

$\mathrm{PrO}_{2}$

$\mathrm{Pr}_{2} \mathrm{O}_{3}$

$\operatorname{Pr}_{6}{ }^{0} 11$

Neodymi um

143

$\mathrm{NdO}_{2}$

$\mathrm{Nd}_{2} \mathrm{O}_{3}$

Reference

Langer et al. 1978

Paulson and Springborn 1968

Dean et a 1. 1975

Steindler et al. 1978; Morewitz 1981

Schmitz, Dean, and Halachmy 1971; Steindler et al. 1978;

Sari, Walker, and Schumacher 1979

Steindler et al. 1978

Davies and Ewart 1971; Sari, Walker, and Schumacher 1979

Paulson and Springborn 1968

Steindler et al. 1978

Steindler et al. 1978

Paulson and Springborn 1968

Paulson and Springborn 1968; Dean et al. 1975

Paulson and Springborn 1968; Dean et al. 1975.

Paulson and Springborn 1968;

Dean et al. 1975; Goode and Cox 1970.

Steindler et al. 1978

Steindler et al. 1978

Paulson and Springborn 1968

Steindler et al. 1978

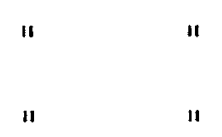

Paulson and Springborn 1968

$\begin{array}{ll}\| & \| \\ \| & \|\end{array}$

Paulson and Springborn 1968

Paulson and Springborn 1968

Steindler et al. 1978 
TABLE II I-3. (Contd)

\begin{tabular}{|c|c|c|}
\hline Fission Product & Mass No. ${ }^{1}$ & Reference \\
\hline Promethium & 147 & Paulson and Springborn 1968 \\
\hline $\mathrm{PmO}_{2}$ & & Steindler et al. 1978 \\
\hline $\mathrm{Pm}_{2} \mathrm{O}_{3}$ & & Steindler et al. 1978 \\
\hline Samarium & $\begin{array}{l}147 \\
149 \\
150 \\
151 \\
152 \\
154\end{array}$ & $\begin{array}{c}\text { Paulson and Springborn } 1968 \\
" 1 " \\
" 1 " \\
" 1 "\end{array}$ \\
\hline $\mathrm{SmO}_{2}$ & & Steindler et al. 1978 \\
\hline $\mathrm{Sm}_{2} \mathrm{O}_{3}$ & & " \\
\hline $\mathrm{EuO}_{2}$ & $\begin{array}{l}153 \\
154 \\
155\end{array}$ & $\begin{array}{l}\text { Paulson and Springborn } 1968 \\
\text { Goode and Cox } 1970 \\
\text { Paulson and Springborn } 1968 \\
\text { Steindler et al. } 1978\end{array}$ \\
\hline $\mathrm{Eu}_{2} \mathrm{O}_{3}$ & & Steindler et al. 1978 \\
\hline Gadol inium & $\begin{array}{l}155 \\
156 \\
157 \\
158 \\
160\end{array}$ & $\begin{array}{c}\text { Paulson and Springborn } 1968 \\
\text { " } \\
" \text { " }\end{array}$ \\
\hline & & $\begin{array}{l}\text { Steindler et al. 1978; Bazin, Jouan, } \\
\text { and Vignesoult } 1974\end{array}$ \\
\hline $\mathrm{Gd}_{2} \mathrm{O}_{3}$ & & Steindler et al. 1978 \\
\hline $\begin{array}{l}\text { Terbium } \\
\text { Tb oxide }\end{array}$ & $\begin{array}{l}159 \\
---\end{array}$ & $\begin{array}{l}\text { Paulson and Springborn } 1968 \\
\text { Bazin, Jouan, and Vignesoult 1974; } \\
\text { Schmitz, Dean, and Halachmy } 1971 \\
\text { Brook } 1972\end{array}$ \\
\hline Dy Oxide & $\begin{array}{l}161 \\
---\end{array}$ & $\begin{array}{l}\text { Paulson and Springborn } 1968 \\
\text { Bazin, Jouan, and Vignesoult 1974; } \\
\text { Schmitz, Dean, and Halachmy } 1971 \\
\text { Brook } 1972\end{array}$ \\
\hline
\end{tabular}


Both Zircaloy cladding in light water reactors and stainless steel cladding in fast breeder reactors react with some of the fission products from $\mathrm{UO}_{2}$ and $(\mathrm{U}, \mathrm{Pu})_{2}$ fuels. Important fission products in fuel/cladding interaction are iodine, tellurium, cesium, hydrogen, and carbon; the oxygen/metal ratio also strongly influences interaction.

In the fabrication of fuel rods, the inside diameter of the cladding is made so that the pellets can be easily inserted. This results in a radial gap between the fuel and cladding which is reduced in magnitude during irradiation. In the reactor, the fue 1 cracks and expands and the stainless steel creeps; eventually the cladding collapses onto the fuel, remaining there until appreciable quantities of fission gases have been released (Cottrell et a1. 1960).

Lawrence, Hata, and Weber (1979) reviewed four mechanisms postulated to be explanations for fuel/cladding chemical interaction. All four were based on either oxidation or material transport studies and were similar in that they required a fission product medium to transport oxygen to the reaction sites. In all the mechanisms, cesium was the important fission product and, generally, the controlling mechanism for the depth of reaction was the oxygen potential in the area of the fuel/cladding gap.

One model proposed that fuel/cladding interaction in stainless-steel-clad mixed oxide fuels was due to cesium and tellurium fission products increasing grain boundary oxidation. The model indicated a combination of reaction paths, but the basic process was oxidation of cladding elements. A second mechanism was an electrochemical dissolution wherein anodic dissolution of the cladding interface occurred by galvanic cell reactions. The third mechanism was basically one of cesium accelerated oxidation. Model four assumed the formation of spinel-type oxides on the cladding surface.

Although the mechanism(s) of fission product attack on the cladding is not clearly understood, Epstein (1975) made some general observations:

- Thermal reactor experience has shown that stoichiometric $\mathrm{UO}_{2}$ is stable with respect to cladding attack. 
- Mixed U, Pu oxide has a greater oxygen potential than pure urania of the same $0 / M$ ratio at equivalent temperature, and $c l$ adding attack is quite sensitive to the local oxygen potential.

- ...it has been found that general cladding attack is limited to about $12 \%$ of the cladding thickness, whereas intergranular penetration can go considerably farther.

- ...cladding attack is not found at cladding temperatures less than $500^{\circ} \mathrm{C}$.

- Whenever cladding attack has been found, Cs and Mo have also been present.

Bazin, Jouan, and Vignesoult (1974) noted the lack of understanding of the fuel/cladding interaction mechanism but did observe a three step oxidezircaloy cladding reaction process. In the first step, optical microscope observations showed no zirconium layer on the inner surface of the cladding. The second stage was a growth several microns thick, which protected the cladding. However, as the layer thickened, cracks appeared and allowed the entry of fission products like cesium. Cesium in joints between the zircaloy grains can weaken the alloy, but Bazin, Jouan, and Vignesoult (1974) rarely saw pins where this occurred. In the third stage the cladding contacted the fuel because of a $\mathrm{UO}_{2}-\mathrm{ZrO}_{2}$ diffusion phenomena. This contact can cause breaks in fuel rods as expansion and contraction occurs, and it is in this contact zone where fission products, especially cesium, were found.

Micrographic examination of the fuel/cladding reaction zone by Bazin, Jouan, and Vignesoult (1974) showed a difference in appearance for small, as opposed to large, fuel/clad gaps. Pins with a large lateral play of $0.30 \mathrm{~mm}$ often formed two sub-layers -- a dense layer next to the cladding comprised of $\mathrm{U}$ and associated $\mathrm{Zr}-\mathrm{Cs}$ elements and a porous 1 ayer which contained $\mathrm{Pd}, \mathrm{Ba}$, and Te. Pins with a small lateral play $(0.15 \mathrm{~mm})$ contained only a single layer consisting of U-Zr associated with $\mathrm{Ba}$ and $\mathrm{Cs}$. Cesium was especially visible in joints of peripheral $\mathrm{UO}_{2}$ grains, and iodine was also in the periphery, particularly in interpellet spaces. Camoszzo (1972) referenced a study which found metallic inclusions within a mixed oxide fuel element; the inclusions 
contained the constituents of the stainless steel cladding ( $\mathrm{Fe}, \mathrm{Cr}, \mathrm{Ni}--\mathrm{see}$ Distribution of Fission Products).

Bazin, Jouan, and Vignesoult (1974) conducted a post irradiation classification of the pins tested to try to correlate the formation of gray layers at the oxide cladding interface with mass combustion and power level. They concluded that below 10,000 MWd/tU, the accumulation of fission products at the interface was probably not enough to allow formation of reaction layers even though the pin may have functioned at a high power level.

\section{Oxygen/Metal Ratio}

"Effects of initial stoichiometry (oxygen-to-metal ratio $(0 / M)$ ) on the character and extent of fuel-cladding chemical interaction (FCCI) were established for mixed uranium and plutonium oxide fuels clad with $20 \%$ coldworked Type 316 stainless steel irradiated to peak burnups of $\sim 3.6$ at.\%" (Lawrence, Hata, and Weber 1979). Reduction or elimination of FCCI can increase a fuel pin's lifetime. Stoichiometry $(0 / M)$, cladding temperature, and burnup (reactor residence time) are important parameters in FCCI. The most straight-forward method to reduce FCCI in U/Pu oxide fuels would be to lower the $0 / M$ ratio as reduction in either reactor residence time or operating temperatures is undesirable in relationship to overall reactor efficiency. However, consideration must be given to fabrication and fuel performance questions. Low $O / M$ fuels require processing in low oxygen content atmospheres and storage in inert atmospheres. Experimental work conducted prior to that of Lawrence, Hata, and Weber (1979) showed that a reduction in the initial $0 / M$ resulted in a corresponding reduction in FCCI.

Lawrence, Hata, and Weber (1979) used fuel pins with average initial 0/M values of $1.94,1.95$, or 1.97 ; pins were removed at $1.1,2.5$, and 3.6 at.\% burnup and examined to characterize the effects of the various $0 / M$ ratios. "At the lower burnup levels (i.e. 1.1 and 2.5 at.\%), the lower $0 / M$ fuel pins exhibited little or no measurable attack. ...A comparison of the two pins at 3.6 at.\% (burnup) indicates an approximate factor of three difference in the depth of attack for the two 0/M levels." (See Fig. III-12) (Lawrence, Hata, and weber 1979). This indicated that the mechanism of FCCI changed as the $0 / M$ ratio was lowered; at the lower $0 / M$ value there was a drastic decrease in the 
cladding attack depth. In the burnup ranges studied, the mechanism of FCCI did not change, but the depth of attack appeared to be linearly dependent on burnup.

Electron microprobe studies on selected samples showed that increasing burnup did not seem to affect the distribution of fuel or cladding

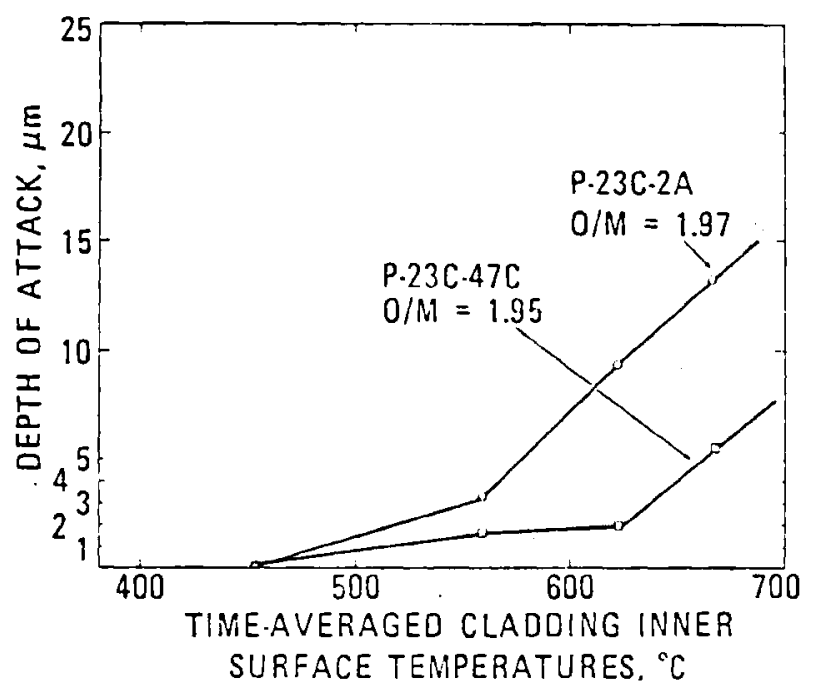

FIGURE III-12. The Effect of Initial Fuel $0 / M$ on the Depth of Attack at 3.6 at.\% Burnup (Lawrence, Hata, and Weber 1979). (Reprinted with permission from American Nuclear Society, LaGrange Park, Illinois ( 1979.)

constituents. Cladding of the lower $0 / M$ samples showed that slight depletions of chromium occurred near the carbide-depleted grains and grain boundaries. Detection of chromium in the fuel's interior at 3.6 at.\% burnup suggested chronium was being depleted from the cladding. Little Cs and Te were detected in fuel/cladding gaps for the 1.94 or $1.950 / M$ levels. A metallic-appearing product in the highest $0 / M$ sample was composed mainly of Fe and $\mathrm{Ni}$, and was depleted in chromium. Regions between the metallic reaction product and cladding matrix were comprised of $\mathrm{Cs}, \mathrm{Cr}$, and sometimes $\mathrm{Mn}$. 
"Segregation of cladding constituents and their association with fission products are consistent with the experimental distributions observed in regions of matrix attack in fuel pins with higher $0 / M^{\prime}$ 's from other experiments." (Lawrence, Hata, and Weber 1979).

Fig. III-13 delineates the oxygen potential as a function of burnup. The formation of carbides and stages of intergranular attack by tellurium and cesium are noted in the figure.

Carbon

Carbon increased intergranular attack when the oxygen potential was slightly greater than the oxidation threshold of stainless steel. Penetration occurred as a result of the formation and decomposition of metastable carbides (see Figure III-13). However, at higher oxygen potentials, carbon-oxygen compounds formed and did not affect the cladding (Epstein 1975).

In Aitken et al.'s (1973b) experiments, sealed stainless steel containers were isothermally heated at $725^{\circ} \mathrm{C}$. Carbon added to liquid tellurium in the containers accelerated the depth of attack from 0 to 6 mils when a $\mathrm{Cr} / \mathrm{Cr}_{2} \mathrm{O}_{3}$ oxygen buffer was used, but an Fe/FeO buffer with excess carbon had an unchanged attack of 1 to 2 mils (results comparing no carbon additive to presence of carbon in liquid tellurium). A microprobe examination of carbon attack regions showed that the grain boundaries were depleted of iron, chromium, and manganese with a slight nickel enrichment relative to the base metal. Previous microprobe work on cladding samples not exposed to carbon showed depletion of only chromium and manganese with a slight iron enrichment, again relative to the base metal. The carbon attack regions depleted of iron and chromium were wider than the grain boundary widths which indicated a diffusion of base metal components near the grain boundry (see Table III-4).

Cesium

Cesium and many of its compounds are highly volatile and move in the radial thermal gradient to the cooler fuel-clad interface. A high $0 / \mathrm{M}$ ratio in the fuel would minimize cesium migration but enhances the conditions for detrimental cladding attack (Epstein 1975). Epstein (1975) conducted a 1 iterature survey on cladding/Cs experiments done out-of-pile. Results of isothermal capsule experiments using cesium as one of the additives are 


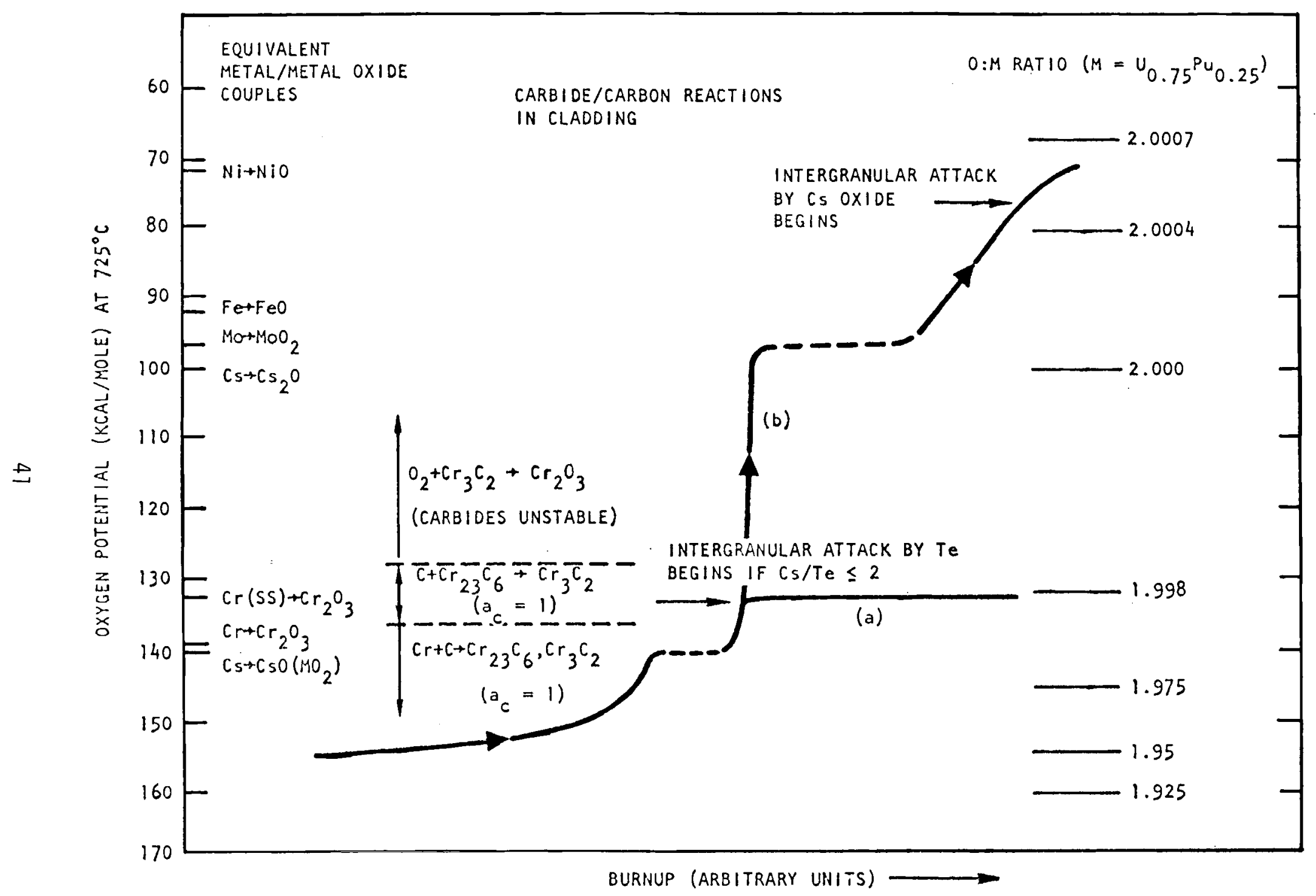

FIGURE III-13. Oxygen Activity Change with Burnup in Fuel-Cladding Gap at $725^{\circ} \mathrm{C}$; Schematic; Oxygen and Carbon from Fuel (Epstein 1975). 
summarized in Table III-4 (Adamson and Aitken 1974). The effect of cesium and tellurium on intergranular cladding attack was found to be dependent on the oxygen potential in the fuel/cladding environment. At temperatures of $900^{\circ} \mathrm{C}$ to $1000^{\circ} \mathrm{C}$, a $\mathrm{Cs}-\mathrm{Te}$ mixture penetrated the cladding wall. Other references indicated a minimum attack for cladding exposed to $\mathrm{Cs}_{2} \mathrm{O}$ and $\mathrm{Cs}$ containing $\mathrm{Cs}_{2} \mathrm{O}$; slightly more attack with $\mathrm{Cs}_{2} \mathrm{O}$ containing $\mathrm{MOO}_{3}$; and the most attack with $\mathrm{Cs}_{2} \mathrm{O}$ containing $\mathrm{CsOH}$. This data suggested a mechanism involving a 1 iquid electrolyte for intergranular attack. $\mathrm{CsOH}$ and $\mathrm{Cs}_{2} \mathrm{O}$ caused cladding samples to rupture at $\sim 650^{\circ} \mathrm{C}$.

Bazin, Jouan, and Vignesoult's (1974) work measured the penetration of Cs into the joints of oxide grains as a function of the combustion rate. Penetration distance increased with increasing combustion rate (see Figure III-14). Microanalysis results indicated that the mean concentration (by weight) of cesium in the oxide-cladding reaction zone is $4 \%$ (see Figure III15).

Hydrogen

Reaction of hydrogen with the Zircaloy cladding causes cladding embrittlement. Defects in the inner side of the zirconium alloy cladding of some fuel elements were found to be "sun bursts" of hydride and therefore attributable to sources of hydrogen inside the fuel (Denovan, Ashley and Longhurst 1971; Funk, Jacobson, and Menon 1977). Although tritium is a ternary fission product, the majority of hydrogen was formed by the irradiation of water adsorbed on the surface of the fuel pellets. Water adsorption was rapid and depended more upon the fuel's surface conditions and atmospheric relative humidity rather than on the time of exposure (Denovan, Ashley, and Longhurst 1971).

Hydrogen reacted with Zircaloy in a steam environinent and appeared to be affected by the $\mathrm{Ni}, \mathrm{Fe}, \mathrm{O}, \mathrm{As}, \mathrm{Sb}$, and Te concentrations as well as the degree of hydrogen dissociated in the stream. Hydriding is first observed as blisters which sometimes crack (Funk, Jacobson, and Menon 1977). Most of the hydrogen formed from residual water in the fuel remained in the tube's free volume until the oxygen partial pressure was below $10^{-5}$ atm.

Embrittlement of the cladding by hydrogen adsorption can be more detrimental than corrosion processes. The acceleration of Zircaloy-2 
TABLE III-4. Summary of Isothermal Capsule Tests Containing Te and 0ther Additives Heated at $725^{\circ} \mathrm{C}$; Series 1 Through 16 (Adamson and Aitken 1974).

\begin{tabular}{|c|c|c|c|c|c|c|c|}
\hline \multirow[b]{2}{*}{ Series } & \multirow{2}{*}{$\begin{array}{c}\text { Capsule } \\
\text { No. }\end{array}$} & \multirow{2}{*}{$\begin{array}{l}\text { Container } \\
\text { Material }\end{array}$} & \multicolumn{4}{|c|}{ Additives (millimoles) } & \multirow[b]{2}{*}{ Results } \\
\hline & & & $\mathrm{Te}$ & Cs & & Others & \\
\hline $100 \mathrm{~h}$ & $\begin{array}{l}1 \\
2 \\
3 \\
4 \\
5 \\
6 \\
7\end{array}$ & $\begin{array}{l}316 \\
316 \\
316 \\
316 \\
316 \\
316 \\
316\end{array}$ & $\begin{array}{l}0.72 \\
0.83 \\
0.78 \\
0.78 \\
0.78 \\
0.78 \\
0.78\end{array}$ & $\begin{array}{l}-- \\
-- \\
-- \\
-- \\
-- \\
-- \\
--\end{array}$ & 0 as & $\begin{aligned} \mathrm{Te}_{2} & =0.2 \\
& =0.25 \\
& =0.06 \\
& =0.012 \\
& =0.006 \\
& =0.003 \\
& =0\end{aligned}$ & $\begin{array}{l}\text { All capsules showed } \\
\text { intergranular attack } \\
\text { and uniform reaction } \\
\text { layer }\end{array}$ \\
\hline \multirow[t]{5}{*}{$100 \mathrm{~h}$} & 1 & 316 & 0.78 & -- & & -- & \multirow{5}{*}{$\begin{array}{l}\text { Reaction layer and } \\
\text { intergranular attack } \\
\text { No attack } \\
\text { No reaction layer, } \\
\text { intergranular attack } \\
\text { Reaction layer, } \\
\text { intergranular attack } \\
\text { No reaction layer, } \\
\text { no intergranular attack } \\
\text { No reaction layer, } \\
\text { no intergranular attack }\end{array}$} \\
\hline & $\begin{array}{l}2 \\
3\end{array}$ & $\begin{array}{l}316 \\
316\end{array}$ & -- & $\begin{array}{l}0.78 \\
0.78\end{array}$ & $<100$ & $\mathrm{ppm} 0$ in Cs & \\
\hline & 4 & 316 & 0.78 & 3.16 & & -- & \\
\hline & 5 & 316 & 0.35 & 0 & & $\mathrm{CrO}_{1.5}=0.27$ & \\
\hline & 6 & 316 & 0.35 & 0.36 & $\mathrm{Cr}=$ & $\mathrm{Cr}_{1.5}=0.27$ & \\
\hline \multirow[t]{6}{*}{$100 \mathrm{~h}$} & 1 & 316 & 0.36 & 0.35 & $\mathrm{Fe}=$ & $\mathrm{FeO}=0.25$ & \multirow{6}{*}{$\begin{array}{l}\text { Reaction layer, } \\
\text { intergranular attack } \\
\text { Reaction layer, } \\
\text { intergranular attack } \\
\text { Reaction layer, } \\
\text { slight intergranular attack } \\
\text { Reaction layer, } \\
\text { intergranular attack - } 2 \mathrm{mils} \\
\text { Reaction layer, } \\
\text { intergranular attack } \\
\text { No reaction layer, } \\
\text { no intergranular attack }\end{array}$} \\
\hline & 2 & 316 & 0.36 & 0.35 & Mo $=$ & $\mathrm{MoO}_{3}=0.25$ & \\
\hline & 3 & $\begin{array}{c}321 \\
\text { Stabilized }\end{array}$ & 0.36 & 0.35 & Same & as 1 & \\
\hline & 4 & $\begin{array}{c}316 \\
\text { 0xidized }\end{array}$ & 0.36 & 0.35 & Same & as 1 & \\
\hline & 5 & $316 \mathrm{CW}$ & 0.36 & 0.35 & Same & as 1 & \\
\hline & 6 & 316 & 0.36 & 0.35 & $\mathrm{Cr}=$ & $\mathrm{Cr}_{1.5}=0.25$ & \\
\hline
\end{tabular}


TABLE III-4. (Contd)

\begin{tabular}{|c|c|c|c|c|c|c|}
\hline \multirow[b]{2}{*}{ Series } & \multirow{2}{*}{$\begin{array}{l}\text { Capsule } \\
\text { No. }\end{array}$} & \multirow{2}{*}{$\begin{array}{l}\text { Container } \\
\text { Material }\end{array}$} & \multicolumn{3}{|c|}{ Additives (millimoles) } & \multirow[b]{2}{*}{ Results } \\
\hline & & & $\mathrm{Te}$ & Cs & Others & \\
\hline \multirow[t]{2}{*}{$\begin{array}{r}4 \\
100 h\end{array}$} & $\begin{array}{l}1 \\
2 \\
3 \\
4 \\
5\end{array}$ & $\begin{array}{l}316 \\
316 \\
316 \\
316 \\
316\end{array}$ & $\begin{array}{l}-- \\
0.39 \\
0.39 \\
0.39 \\
0.39\end{array}$ & $\begin{array}{l}0.39 \\
0.39 \\
1.56 \\
3.90 \\
0.39\end{array}$ & \multirow{2}{*}{$\begin{array}{l}\mathrm{Fe}=\mathrm{Fe} 0=0.25 \\
\mathrm{Mo}=\mathrm{MoO}_{2}=0.25 \\
\text { Same as } 1 \\
\text { Same as } 1 \\
\text { Same as } 1 \text { plus } \\
0.6 \text { Carbon } \\
\mathrm{Cr}=\mathrm{Cr} 0_{1}=0.25 \\
\text { plus } 0.6 \text { Carbon }\end{array}$} & $\begin{array}{l}\text { No intergranular attack } \\
\text { Pitting type of attack } \\
\text { No intergranular attack } \\
\text { No intergranular attack } \\
\text { Intergranular attack } ~ 1.5 \mathrm{mils}\end{array}$ \\
\hline & 6 & 316 & 0.39 & 0.39 & & Intergranular attack $\sim 1.5 \mathrm{mils}$ \\
\hline \multirow{5}{*}{$100^{\star} \mathrm{h}$} & 1 & \multirow[t]{5}{*}{316} & \multirow[t]{5}{*}{0.39} & \multirow[t]{5}{*}{0.39} & \multirow{5}{*}{$\begin{array}{l}\mathrm{Cr}=\mathrm{Cr} 0_{1}=0.25 \\
\mathrm{Carbon}=0.6 \\
\mathrm{Cr}=\mathrm{Cr} 0_{1}=0.25 \\
\mathrm{Carbon}=0.3 \\
\mathrm{Cr}=\mathrm{Cr} 0_{1}=0.25 \\
\mathrm{Carbon}=0.075 \\
\mathrm{Cr}=\mathrm{Cr} 0_{1}=0.25 \\
\mathrm{Carbon}=0.0375 \\
\mathrm{Cr}=\mathrm{Cr} 0_{1.5}=0.25 \\
\text { No carbon }\end{array}$} & $\begin{array}{l}\text { Intergranular attack } \\
5-6 \text { mils spotty }\end{array}$ \\
\hline & 2 & & & & & Up to 2 mils spotty \\
\hline & 3 & & & & & $1-2 \mathrm{mils}$ \\
\hline & 4 & & & & & $1-2 \mathrm{mils}$ \\
\hline & 5 & & & & & $1-2 \mathrm{mils}$ \\
\hline \multirow[t]{2}{*}{$100^{\star} h$} & $\begin{array}{l}1 \\
2 \\
3\end{array}$ & \multirow[t]{2}{*}{316} & 0.39 & \multirow[t]{2}{*}{0.39} & $\begin{array}{l}\mathrm{Fe}=\mathrm{Fe} 0=0.25 \\
\mathrm{Cr}=\mathrm{Cr} 0_{1.5}=0.25 \\
\mathrm{Cr}=\mathrm{Cr} 0_{1}=0.25 \\
\text { Carbon }=0.6\end{array}$ & $\begin{array}{l}\sim 4 \mathrm{mils} \\
\sim 4 \mathrm{mils} \\
\sim \widetilde{\mathrm{mils}}\end{array}$ \\
\hline & 4 & & 0 & & $\mathrm{Fe}=\mathrm{Fe} 0=0.25$ & No attack \\
\hline \multirow{4}{*}{$\begin{array}{l}5 R \text { (repeat) } \\
100 \mathrm{~h}\end{array}$} & 1 & \multirow[t]{4}{*}{316} & \multirow[t]{4}{*}{0.39} & \multirow[t]{4}{*}{0.39} & \multirow{4}{*}{$\begin{array}{l}\mathrm{Cr}=\mathrm{CrO}_{1} 5=0.25 \\
\text { Carbon }=0.6 \\
\mathrm{Cr}=\mathrm{Cr} 0_{1}=0.25 \\
\text { Carbon }=0.03 \\
\mathrm{Cr}=\mathrm{Cr} 0_{1}=0.25 \\
\text { Carbon }={ }_{0}=.075 \\
\mathrm{Cr}=\mathrm{Cr} 0_{1.5}=0.25 \\
\text { No carbon }\end{array}$} & Intergranular attack $\sim 4 \mathrm{mils}$ \\
\hline & 2 & & & & & Intergranular attack $\sim 4 \mathrm{mils}$ \\
\hline & 3 & & & & & No attack \\
\hline & 4 & & & & & No attack \\
\hline
\end{tabular}


TABLE III-4. (contd)

\begin{tabular}{|c|c|c|c|c|c|c|}
\hline \multirow[b]{2}{*}{ Series } & \multirow{2}{*}{$\begin{array}{c}\text { Capsule } \\
\text { No. }\end{array}$} & \multirow{2}{*}{$\begin{array}{l}\text { Container } \\
\text { Material }\end{array}$} & \multicolumn{3}{|c|}{ Additives (millimoles) } & \multirow[b]{2}{*}{ Results } \\
\hline & & & $\mathrm{Te}$ & $\mathrm{Cs}$ & Others & \\
\hline \multirow[t]{2}{*}{$\begin{array}{l}\text { 6R (repeat) } \\
1000 \mathrm{~h}\end{array}$} & 1 & 316 & 0.39 & 0.39 & $\mathrm{Fe}=\mathrm{Fe} 0=0.25$ & $\begin{array}{l}\text { Reaction layer }(\sim 1 \text { mil), } \\
\text { intergranular attack }(<1 \text { mi } 1)\end{array}$ \\
\hline & $\begin{array}{l}2 \\
3\end{array}$ & & & & $\begin{array}{l}\mathrm{Cr}=\mathrm{Cr}_{1} 0_{1.5}=0.25 \\
\mathrm{Cr}=\mathrm{CrO}_{1}=0.25 \\
\text { Carbon }=0.6\end{array}$ & $\begin{array}{l}\text { No attack } \\
\text { Intergranular attack } \sim 4 \text { mils, } \\
\text { spotty with grain pullout }\end{array}$ \\
\hline \multirow[t]{3}{*}{$\stackrel{7}{1000 \mathrm{~h}}$} & 1 & 316 & 0.39 & 0.39 & \multirow{3}{*}{$\begin{array}{l}\mathrm{Fe}=\mathrm{Fe} 0=0.50 \\
\mathrm{Cr}=\mathrm{Cr} 0_{1}=0.50 \\
\text { Carbon }=1.2 \\
\mathrm{Cr}=\mathrm{Fe} 0=0.50 \\
\text { Carbon }=1.2\end{array}$} & \multirow{3}{*}{$\begin{array}{l}\text { Patchy reaction layer }(\sim 1.5 \mathrm{mils}) \text {, } \\
\text { traces intergranular attack } \\
\text { Intergranular attack, } 5 \text { to } 7 \mathrm{mils} \text {, } \\
\text { spotty } \\
\text { Reaction layer }(\sim 1.5 \mathrm{mil}), \\
\text { intergranular attack }(\sim 1 \mathrm{mil})\end{array}$} \\
\hline & 2 & & 0.78 & 0.78 & & \\
\hline & 3 & & 0.78 & 0.78 & & \\
\hline $\begin{array}{c}8 \\
100 h\end{array}$ & $\begin{array}{l}1 \\
2 \\
3\end{array}$ & 316 & $\begin{array}{l}0 \\
0 \\
0\end{array}$ & 0.39 & $\begin{array}{l}\mathrm{Ni}=\mathrm{NiO}=0.25 \\
\mathrm{Mo}=\mathrm{MoO}_{2}=0.25 \\
\mathrm{Cu}=\mathrm{Cu}_{2} \mathrm{O}=0.25\end{array}$ & $\begin{array}{l}\text { Intergranular attack } \sim 3 \mathrm{mils} \\
\text { No attack } \\
\text { No attack - coating on surface }\end{array}$ \\
\hline \multirow[t]{2}{*}{$\stackrel{9}{100 h}$} & 1 & 316 & 0.39 & 0.39 & $\mathrm{Cu}=\mathrm{Cu}_{2} \mathrm{O}=0.25$ & \multirow{2}{*}{$\begin{array}{l}\text { No intergranular attack } \\
\text { Surface deposit } \\
\text { No attack - coating on surface }\end{array}$} \\
\hline & 2 & 316 & 0 & 0.39 & $\mathrm{Cu}=\mathrm{Cu}_{2} \mathrm{O}=0.25$ & \\
\hline \multirow[t]{2}{*}{$10 t$} & $1(100$ & h) 316 & 0.39 & 0.39 & $\mathrm{Fe}=\mathrm{Fe} 0=0.25$ & \multirow{2}{*}{$\begin{array}{l}\text { Inside surface attacked } \sim 1 \mathrm{mil} \\
\text { Outside surface carburized } \sim 5 \mathrm{mils} \\
\text { Outer surface carburized }>10 \mathrm{mils} \\
\text { Inner surface attacked } \sim 1 \mathrm{mil}\end{array}$} \\
\hline & 21500 & h) 316 & 0.39 & 0.39 & $\mathrm{Fe}=\mathrm{Fe} 0=0.25$ & \\
\hline \multirow{3}{*}{$\begin{array}{l}11 \\
100 h\end{array}$} & 1 & 316 & 0.39 & 0.39 & \multirow{3}{*}{$\begin{array}{l}\mathrm{Cr}=\mathrm{Cr}_{1}{ }_{1}=0.25 \\
\text { Carbon }={ }_{0}=6 \\
\mathrm{Cr}=0.25 \mathrm{Cr}_{1.5}= \\
\text { Carbon }=0.6 \\
\mathrm{Cr}=0.25 \mathrm{Cr}_{1.5}= \\
\text { Carbon }=0.6\end{array}$} & \multirow[t]{3}{*}{ Intergranular attack $\sim 5 \mathrm{mils}$} \\
\hline & 2 & 316 & 0.39 & 0.39 & & \\
\hline & 3 & 316 & 0.39 & 0.39 & & \\
\hline
\end{tabular}


TABLE III-4. (Contd)

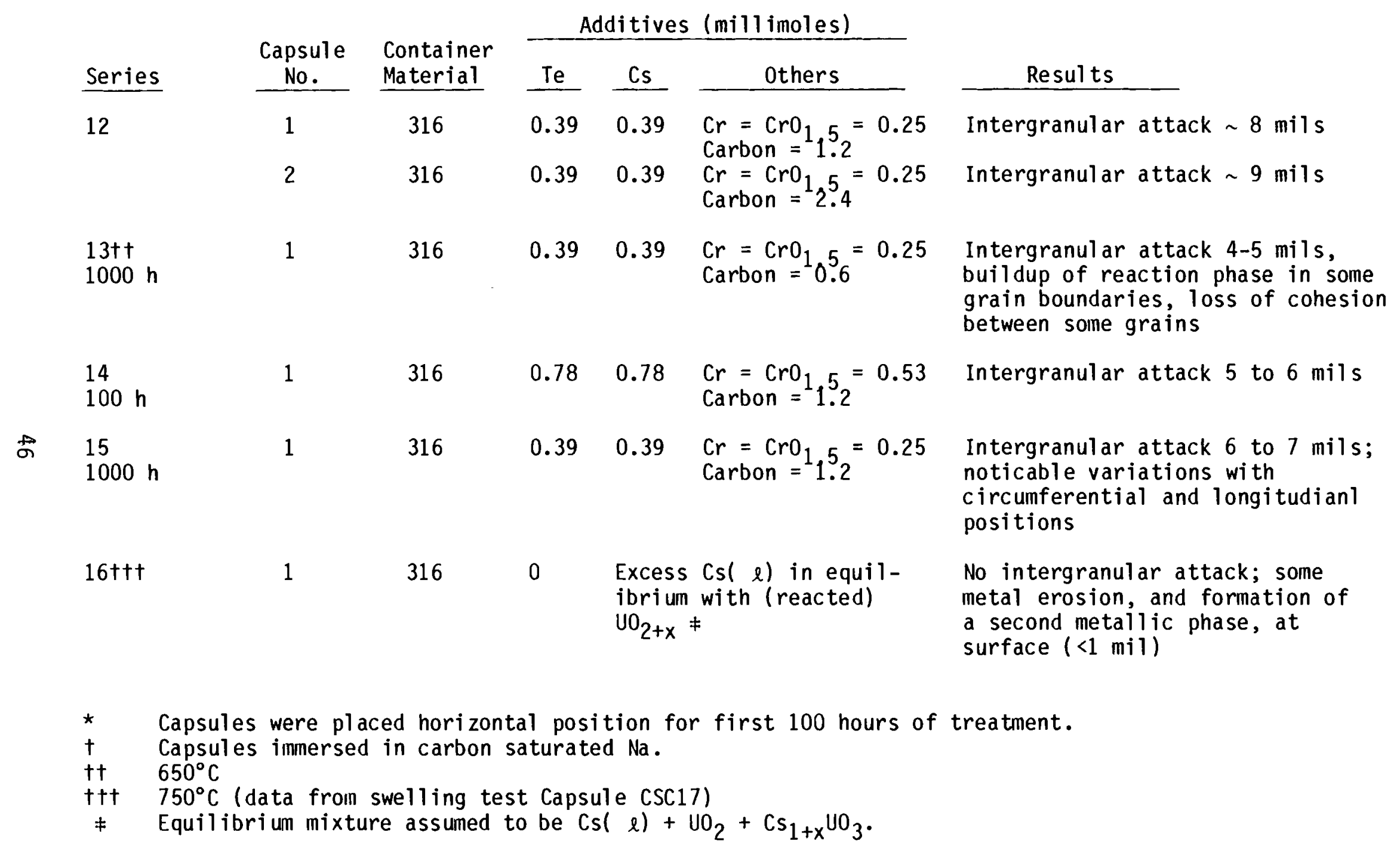




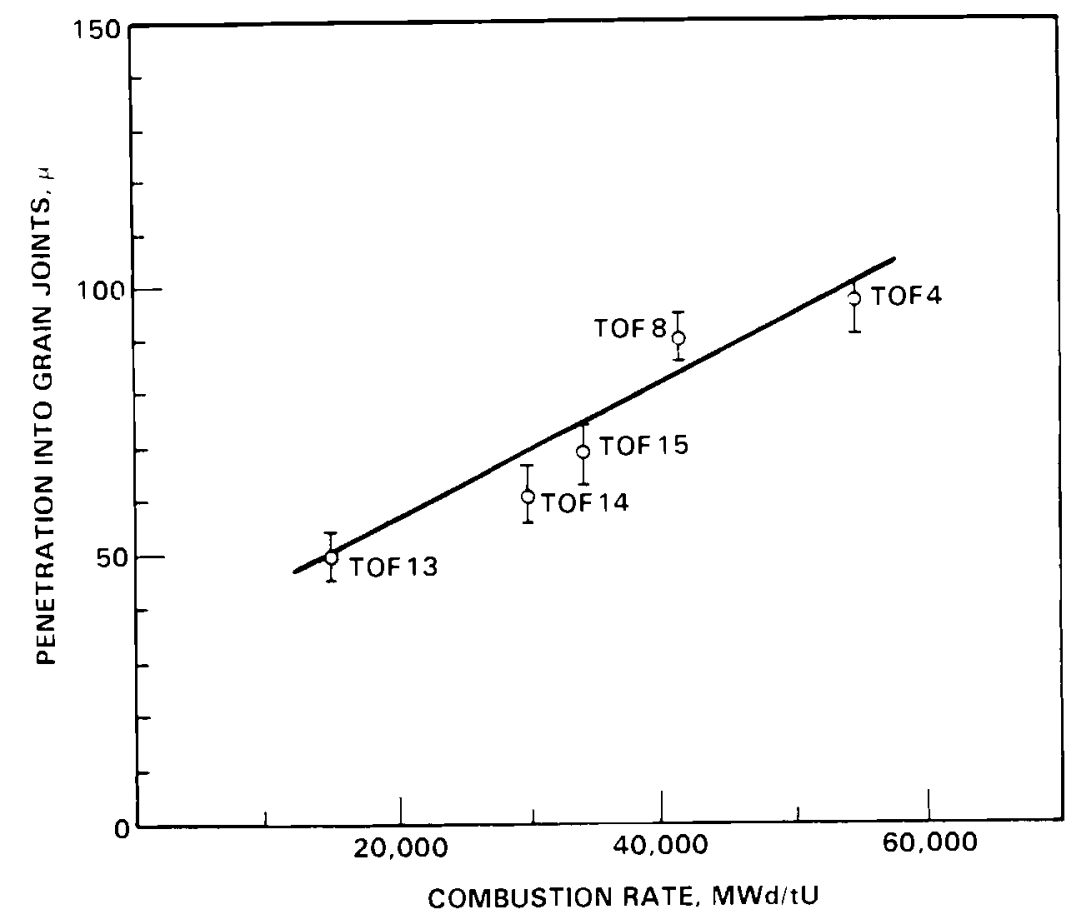

FIGURE III-14. Maximuin Penetration by Fission Products into the Joints of Oxide Grains at the Oxide-Cladding Interface. Element Measured: $C s$ in Grain Joints (Bazin, Jouan, and Vignesoult 1974).

FIGURE III-15. Microanalysis of the Zone of Contact Between Oxide and Cladding in Pin TOF 32 (Bazin, Jouan, and Vignesoult 1974).

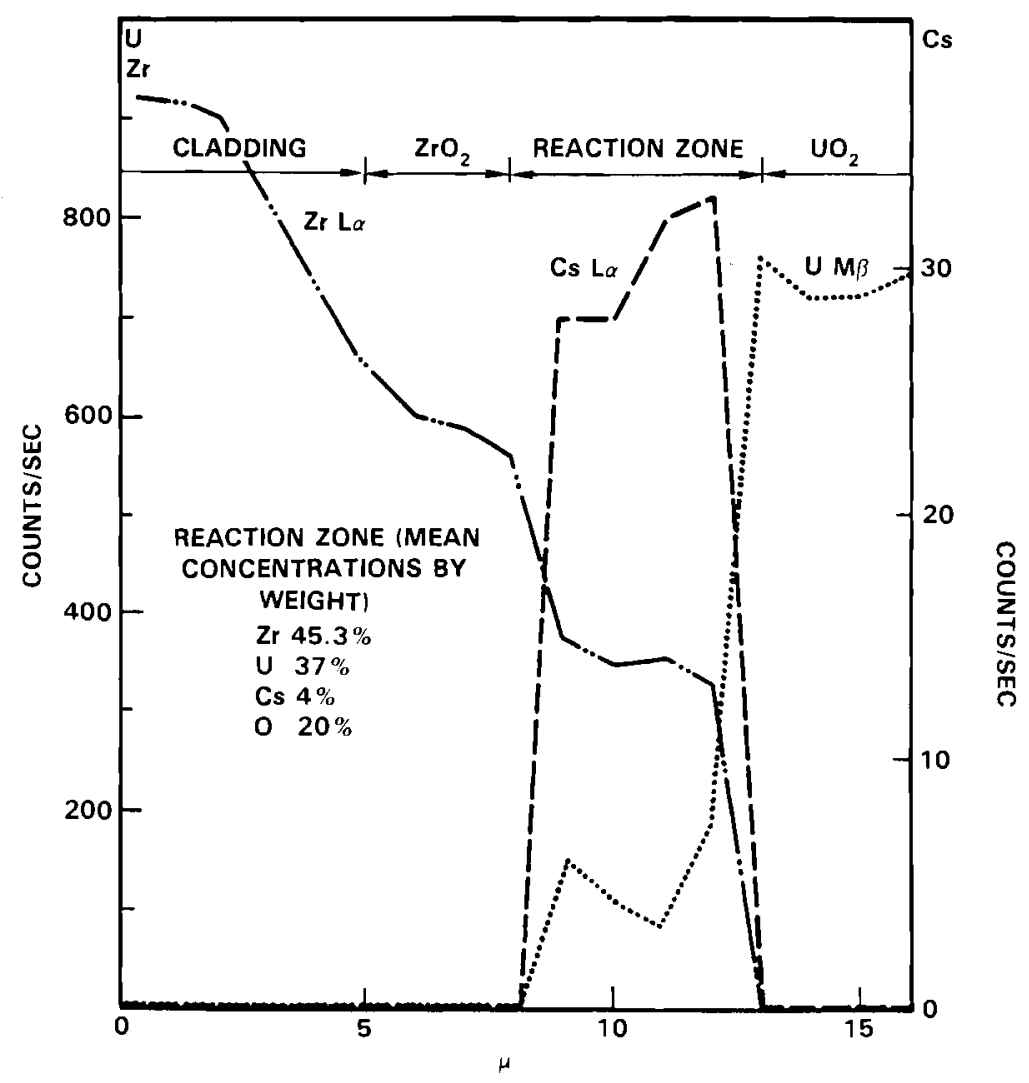


corrosion, induced by irradiation, was accompanied by reduced hydrogen adsorption. Less than half of the anticipated hydrogen uptake was found in the cladding. Clad breaching by hydriding has been prevented by increasing the density and reducing the water content of $\mathrm{UO}_{2}$ pellets during fabrication.

Iodine

Approximately one third of the stainless steel clad pins examined from the Dounreay reactor were found to have intergranular cladding attack to depths of 25-75 $\mu \mathrm{m}$. The corrosion mechanism is not yet known (Bramman and Powe 11 1975). Other researchers cited by Bramman and Powel1 (1975) have noted the presence of iodine and cesium in the areas of intergranular attack in EBRII (Experimental Breeder Reactor II) pins as well as the fact that iodine and tellurium caused corrosion of stainless steel under appropriate conditions; researchers working with EBR-II pins postulated a cyclic van Arkel process involving the formation and decomposition of ferrous iodide as the corrosion mechanism. Bramman and Powell (1975), however, believe the van Arkel cycle is not important for two reasons: (1) high iodine concentration and the worst intergranular attack were found at opposite ends of the fuel pin, and (2) the severity of attack in the Dounreay pins showed little dependence on burn-up or cladding temperature.

The formation of CSI on the inner cladding surface has been noted by several authors. Clayton and Riddle (1969) indicated a trace amount of ${ }^{129}$ I activity was detected in $\mathrm{UO}_{2}$ and $\mathrm{CSI}$ was observed on the inner cladding surface of irradiated $\mathrm{UO}_{2}$ rods. Morewitz's (1981) literature review included these observations: (1) molecular iodine is easily adsorbed onto clean stainless steel walls; (2) deposition of CSI (solid) occurred at the cladding's inner surface; (3) cubic crystals adhering to the inner zircaloy cladding from irradiated LWR fuel rods were positively identified by $x$-ray fluorescence as CsI.

Davies (1977) references the facts that iodine caused stress corrosion cracking of Zircaloy, and that high localized concentrations of iodine were noted on the cladding opposite fuel pellet cracks and interfaces. However, Davies (1977) maintains that the concentration of an element does not give information about its chemical activity and cannot be assumed that fission product iodine indeed causes stress corrosion cracking of fuel cladding. 
A nuclear accident resulting in escape of fission products from fuel rods involves both high fuel and high cladding temperatures. Under these conditions, the Zircaloy cladding is a strong reductant; the coolant is reduced by the cladding to form hydrogen which is also a reductant. Campbell, Mal inauskas, and Stratton (1981) concluded that fission product iodine that can be released in an accident from LWR fuel rods existed in the rod as a metal iodide rather than elemental iodine as previously assumed. Under these chemically reducing conditions, iodine is not expected to change its valence.

Funk, Jacobson, and Menon's (1977) 1iterature review indicated that stress corrosion cracking of Zircaloy near the end-of-life has been surmised to be caused by halide fission products. Iodine and Cs are specific products identified as causes for cracking. Zircaloy tested for corrosion in an iodine atmosphere had fractures that were microstructurally similar to those seen in Zircaloy-2 cladding failure of reactor fuel pins. Axial cracks of varying lengths from pinholes to several inches long have been found. "Zircaloy fabricated by tube reduction and annealing for one hour at $923^{\circ} \mathrm{K}\left(650^{\circ} \mathrm{C}\right)$ or higher has increased resistance to iodine stress corrosion. There are also indications that fully-annealed Zircaloy cladding is more resistant to low ductility failure than cold-worked Zircaloy." (Funk, Jacobson, and Menon 1977).

Tel1urium

In a study conducted by Aitken, et al. (1972 a,b; 1973 a,b) and Adamson and Aitken (1974), reaction was evident where liquid tellurium contacted a stainless steel container but no reaction was observed above the liquid leve1. Cesium, carbon, and oxygen buffers in various amounts were added to the tellurium and the degree of attack noted. Experimental results indicated that at Cs:Te ratios of $1: 1,4: 1$, or $10: 1$, no attack occurred on the stainless steel. No intergranular attack occurred if the oxygen activity set by the buffers was below the oxidation threshold for the stainless steel. Table III-4, taken from Adamson and Aitken (1974), delineates some of their experimental results.

Electron microprobe studies have revealed some insight into the intergranular attack by tellurium. Chromium and manganese, leached from the grain boundaries, were deposited in a layer on the surface which was already 
rich in cesium and tellurium. Iron remained in the grain boundaries where cesium and tellurium had penetrated (Aitken et al. 1973a). 


\section{THEORETICAL CONSIDERATIONS}

OXYGEN BALANCE

Introduction

The fission of an atom of uranium or plutonium, in their respective dioxides, yields two fission product atoms and two oxygen atoms. The mean valency of the soluble fission products has been found to be equal to 3.50 , independent of burnup and fuel type (Schmitz, Dean, and Halachmy 1971). Thus, based on this information alone, one would not expect the fuel's $0 /(U+P u)$ ratio to remain constant during irradiation.

Stoichiometric fuel is preferred because of its properties, behavior, and fabrication costs. Calculations based on initial stoichiometry, burnup, and mean valency showed that a hypostoichiometric fuel would quickly become hyperstoichiometric if the fuel matrix absorbed all of the oxygen released during fission. This suggested a need to use fuels with a low initial stoichiometry. However, oxidation of molybdenum and perhaps the stainless steel cladding stabilized the matrix so that a value of $0 /(U+P u)=2.00$ was found. This ratio remained constant, but the overall $0 /(U+P u)+$ fission products) stoichiometry decreases due to fission product dissolution with increasing burnup. These experimental results would support a choice of initial fuel stoichiometry in the range $1.98<0 /(U+P u)<2.00$ (Schmitz, Dean, and Halachmy 1971).

Little experimental work dealing specifically with the oxygen balance in fuels was found in this literature survey. Much of the work is theoretical, dealing with the effects of fission product valence states and oxygen to metal $(\mathrm{O} / \mathrm{M})$ ratios on the oxygen content.

Oxygen Mobility/Migration

Post irradiation examination of mixed oxide fuels has indicated the radial oxygen potential gradient occurred early in the course of irradiation. Gradient establishment was concurrent with fuel structure establishment and independent of burnup. The gradient was experimentally determined by microprobe analysis of the molybdenum content in inclusions (found in the equiaxed and columnar grain regions) and in the oxide matrix 
surrounding the inclusions. The mechanism of transport was not clearly ascertained, but Epstein (1975) refuted the predominance of an ionic, solid state diffusion process for either radial or axial oxygen transport. Volatile compound formation may take part in a gas-phase oxygen transport mechanism. With a low $0 /(U+P u)$ value, oxygen was transported from the hotter to cooler fuel region. In contrast, oxygen concentrated in the hotter region of the fuel when the urania blanket material became hyperstoichiometric (Epstein 1975).

Oxygen's activity in the fuel-clad interface is variable, depending on the initial $0 / M$ fuel ratio, burnup, and temperature. Tests were run on $\mathrm{CS}$, Te, I, and Mo migration and their influence on intergranular attack at a controlled oxygen level. It was anticipated that the oxygen mobility would be slow, and that concentration changes would be minimal unless high experimental temperatures were used. Experimental data, however, showed that the presence of cesium increased oxygen mobility, probably transporting the oxygen as gaseous cesium oxide. Replicate samples showed oxygen was reproducibly redistributed along the temperature gradient, with redistribution occurring more rapidly in capsules containing cesium than similar capsules without Cs.

Burnup of fast breeder fuels which contain no enriched uranium will produce more excess oxygen than model fuels using some $235_{U}$ as fissile material. One calculation indicated that excess oxygen would be approximately two times greater than that produced in test fuel rods, and that the oxygen absorbing sink would be the cladding (Epstein 1975).

Thermodynamic Considerations

The oxygen potential varies from that of the initial material with irradiation, as does the mean valency of the fission products. Fission product valency affects the oxygen requirements of both the fuel and fission products. This is controlled by the oxygen potential (partial molar free energy denoted as $\Delta \bar{G}\left(\mathrm{O}_{2}\right)$ ) of the reaction

$$
M(s)+\frac{X}{2} O_{2}(g) \rightarrow M O_{x}(s)
$$

A system in thermodynamic equilibrium tends toward a free energy minimum; it is on this basis that predictions of the chemical state of oxide fuels are 
made. Three classes of fission products can be delineated: those which will not oxidize (alkali and noble metals, rare gases), stable oxides, and molybdenum oxide (Davies and Ewart 1971).

\section{Oxide Formation}

Bazin, Jouan, and Vignesoult (1974) distributed the oxygen generated only among the fission products, assuming that oxides of the empirical formula $\mathrm{MO}_{2}$ would form (see Table IV-1). Zirconium, yttrium, niobium, and the rare earths can form oxides of the $\mathrm{MO}_{2}$ or $\mathrm{M}_{2} \mathrm{O}_{3}$ form where the mean valence of these oxides soluble in the $\mathrm{UO}_{2}$ matrix is 3.5 .

Bullard (1978) has compiled a list of probable forms of fission products (see Table IV-2). His choice of forms was based partially on experimental data, but the majority of the decisions came from free energy values, available oxygen values and chemical properties of the elements. Bullard noted that experimental results for $\mathrm{UO}_{2}$ and $(U, \mathrm{Pu}) \mathrm{O}_{2}$ fuels have shown that excess oxygen was available to oxidize the cladding and increase the valence of fissile elements.

Davies and Ewart (1971) used a computer program to look at the chemical effects of composition changes in the fuel. Isotopic concentrations were calculated as a function of time using fission yield and cross-section data. Table IV-3 is a condensed form of their (Davies and Ewart 1971) results. 
TABLE IV-1. Distribution of fission-freed oxygen among fission products (Bazin, Jouan and Vignesoult 1974). *Fission yield for $\mathrm{UO}_{2}$ exposed to thermic neutrons after 100 days of irradiation and 100 days of cooling.

$\begin{array}{cclc}Y & 5.2 & \mathrm{YO}_{2} & 10.4 \\ \mathrm{La} & 6.5 & \mathrm{LaO}_{2} & 13 \\ \mathrm{Ce} & 16.3 & \mathrm{CeO}_{2} & 32.6 \\ \mathrm{Pr} & 5.8 & \mathrm{PrO}_{2} & 11.6 \\ \mathrm{Nd} & 16.8 & \mathrm{NdO}_{2} & 33.6 \\ \mathrm{Pm} & 1.9 & \mathrm{PmO}_{2} & 3.8 \\ \mathrm{Sm} & 2 & \mathrm{SmO}_{2} & 4 \\ \mathrm{Eu} & 0.18 & \mathrm{EuO}_{2} & 0.36 \\ \mathrm{Gd}-\mathrm{Tb}-\mathrm{Dy} & 0.044 & \mathrm{GdO}_{2} & 0.08 \\ \mathrm{Sr} & 10 & \mathrm{SrO}^{2} & 10 \\ \mathrm{Ba} & 6.8 & \mathrm{BaO}^{2} & 6.8 \\ \mathrm{Zr} & 34.2 & \mathrm{ZrO}_{2} & 68.4 \\ \mathrm{Nb} & 1.1 & \mathrm{Nb}_{2} \mathrm{O}_{5} & 2.76 \\ \mathrm{Mo} & 20.6 & \mathrm{MoO}_{2} & (2) \\ \text { Total } & 127.4 & & 199.4\end{array}$

(2) Number of oxygen atoms available to oxidize molybdenum. 
TABLE IV-2. Oxygen Demand of Fission Product Compounds (BuTlard 1978)

\begin{tabular}{|c|c|c|c|}
\hline Element & Compound & $\begin{array}{c}\text { Atoms } \\
100 \\
\text { Fissions } \\
\end{array}$ & $\begin{array}{l}\text { Oxygen } \\
\text { Atoms } \\
\text { Demand }\end{array}$ \\
\hline $\mathrm{Rb}$ & $\mathrm{Rb}_{2} \mathrm{O}$ & 5.70 & 2.8 \\
\hline $\mathrm{Sr}$ & $\mathrm{SrO}_{\mathrm{ZrO}}$ & 12.2 & 12.2 \\
\hline $\mathrm{Zr}$ & $\mathrm{ZrO}_{2}$ & 32.6 & 65.2 \\
\hline Y & $\mathrm{YO}_{2}$ & 6.2 & 12.4 \\
\hline Mo & $\mathrm{MoO}_{2}$ & 21.2 & 42.4 \\
\hline Cs & $\mathrm{Cs}_{2} \mathrm{O}$ & 19.0 & 8.5 \\
\hline $\mathrm{Ba}$ & $\mathrm{BaO} \mathrm{ZrO}_{2}$ & 6.0 & 6.0 \\
\hline La & $\mathrm{LaO}_{2}$ & 6.4 & 12.8 \\
\hline $\mathrm{Ce}$ & $\mathrm{CeO}_{2}$ & 17.7 & 35.4 \\
\hline $\mathrm{Pr}$ & $\mathrm{PrO}_{2}$ & 6.6 & 13.2 \\
\hline $\mathrm{Nd}$ & $\mathrm{NdO}_{2}$ & 13.55 & 27.1 \\
\hline $\mathrm{Pm}$ & $\mathrm{PmO}_{2}$ & 1.77 & 3.5 \\
\hline $\mathrm{Sm}$ & $\mathrm{SmO}_{2}$ & 1.34 & 2.7 \\
\hline Eu & $\mathrm{EuO}_{2}$ & .13 & .26 \\
\hline
\end{tabular}


TABLE IV-3. Final Fuel Composition in Atomic Percentage at 10\% Burnup and Calculation of Oxygen Balance. Condensed from (Davies and Ewart 1971) (Reprinted with permission from North Holland Publishing Company, Amsterdam $\odot 1971$.

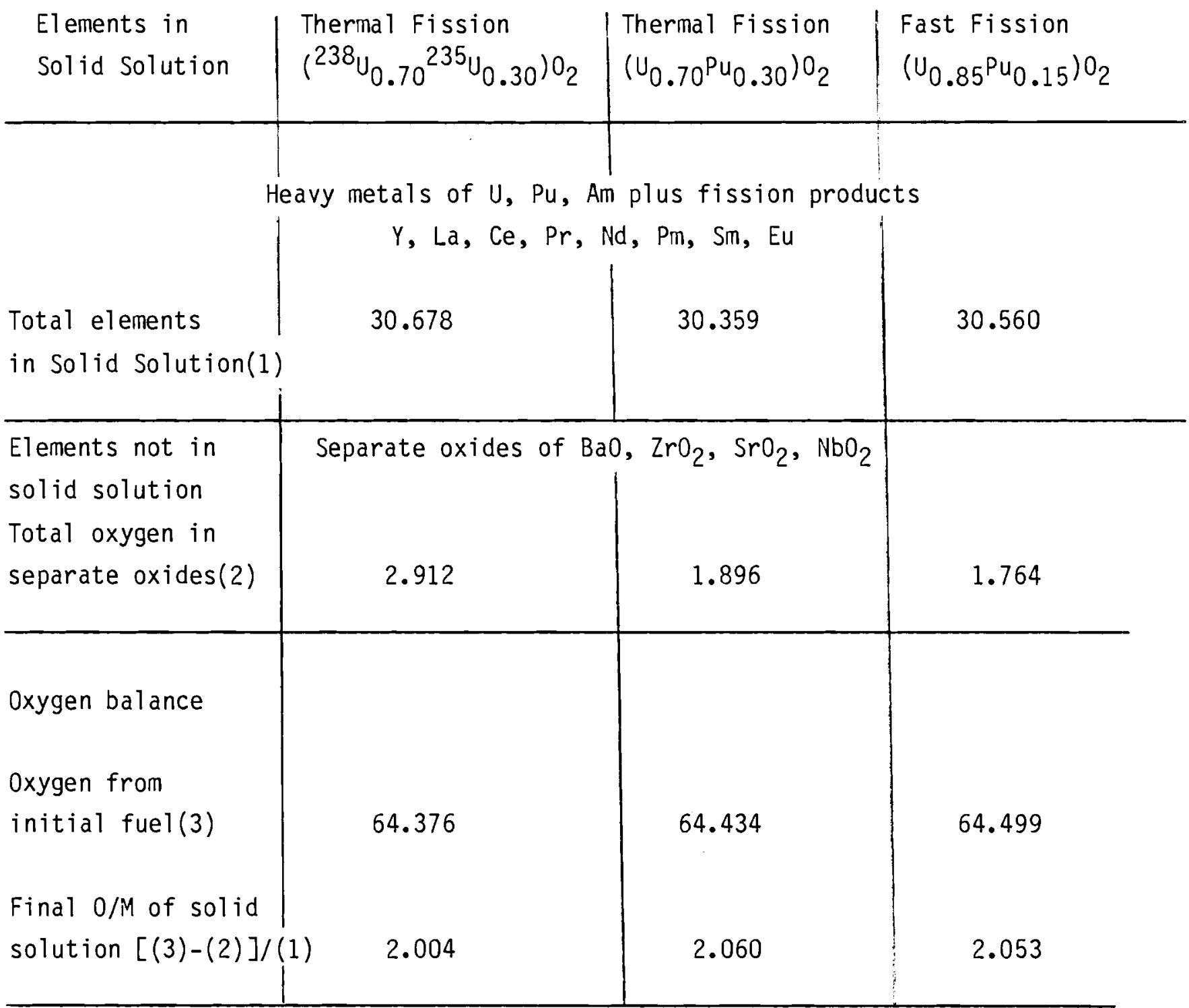

Experimental Data

Samples of fuel (pure and mixed oxide) were irradiated to varying degrees of burnup and the oxygen to metal ratio measured using the $\mathrm{CO} / \mathrm{CO}_{2}$ gas equilibration method (Davies and Ewart 1971). Experinental difficulties encountered yielded oxygen values that may have been as much as 30\% low. However, the data indicated a clear trend of increasing $0 / M$ with higher burnup (see Table IV-4). 
TABLE IV-4. Measured Oxygen "Excess" in Irradiated

Oxide Fuels vs Burnup (Davies and Ewart 1971)

\begin{tabular}{ccc}
$\begin{array}{c}\text { Fuel } \\
\text { Initial Composition }\end{array}$ & $\begin{array}{c}\text { Burnup } \\
\text { Atom Percent }\end{array}$ & $\begin{array}{c}\text { Oxygen excess } \\
\text { O/M units }\end{array}$ \\
\cline { 2 - 3 }$\left(\mathrm{U}_{0.7} \mathrm{Pu}_{0.3}\right)_{2.00}$ & 4.3 & 0.006 \\
& 4.4 & 0.012 \\
& 7.6 & 0.014 \\
& 8.0 & 0.018 \\
& 8.1 & 0.021 \\
& 8.8 & 0.022 \\
& 10.6 & 0.053 \\
& 10.8 & 0.040 \\
$\mathrm{PuO}_{2.00}$ & 10.3 & \\
& 11.7 & 0.056 \\
& 15.9 & 0.051 \\
16.8 & 0.086 \\
& & 0.098
\end{tabular}

\section{Oxygen Reactions with Fission Products}

Experimental observations and thermodynamic calculations by Lorentz et a1. (1980) dealt with the reaction of oxygen with fission products. Experimental results on the reactivity of CSI with urania showed the dependence of the reactivity on the stoichiometry of the urania. Higher O/U ratios yielded greater amounts of elemental iodine per given amount of CSI. Antimony is not affected by oxygen at ordinary temperatures but given the correct oxygen potential at temperatures greater than $400^{\circ} \mathrm{C}, \mathrm{Sb}_{2} \mathrm{O}_{3}$ can be formed. Thermodynamic calculations show antimony should be present in LWR fuel rods as an element rather than an oxide. Ruthenium is resistant to oxidation in air at moderate temperatures. Consideration of the probable oxygen potential in the fuel-clad gap of $H$. B. Robinson fuel segments prior to testing and thermodynamic calculations indicate the probability that elemental $\mathrm{Ru}$ ( not $\mathrm{RuO}_{2}$ ) was the major condensed species. 
Al though it is not clear which cesium-oxygen species is the more important, thermal gradient experiments using ( $U, \mathrm{Pu}) \mathrm{O}_{2}$ fuels have shown that cesium is important in gas-phase oxygen redistribution. Cesium can form uranates by reacting with excess oxygen in the urania (temperature range 500$\left.1000^{\circ} \mathrm{C}\right)$. At low $\Delta G\left(\mathrm{O}_{2}\right)$ values and a strong hydrogen pressure, $\mathrm{CsOH}$ is the species likely to be present; $\mathrm{Cs}_{2} \mathrm{O}, \mathrm{Cs}_{2} \mathrm{O}_{2}$, and $\mathrm{CsO}_{2}$ can become important as the $\Delta G\left(\mathrm{O}_{2}\right)$ increases. Higher oxygen potential values appear to involve a compound $1 \mathrm{ike} \mathrm{Cs}_{2} \mathrm{MoO}_{4}$ in a gas-phase oxygen transport mechanism. It was suggested that a solid-state mechanism would dominate only above a certain critical temperature; gaseous diffusion would predominate below this temperature (Epstein 1975).

Dean et a1. (1975) hypothesized the formation of cesium-oxygen-molybdenum $\left(\mathrm{Cs}_{2} \mathrm{MoO}_{4}\right)$ compounds in mixed oxide fuels. Oxygen and molybdenum were theorized to be transported from the core to the fuel's periphery through intermediate gas phases: $\mathrm{MOO}_{2}, \mathrm{MoO}_{3}$, and $\mathrm{MoO}_{2} \mathrm{I}_{2}$.

Both a low cladding temperature and a high $0 / M$ ratio in the fuel promoted the retention of ${ }^{137} \mathrm{Cs}$ in the fuel region. In contrast, ${ }^{134} \mathrm{Cs}$ retention was not dependent on the $0 / M$ ratio (see Figure IV-1). The results seemed logical as a large part of the mass 137 chain is released as cesium (binding energy dependent on $0 / M$ ratio) while ${ }^{134} \mathrm{Cs}$ is released as ${ }^{133} \mathrm{Xe}$ (Langer et al. 1978).

Capsule tube experiments involving cesium and fuel pellets indicated the tendency of cesium compounds formed to migrate down the applied temperature gradient. Composition of the compounds appeared to depend on the levels of oxygen and cesium activity. Stability of Cs-fuel compounds depended on temperature, oxygen availability, and oxygen activity. If enough oxygen was not available, all of the cesium did not react with the fuel; the unreacted cesium migrated rapidly. When the $0: U+P u$ ratios exceeded 1.985 , there was sufficient oxygen for the cesium to react with the fuel and the thermomigration occurred at a slower rate. A chemical transport model was advanced to explain these observations (Vaidyanathan and Adamson 1979). 


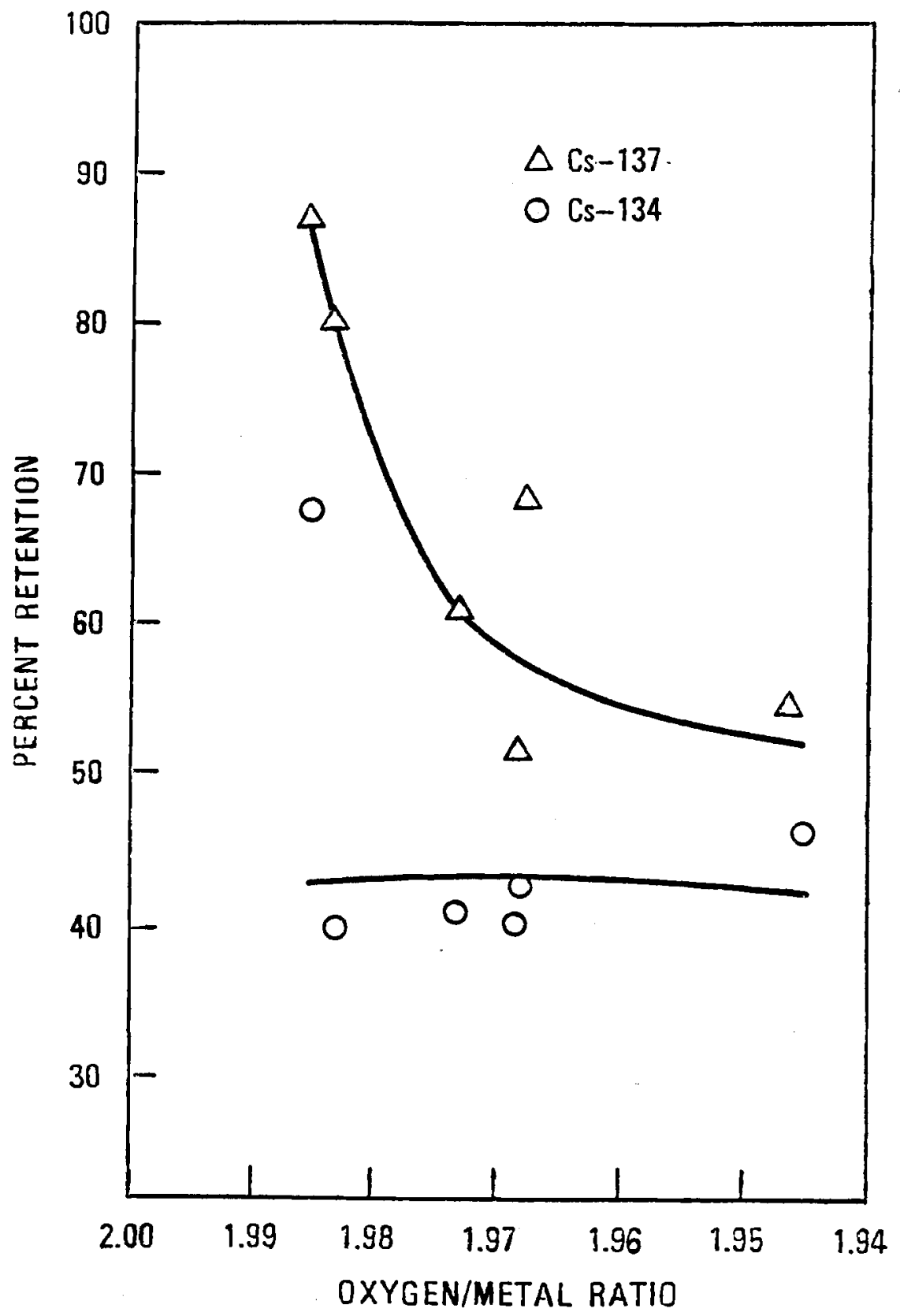

FIGURE IV-1. Cesium Retention in Fuel Region as a Function of $0 / M$ Ratio (Langer et al. 1978). 
A computer model incorporating various parameters has been written to delineate the axial cesium thermomigration. The features considered were in part:

\begin{abstract}
"A description of oxygen redistribution at power due to the steep radial temperature gradients; an estimate of the availability of oxygen for cesium-fuel compound formation in the radial zone favorable for reaction $\left(T<1100^{\circ} \mathrm{C}\right)$; an inventory module that describes oxygen and cesium production with burnup;..." (Vaidyanathan and Adamson 1979).
\end{abstract}

The salient point to note is the dependence of the model on the oxygen balance.

Vaidyanathan and Adamson (1979) al so noted that another key variable expected to influence cesium migration is the initial fuel $0 / M$ ratio. Pins operating at greater than or equal to $10 \mathrm{~kW} / \mathrm{ft}$ with an initial $0 / \mathrm{M}$ ratio greater than 1.96 have enough oxygen for a cesium-fuel reaction. If the $0 / M$ ratio is less than 1.93, not enough oxygen is available for reaction and the cesium migrates to the ends of the fuel column or, under favorable conditions, condenses in the fuel-cladding gap. At lower operating powers, higher initial $O / M$ values are needed for a cesium-fuel reaction because of smaller radial redistribution of oxygen.

Other $0 / M$ Effects

Cottrell et a1. (1960) surveyed the 1 iterature on the effects of the oxygen-to-uranium ratio. Survey results indicated that grain growth proceeded at a lower temperature in a nonstoichiometric oxide in comparison with a stoichiometric one. Chalk River reported that oxides with higher oxygen-touranium ratios released 100 to 200 times more fission gas than fuels with near stoichiometric ratios. It was found that the diffusion constant for ${ }^{133} \mathrm{Xe}$ was sensitive to the fuel's oxygen content; the constant was higher for $\mathrm{U}_{3} \mathrm{O}_{8}$ than $\mathrm{UO}_{2}$. Excess oxygen al so affected plasticity; the plasticity of $\mathrm{UO}_{2.06}$ at $800^{\circ} \mathrm{C}$ was reported to be equivalent to that of $\mathrm{UO}_{2.0}$ at $1100^{\circ} \mathrm{C}$. It was suggested that excess oxygen may act as a carrier in a distillation process, postulated to explain the central void in fuel elements where melting has not occurred. 
Experimental measurements showed a clear trend for radial plutonium redistribution which depended mainly on the initial $0 / M$ ratio in the fue 1. Results of a literature survey (Meyer, O'Boyle, and Butler 1973) indicated that $\mathrm{Pu}$ enrichment occurred near the fuel's centerline for stoichiometric fuels; conversely, uranium enrichment near the center occurred in mixed oxide fuels with an initial $0 / M$ value of less than 1.96 . No measurable radial redistribution of the actinide elements was found in fuels with an initial $0 / M$ value of 1.96. The ratio of $\mathrm{Pu} / \mathrm{U}$ in the vapor phase is dependent on the $0 / M$ ratio and the temperature; as the $O / M$ value is reduced, the vapor becomes $\mathrm{Pu}$ rich. Uranium species are predominant in the vapor for nearly stoichiometric material (Meyer, O'Boyle, and Butler 1973). 


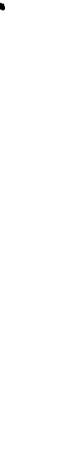




\section{CONCLUSIONS}

Both physical and chemical factors are important to the thermal release of volatile fission products from irradiated nuclear fuel. Swelling is the obvious physical change of irradiated nuclear fuel and has been extensively studied. To a large extent swelling is related to release of gases from fuel grains, and this is related to eventual release from the fuel. Most data are obtained from post reactor measurements and from modeling efforts.

Considerable data was found on the location of various fission products in the irradiated fuel and on their chemical forms. These data provide information on migration of individual fission products although considerable care must be taken to relate out-of-reactor observation to precursor events possibly involving different chemical elements.

Suggested mechanisms for fission product-cladding interaction provide additional clues to migration behavior and permit postulation of source release reactions.

The predorninant chemical factor may be the oxygen potential. The oxygen potential is related to the metal/oxygen ratio which in turn depends on the fuel composition (including the preparation) and the burnup. Considerable work has been reported, but the picture is not yet complete. 


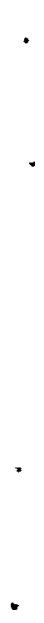




\section{REFERENCES}

Adamson, M. G. and E. A. Aitken. 1974. A Thermodynamic Data Program Involving Plutonia and Urania at High Temperatures. Quarterly Report, GEAP12511, General Electric Company, ValTecitos NucTear Center, Pleasanton, California.

Aitken, E. A., M. G. Adamson, D. Dutina, S. K. Evans, and T. E. Ludlow. 1972a. A Thermodynamic Data Program Involving Plutonia and Urania at High Temperatures. Quarterly Report No. 20, GEAP-12355, General Electric Company, Vallecitos Nuclear Center, Pleasanton, California.

Aitken, E. A., M. G. Adamson, D. Dutina, S. K. Evans, and T. E. Ludlow. 1972b. A Thermodynamic Data Program Involving Plutonia and Urania at High Temperatures. Quarterly Report No. 21, GEAP-12368, General ETectric Company, Va17ecitos Nuclear Center, Pleasanton, California.

Aitken, E. A., M. G. Adamson, D. Dutina, S. K. Evans, and T. E. Ludlow. 1973a. A Thermodynamic Data Program Involving Plutonia and Urania at High Temperatures. Quarterly Report No. 22, GEAP-12389, General Electric Company, Vallecitos Nuclear Center, Pleasanton, California.

Aitken, E. A., M. G. Adamson, D. Dutina, S. K. Evans, and T. E. Ludlow. 1973b. A Thermodynamic Data Program Involving Plutonia and Urania at High Temperatures. Quarterly Report No. 23, GEAP-12418, General Electric Company, Vallecitos Nuclear Center, Pleasanton, California.

Anselin, F. 1969. The Role of Fission-Products in the Swelling of Irradiated $\mathrm{UO}_{2}-(\mathrm{U}, \mathrm{Pu}) \mathrm{O}_{2}$-Fue1. U. S. GeneraT ETectric Co., Report GEAP 5583. ResuTts reported in Bramman, J. I. and H. J. Powell. 1975. "Redistribution of Fuel and Fission Products in Irradiated Oxide Fuel Pins." J. Br. Nucl. Energy Soc. 14(1):63-75.

Bazin, J., J. Jouan and N. Vignesoult. 1974. "Behavior and Physico-Chemical State of Fission Products in Fuel Elements for Pressurized Water Reactors." Bull. Inform. Sci. Tech. (Paris). 196:55-71. English translation avaiTable as NRC-TR-1. 1976. United States Nuclear Regulatory Commission.

Bramman, J. I. and H. J. Powell. 1975. "Redistribution of Fuel and Fission Products in Irradiated Oxide Fuel Pins." J. Br. Nucl. Energy Soc. 14(1): 63-75.

Brook, A. J. 1972. "Some Preliminary Considerations Relating to an Equation of State for Irradiated Nuclear Fue1." Nucl. Safety 13:467-477.

Bullard, J. E. 1978. Personal Communication.

Camoszzo, G. 1972. Physical-Chemical State of Fission Products in Irradiated $(\mathrm{U}, \mathrm{Pu}) \mathrm{O}_{2}$ Fuels. BNWL-TR-80, Pacific Northwest Laboratory, Richland, Washington. Translated by E. R. Appleby from EUR 4613f (1971). 
Campbe11, D. 0., A. P. Malinauskas, and W. R. Stratton. 1981. "The Chemical Behavior of Fission Product Iodine in Light Water Reactor Accidents." Nucl. Tech. 53:111-119.

Childs, B. G. 1963. "Fission Effects in Uranium Dioxide." J. Nuc1. Mater. $9(3): 217-244$.

Clayton, J. C. and J. M. Riddles 1969. Some Studies on the Oxidation States of Fission-Product Iodine $\left(\mathrm{I}^{\mathrm{I}}{ }^{29}\right.$ ) in Irradiated $\mathrm{UO}_{2}$ (LWBR Development Program. WAPD-TM-851, Westinghouse Electric Corporation, Bettis Átomic Power Laboratory, Pi ttsburgh, Pennsylvania.

Cottre11, W. B., H. N. Culver, J. L. Scott, and M. M. Yarosh. 1960. Fission Product Release from $\mathrm{UO}_{2}$. ORNL-2935, Oak Ridge National Laboratory, Oak Ridge, Tennessee.

Davies, J. H. 1977. Personal Communication

Davies, J. H. and F. T. Ewart. 1971. "The Chemical Effects of Composition Changes in Irradiated Oxide Fuel Materials." J. Nucl. Mater. 41:143-155.

Dean, G., M. Mouchinino, R. Sauvage, and F. Schmitz. 1975. Fission Product Migration and Vapor Pressures in an Irradiated Mixed Oxide. ANL-TRANS-970, Argonne National Laboratory, Argonne, IlTinois.

Denovan, A. S., R. W. Ashley, and T. H. Longhurst. 1971. Internal Sources of Hydrogen in Unirradiated U0,Fuel Elements. AECL-4063, Chalk River Nuclear Laboratories, Chalk River, Ontario, Canada.

Dollins, C. C. 1981. Swelling and Gas Release in Oxide Fuels During Fast Temperature Transients (AWBA Development Program). WAPD-TM-1467, Westinghouse Electric Corporation, Bettis Atomic Power Laboratory, West Mifflin, Pennsylvania.

Dollins, C. C. 1973. "Fission Gas Swelling and Long-Range Migration of Low Temperatures." J. Nuc1. Mater. 49:10-20.

Epstein, B. D. 1975. A Review of the Literature Pertinent to Fission-Product Migration and Interaction in Fuel Rods. GA-A13423, General Atomic, San Diego, California.

Friskney, C. A. and K. A. Simpson. 1975. "The Behavior of Fission-Product Barium and Strontium in Irradiated $\mathrm{UO}_{2} . " \mathrm{~J}$. Nucl. Mater. 57:121-122.

Frost, B. R. T. and E. Wait. 1967. "Irradiation Experiments on Plutonium Fuels for Fast Reactors." Plutoni um as a Reactor Fue1. International Atomic Energy Authority, 469-489. Results reported in Bramman, J. I. and $H$. J. Powe11. 1975. "Redistribution of Fuel and Fission Products in Irradiated Oxide Fuel Pins." J. Br. Nuc1. Energy Soc. 14(1):63-75.

Funk, C. W., L. D. Jacobson, and M. N. Menon. 1977. Effects of Environments on Spent Fue1. HEDL-TME 77-22, Hanford Engineering Development Laboratory, Richland, Washington. 
Goode, J. H., and C. M. Cox. 1970. The Distribution of Fission Product Tritium in a Zircaloy-Clad $\mathrm{UO}_{2} \mathrm{Bl}$ anket Rod from PWR-1. ORNL-TM-2994, Oak Ridge National Laboratory, Oak Ridge, Tennessee.

Grossman, L. N., and J. 0. Hegland. 1971. Tritium Distribution in High Power Zircaloy Fuel Elements. GEAP-12205, General Electric Company, Vallecitos Nuclear Center, Pleasanton, Cal ifornia.

Hargreaves, R. and D. A. Collins. 1976. "A Quantitative Model for Fission Gas Release and Swelling in Irradiated Uranium Dioxide." J. Brit. Nucl. Energy Soc. 15(4):311-318.

Hastings, I. J., M. J. F. Notley, and D. H. Rose. 1978. "Irradiation-Induced Vol ume Changes in Commercial $\mathrm{UO}_{2}$ Fuel: Comparison with Model Prediction." J. Nuc 1. Mater. 75:301-303.

Hayns, M. R. and M. H. Wood. 1977. "Models of Fission Gas Behaviour in Fast Reactor Fuels under Steady State and Transient Conditions." J. Nucl. Mater. 67:155-170.

Ivak, D. M., and L. A. Waldman. 1979. Iodine and Cesium in Oxide Fuel Pellets and Zircaloy-4 Cladding of Irradiated Fuel Rods. WAPD-TM-1394, Westinghouse Electric Corporation, Bettis Atomic Power Laboratory, West Mifflin, Pennsylvania.

Jenks, G. H. 1979. Effects of Gaseous Radioactive Nuclides on the Design and Operation of Repositories for Spent LWR Fuel in Rock Salt. ORNL-5578, Oak Ridge National Laboratory, Oak Ridge, Tennessee.

Johnson, G. W. and R. W. Shuttleworth. 1959. Phil. Mag. 4:957. Results reported in Hayns, M. R. and M. H. Wood. 1977. "Models of Fission Gas Behaviour in Fast Reactor Fuels under Steady State and Transient Conditions." J. Nucl. Mater. 67:155-170.

Kelman, L. R. (coorindator). 1975. "Transient Fuel Response and FissionProduct Release Program." In Light-Water-Reactor Safety Resarch Program: Quarterly Progress Report. ANL-75-72, Argonne National Laboratory, Argonne, ITTinois.

Langer. S., G, Buzzelli, J.R. Lindgren, P.W. Flynn, R.J. Campana, L. Neimark, S. Greenberg and C.E. Johnson. 1978. Fission Product Release and Transport in Gas-Cooled Fast Breeder Reactor Sealed and Vented Irradiation Experiments. GA-A15197, General Atomic Company, San Diego, Calífornia.

Lawrence, L. A., D. C. Hata and J. W. Weber. 1979. "The Effects of Stoichiometry on $\mathrm{Cl}$ adding Attack in $\mathrm{UO}_{2}-\mathrm{PuO}_{2} \cdot "$ Nucl. Tech. 42:195-206.

Lorenz, R. A., J. L. Collins, A. P. Malinauskas, 0. L. Kirkland, and R. L. Towns. 1980. Fission Product Release from Highly Irradiated LWR Fuel. NUREG/CR-0722; ORNL/NUREG/TM-2877R2, Oak Ridge NationaT Laboratory, Oak Ridge, Tennessee. 
Meyer, R. O., D. R. O'Boyle, and E. M. Butler. 1973. "Effect of Oxygen-toMetal Ratio on Plutonium Redistribution in Irradiated Mixed-oxide Fuels." J. Nucl. Mater. 47:265-267.

Morewitz, H. A. 1981. "Fission Product and Aerosol Behavior Following Degraded Core Accidents." Nucl. Tech. 53:120-134.

Nelson, R. C. and E. L. Zebroski. Trans. ANS, 1966, 9, 412. Reference reported in Robertson, J.A.L. 19T3. "Keynote Address: Introductory Survey on Swelling and Gas Release." In Physical Metallurgy of Reactor Fuel Elements, ed. J. E. Harris and E. C. Sykes. The Metals Society, London, England.

Paulson, W. A., and R. H. Springborn. 1968. Estimation of Fission-Product Gas Pressure in Uranium Dioxide Ceramic Fuel Elements. NASA-TN-D-4823. National Aeronautics and Space Administration Technical Note, Lewis Research Center, Cleveland, Ohio.

Randklev, E. H. 1978. "Radial Distribution of Retained Fission Gas in Irradiated Mixed-Oxide Fuel." Am. Nuc. Soc. Trans. 28:234-236.

Sari, C., C. T. Walker, and G. Schumacher. 1979. "Solubility and Migration of Fission Product Barium in Oxide Fuel." J. Nucl. Mater. 79:255-259.

Scargi11, D. 1978. "Diffusion of Fission Product Tritium in Irradiated $\mathrm{UO}_{2}$." J. Nucl. Mater. 74:62-67.

Schmitz, F., G. Dean, and M. Halachmy. 1971. "Application of Lattice Constant Measurements for Stoichiometry Determination in Irradiated U-Pu Mixed Oxide Fuels." J. Nucl. Mater. 40:325-337.

Speight, M. W. 1969. "A Calculation on the Migration of Fission Gas in Material Exhibiting Precipitation on Re-Solution of Gas Atoms Under Irradiation. Nucl. Sci. Eng. 37(2):180-185.

Stalica, N. R. and C. A. Seils. 1969. "Electron-Probe Microanalysis of Irradiated Oxide Fuels." Ceramic Nuclear Fuels. American Ceramic Society, 211-224. Results reported in Bramman, J. I. and H. J. Powell. 1975. "Redistribution of Fuel and Fission Products in Irradiated Oxide Fuel Pins." J. Br. Nucl. Energy Soc. 14(1):63-75.

Steindler, M. J. et al. 1978. Chemical Engineering Division Fuel Cycle Cycle Programs Quarterly Progress Report. ANL-78-76, Argonne National Laboratory, Argonne, ITTinois.

Turnbul1, J.A. "The Effect of Grain Size on the Swelling and Gas Release Properties of $\mathrm{UO}_{2}$ During Irradiation." Nuclear Fuel Performance. British Nuclear Energy Society, London, 1973, Paper 48. Results reported in Hargreaves, R. and D. A. Collins. 1976. "A Quantitative Model for Fission Gas Release and Swelling in Irradiated Uranium Dioxide." J. Br. Nucl. Energy Soc. 15(4):311-318. 
Vaidyanathan, S. and M. G. Adamson. 1979. A Model for Axial Cesium Thermomigration in Oxide Fuel Pins. GEFR-00496, General Electric Company, Sunnyvale, California.

Zimmerman, H. 1978. "Investigations on Swelling and Fission Gas Behavior in Urani um Dioxide." J. Nucl. Mater. 75:154-161. 


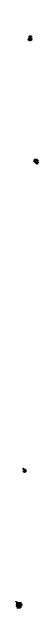


No. of

Copies

\section{OFFSITE}

27 DOE Technical Information Center

2 Geologic Repository Division DOE Nuclear Waste Policy Act GTN Project Office

Washington, DC 20545

Attn: J. W. Bennett

C. R. Cooley

M. J. Lawrence

DOE Nuclear Waste Policy Act

Project Office

S-10, Forrestal

Washington, D. C. 20585

D. B. LeClaire

DOE Office of Defense Waste \&

Byproducts Management

DP-12, GTN

Washington, DC 20545

4 DOE Terminal Waste Disposal

GTN

\& Remedial Action

Washington, DC 20545

Attn: C. B. Bastin, NE-42

J. E. Baublitz, NE-24

F. E. Coffman, NE-20

H. E. Stelling, NE-44

M. J. Bell

Division of Nuclear Materials Safety \& Safeguards

Mail Station 881-SS

Nuclear Regulatory Commission

Washington, DC 20555

W. J. Dircks

Office of the Executive

Director for Operations

Mail Station 6209

Nuclear Regulatory Commission

Washington, DC 20555
No. of

Copies

G. L. Sjoblom

Environmental Protection Agency

Office of Radiation Programs

401 M. Street, S. W.

Washington, DC 20460

R. Y. Lowrey

DOE Alburquerque Operations

Office

P.0. Box 5400

Albuquerque, NM 87185

2 DOE Idaho Operations Office

550 Second Street

Idaho Falls, ID 83401

Attn: J. D. Hamric

J. B. Whitsett

L. Lanni

DOE San Francisco Operations Office

1333 Broadway

San Francisco, CA 94612

D. E. Large

DOE Oak Ridge Operations Office

P. O. Box E

Oak Ridge, TN 37830

S. A. Mann

DOE Chicago Operations Office

9800 South Cass Avenue

Argonne, IL 60439

J. 0. Neff

DOE National Waste Program Office

505 King Avenue

Columbus, $\mathrm{OH} 43201$

3 DOE Savannah River Operations Office P.0. Box A

Aiken, SC 29801

ATTN: E. S. Golberg

T. B. Hindman

G. K. Oertel 
No. of

Copies

D. L. Vieth

DOE Nevada Operations Office

P.0. Box 14100

Las Vegas, NV 89114

2 Argonne National Laboratory

9700 South Cass Avenue

Argonne, IL 60439

ATTN: C. S. Abrams/J. H. Kittell

M. J. Steindler/

L. E. Treverrow

4 Battelle Memorial Institute

Project Management Division

505 King Avenue

Columbus, $\mathrm{OH} 43201$

ATTN: W. A. Carbeiner/S. H. Basham

N. E. Carter

S. Goldsmith/J. F. Kircher

B. Rawles

F. Holzer

Lawrence Livermore National

Laboratory

University of California

P.0. Box 808

Livermore, CA 94550

D. T. Oakley, MS 671

Los Alamos Scientific Laboratory

P.0. Box 1663

Los Alamos, NM 87544

5 Oak Ridge National Laboratory

P.0. Box $X$

Oak Ridge, TN 37830

ATTN: R. E. Bl anco

W. D. Burch

R. T. Jubin

T. H. Row

R. G. Weimer
No. of

Copies

2 Sandia Laboratories

P.0.Box 5800

Albuquerque, NM 87185

ATTN: D. R. Anderson

Technical Library

4 Westinghouse Idaho Nuclear

Co., Inc.

P. 0. Box 4000

Idaho Falls, ID 83401

ATTN: R. A. Brown

J. D. Christian

T. R. Thomas

B. R. Wheeler

3 E. I. du Pont de Nemours Company

Savannah River Laboratory

Aiken, SC 29801

ATTN: J. L. Crandall

E. J. Hennelly

S. Mirshak

E. A. Jennrich

EG\&G Idaho

P. 0. Box 1625

Idaho Falls, ID 83415

K. V. Gilbert/P. G. Hagen

Rockwell International

Rocky Flats Plant

P. 0. Box 464

Golden, C0 80401

G. W. Meyers

Atomics International Division

Rockwe 11 International

8900 DeSoto Avenue

Canoga Park, CA 91304

T. H. Pigford

Department of Nuclear Engineering

University of California

Berkeley, CA 94720 
No. of

Copies

R. G. Wilbourn

G. A. Technologies, Inc.

P. 0. Box 81608

San Diego, CA 81608

M. E. Spaeth

Science Applications, Inc.

2769 South Highland

Las Vegas, NV 89109

J. F. Strahl

Weston

2301 Research Boulevard

Third Floor

Rockville, MD 20850

R. Williams

Electric Power Research Institute 3412 Hillview Avenue

P. 0. Box 10412

Palo Alto, CA 94304

W. A. Freeby/J. L. Jardine

Bechtel National, Inc.

P.0. Box 3965

San Francisco, CA 94119

J. L. Larocca, Chairman

Energy Research and Development Authority

Empire State Plaza

Al bany, NY 12223

R. G. Post

College of Engineering

University of Arizona

Tucson, AZ 85721

\section{ONSITE}

5 DOE Richland Operations Office

J. H. Antonnen/P. A. Craig
No. of

Copies

0. J. El gert

H. E. Ransom

M. W. Shupe

J. D. White/R. D. Izatt

7 Rockwell Hanford Operations

R. C. Roal

H. E. McGuire

W. W. Schulz

M. J. Smith/J. H. Roecker

D. D. Wodrich

L. L. Zahn

File Copy

UNC United Nuclear Industries

T. E. Dabrowski/W. J. Kyriazis

Westinghouse Hanford Company

A. G. Blasewitz/J. D. Watrous

R. E. Lerch

61 Pacific Northwest Laboratory

W. F. Bonner

L. A. Bray (10)

L. L. Burger (10)

T. D. Chikalla

C. R. Hann

J. H. Jarrett

L. T. Lakey

R. C. Liikala

R. P. Marshall

C. L. Matsuzaki

J. L. McETroy

L. G. Morgan (10)

J. M. Nielsen/R. W. Perkins

R. E. Nightingale

F. E. Panisko

A. M. Platt

R. D. Scheele

J. K. Soldat 
No. of

Copies

J. L. Swanson

G. L. Tingey

R. P. Turcotte

C. M. Unruh

H. H. Van Tuyl

B. E. Vaughn

E. C. Watson

E. J. Wheelwright

W. R. Wiley

Technical Information (5)

Publishing Coordination (2) 